ADRIANO FELIPE PEREZ SIQUEIRA

EFEITO DO LASER DE BAIXA POTÊNCIA SOBRE A VIABILIDADE ESPERMÁTICA E A PRODUÇÃO IN VITRO DE EMBRIÕES BOVINOS

SÃO PAULO 


\title{
Efeito do laser de baixa potência sobre a viabilidade espermática e a produção in vitro de embriões bovinos
}

Dissertação apresentada ao Programa de PósGraduação em Reprodução Animal da Faculdade de Medicina Veterinária e Zootecnia da Universidade de São Paulo para obtenção do título de Mestre em Ciências

\section{Departamento:}

Reprodução Animal

\author{
Área de concentração: \\ Reprodução Animal \\ Orientadora: \\ Profa. Dra. Mayra Elena Ortiz D’Ávila Assumpção
}


Autorizo a reprodução parcial ou total desta obra, para fins acadêmicos, desde que citada a fonte.

DADOS INTERNACIONAIS dE CATALOGAÇÃOO-NA-PUBUCAÇÃO

[Biblioteca Virginie Buff D'Ápice da Faculdade de Medicina Veterinária e Zootecnia da Universidade de SSo Paulo)

Siqueira, Adriano Felipe Perez

Efeito do laser de baixa poténcia sabre a viabilidade espermaítica e a produçioio in vitro de embriốes bovinos / Adriano Felipe Perez Siqueira-- 2011.

124 f.: il.

Díssertação (Mestrado) - Universidade de São Paulo. Faculdade de Medicina Veterinária e Zootecrnia. Departamento de Reprodução Animal, Șao Paula, 2011.

Programa de Pás-Graduaģio: Reproduçẫo Animal.

Área de concentraçăo: Reproduçio Animal.

Orientador: Profa. Dra Mayra Elena Ortiz D'Ávila Assumpçio

1. Fotobioestimulaçāo. 2. Laser He-Ne. 3. Citometria de fluxa 4. Espermatozbides. 5. Fecundaçẫo in vitro. I. Título. 


\section{CERTIFICADO}

Certificamos que o Projeto intitulado "Efeito do laser de baixa potência sobre a viabilidade espermática e a produção in vitro de embriões bovinos", utilizando material biológico: doses de sêmen congelado de touros de centrais de reprodução e ovários de animais destinados ao abate comercial, ou seja resíduos descartados no processo de abate comercial, protocolado sob o n¹688/2009, sob a responsabilidade da Profa Dra Mayra Elena Ortiz D’Avila Assumpção, está de acordo com os princípios éticos de experimentação animal da Comissão de Bioética da Faculdade de Medicina Veterinária e Zootecnia da Universidade de São Paulo e foi aprovado em reunião de 01/07/09.

We certify that the Research "Low power laser effect on sperm viability and bovine embryo in vitro production", protocol number 1688/2009, under the responsibility Profa Dra Mayra Elena Ortiz D'Avila Assumpção, agree with Ethical Principles in Animal Research adopted by Bioethic Commission of the School of Veterinary Medicine and Animal Science of University of São Paulo and was approved in the meeting of day 07/01/09.

São Paulo, 13 de julho de 2009

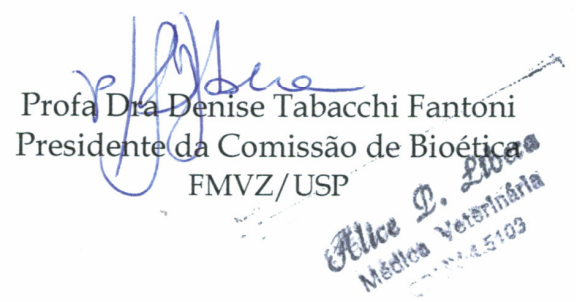




\section{FOLHA DE AVALIAÇÃO}

Nome: SIQUEIRA, Adriano Felipe Perez

Título: Efeito do laser de baixa potência sobre a viabilidade espermática e a produção in vitro de embriões bovinos

Dissertação apresentada ao Programa de Pós-Graduação em Reprodução Animal da Faculdade de Medicina Veterinária e Zootecnia da Universidade de São Paulo para a obtenção do título de Mestre em Ciências

Data:

Banca Examinadora

Prof. Dr. Mario Binelli

FMVZ/USP

Dr. Ricardo Pimenta Bertolla

Chefe do Centro de Pesquisas em Andrologia do Departamento Cirurgia, Setor integrado Reprodução Humana/ UNIFESP

Profa. Dra. Mayra Elena Ortiz D'Ávila Assumpção

FMVZ/USP 
Ao Deus Criador, aos meus pais, à minha família, aos meus amigos, ao querido Simon, pelo apoio, carinho e amor incondicional! 


\section{Agradecimentos}

Esta parte promete ser longa, o que me faz ter mais motivos a agradecer!

À minha mãe, Terezinha, ao pai, Siqueira e ao meu irmão, André, por me apoiar ao longo destes anos, por vibrar e se orgulhar de minhas conquistas, por incentivar minhas aspirações. À minha mãe em especial, sempre disposta e preocupada em ajudar, pelos mimos e lanchinhos sempre muito carinhosos. Ao Simon pela companhia, por ser sempre o primeiro a me receber com felicidade independente da hora que eu chegasse.

À minha família por entender minha ausência quando necessária, pelo apoio quando necessário e por estar presente nos momentos importantes.

À Faculdade de Medicina Veterinária e Zootecnia da Universidade de São Paulo Ao Departamento de Reprodução Animal, representado pelo chefe professor Pietro Sampaio Baruselli, por me acolher nestes quase sete longos anos de muitas gargalhadas e estripulias.

Ao Programa de Pós Graduação que me acolheu, representados pelo professor Marcelo e Harumi por me ajudarem com as partes burocráticas.

À professora Mayra Elena Ortiz D’Ávila Assumpção, minha orientadora, por todo carinho e preocupação, por sempre sacrificar suas madrugadas e momentos com os meninos (Xi e João, obrigado por dividir a atenção e o tempo) quando os prazos eram apertados. Por dividir sua vaga no estacionamento (rsssss) e a guarda compartilhada do MAC. Pelo incentivo e pela confiança depositada em mim. Confirmando seu dedo podre em escolher os orientados, todos TOTALLY CRAZY, mas juntos quase uma família normal! OBRIGADUUUUUU....

Ao professor Mário Binelli, primeiro orientador, que acreditou no meu potencial mesmo desastrado - despertou minha fascinação pela pesquisa e possibilitou que hoje este momento fosse possível e me apóia e ajuda sempre que preciso...

Ao professor José Antônio Visinin, por ter me adotado na ausência da Mayra, pelas dicas tão pertinentes, por permitir e me acolher em seu grupo. 
Aos colegas de Laboratório Thomitas (Giassetti), Fê pelo companheirismo e diversão no LAB, pela fiel parceria nas baladas....me acolherem nas noites de ESQUILOS ATIVAR, por serem minhas mãos extras, por dias de incubação no escuro hauaha (Fê horas de vôo no citômetro...), pelos mimos, pelas roupas extras (mesmo quando o tamanho era menor né Thomitas!!).

A Júlia (Julietaaaa) pela amizade sincera...desde as caronas, as aventuras, por trazer a maça (vai Evaaaaa!!)....por estar sempre preocupada comigo, por ser meio confidente e conselheira.

Thaís pela volta ao mundo completada em corridas do SAS, pela preocupação e disposição.

Flávia (ou Flavííía) pelos conselhos em assuntos aleatórios, exemplo de dedicação, sempre muito aplicada e íntegra...ahhh não poderia esquecer dos lanches do Mc e dos momentos WII.

A Camilla (Camis) pelas idéias, pela disposição, por toda ajuda, além dos bolos, omeletes, drinks....hauahauhau

À Rafaela (Rafaídia de Jesuis), ao Pedro (Pedrííínho) pelas dias musicais no fluxo, pelos meios divididos (hauahaua) e por toda amizade e agradável convivência!!

Ao Zeca, Robinson, Samir, Everton, Jéssica pelos divertidos momentos em nossa aconchegante salinha de estudos...pela convivência e muitos momentos de risada.

Aos ICS do laboratório Giana, Érica, Alexandre, Mariana, Thais (uma das duas que eu não consigo acertar o nome!!). Em especial à Xum por todos os compartilhamentos de comida ("Me dá um peda??), pelo alto astral e exemplo de superação. A Letícia (por quase perder todas as minhas palhetas e destruir o laboratório comigo... mas pelo menos você dividiu os urubus....)

Aos estagiários que passaram durante estes anos, sempre interessados e dispostos a ajudar, Mariana Gurgel, Marcos, Letícia, Jonathan, Andrez, Lívia e todos os outros 
Aos que não estão mais aqui... Paulo, Rê, Groke, Alê, Febem, Marcinha, Doci, Alberto que participaram em algum momento desta minha jornada, alguns bem anteriores a mim e que incentivaram meu interesse pela pesquisa.

A Marcella (Coooooo) e Fabíola, pelas idéias e trabalhos loucos com a luz Jedai (é assim que escreve?), por empenhar-se em ajudar nos obstáculos surgidos ao longo desta aventura, pelo interesse e dedicação! Ao Thiago e Taciana pelas assistências em Física, pela ajuda com o laser e pela ponte ABC-USP.

A Professora Valquíria, Professor Renato, Marcílio, Andressa, Paola, João Diego, Roberta, Rodrigo, Eduardo, Mariana, Daniele do LA, pelo empréstimo do CASA, pelos dias disponíveis e pelos almoços corridos nos dias de amostras (né Andressa?). Em especial ao Marcílio pela assistência estatística também sempre disponível e preocupado, membro cativo das discussões SAS...e amigo da família VRA.

Falando em Família VRA A todos os funcionários do VRA, em especial a Dona Sílvia e a Dona Sandra, as primeiras que eu encontro após uma longa madrugada de trabalho, sempre receptivas e carinhosas, e ao Miguel exemplo de organização e cortesia.

Aos alunos da Pós, pela convivência, pelos churrascos animados, em especial a Camila e suas meninas e menino, Liege, Cris, Loira, Déniel, Gi e ICs. Ao Peixe-Boi, a Lili, a Manu, a Jú, a Cínthia, a Saara, Manolo, Lindsay, Zé, Henderson, Júlia, Robertinha.

Aos demais professores do VRA em especial a Claudinha, Simprão, Ricardo, Carlinha.

Kustela (Jú, tia e tio agregados), Keiloka, Fusketa, Ralé, amigos eternos desde o início da vida veterinária, sempre preocupados mesmo após a formatura sententiniana, falando em Setenta, a todos os setentianos queridos sempre muito lembrados......

Ao pessoal da UNIFESP, Paulinha, Thiesa, Bobes e Snarf pelos momentos divertidos e amizade eterna....as diversões nos Japas e Karaokês da vida...

Aos amigos Henrique e Marcelo (não-vets), mas não menos importantes que mesmo de longe ou "MUITO LONGE" sempre torcem pelo meu sucesso. 


\section{É o Créu do Adriano...}

\author{
É créu! \\ É créu neles! \\ É créu! \\ É créu no Laser! \\ "Vambora, que vamo"! \\ "Vambora, que vamo"! \\ Prá fazer mestrado \\ Tem que ter disposição \\ Prá fazer mestrado \\ Tem que ter habilidade \\ Pois essa fase \\ Ela não é mole não \\ Eu venho te lembrar
}

Que tem que ter capacidade

Prá fazer embrião

Tem que ter concentração

Prá fazer FIV

Tem que ter motilidade

Pois essa dança

Ela não é mole não

Citômetro, TUNEL e integridade

Eu venho te lembrar

Que para defender são 5 dificuldades...

A primeira é devagarzinho

Só o aprendizado. (De física!!!)

É assim, oh! Fluência?? Fluência?! Fluência!!!

Se ligou? De novo! Fluência!!! Alinhamento!!! Angulosidade!!!

Número 2!

Citômetro!! SCSA, FITC-PSA - PI, JC1

Continua fácil, né?

É, mais no final não deu concentração!!
Faz tudo de novo!

SCSA, FITC-PSA - PI, JC1 Créu, créu, créu!

Número 3 !

MIV, FIV, CIV, créu! (Todas no mesmo dia!!)

Tá ficando dificil, hein?

MIV, FIV, CIV, créu!

Agora eu quero ver a 4 !

TUNEL, TUNEL, TUNEL,

Até as duas da manhã?? Que isso??

Tá aumentando mané!

Segura DJ! (Mayra, Marcílio, Rodrigo, Flávia, Thaís e Mário)

Vou confessar a vocês

Que eu não consigo

Essa tal de ESTATÍSTICA!!

A número 5

DJ!Velocidade $\mathrm{p}<0,005$

Na dança do créu!!

É o SAS, SAS, SAS, SAS, SAS, SAAAAAAAAS

Hahahahaha

PROC-teste-pós teste-Rodou??-Rodou??...

Prá fazer mestrado

Tem que ter disposição

Prá fazer mestrado

Tem que ter habilidade

Pois essa fase

Ela não é mole não

Eu venho te lembrar

Que tem que ter capacidade

É assim, oh!Créeeeu... 
Chego à conclusão que o não saber é uma DÁDIVA, que nos permite desfrutar a FANTÁSTICA experiência do APRENDER! 


\section{RESUMO}

SIQUEIRA, A. F. P. Efeito do laser de baixa potência sobre a viabilidade espermática e a produção in vitro de embriões bovinos. [Effect of low-power laser on sperm viability and in vitro production of bovine embryos], 2011. 124f. Dissertação (Mestrado em Ciências) Faculdade de Medicina Veterinária e Zootecnia, Universidade de São Paulo, São Paulo, 2011.

O sucesso da fecundação e da sustentação do desenvolvimento embrionário subseqüente é dependente de atributos espermáticos relacionados à qualidade seminal. A produção in vitro de embriões em bovinos é uma ferramenta fundamental para a aceleração do ganho genético do rebanho, porém o uso comercial depende diretamente da melhoria do sistema de produções in vitro de embriões a um baixo custo. Técnicas que proporcionem melhoria da qualidade seminal possibilitando um incremento na produção in vitro de embriões e ainda a um baixo custo possuem apelo econômico. O laser de baixa potência emite ondas eletromagnéticas com efeitos biológicos. Este efeito é dependente dos parâmetros de irradiação e do tipo celular alvo. Trabalhos avaliando o laser de baixa potência em amostras seminais sugerem que seja utilizado para melhorar os atributos espermáticos e, conseqüentemente, a produção in vitro de embriões. Este estudo teve como objetivo avaliar o efeito do laser de baixa potência sobre a viabilidade espermática e averiguar o efeito desta estimulação na produção in vitro de embriões bovinos. Para isso, amostras comerciais de sêmen criopreservado foram descongeladas e submetidas à irradiação com laser He-NE. No experimento 1 foram testadas as potências de $0 ; 5 ; 7,5$ e $10 \mathrm{~mW}$, por 5 ou 10 minutos de tratamento. As amostras de sêmen foram avaliadas imediatamente após a irradiação e após 30 minutos de incubação. Foram verificadas possíveis interações duplas (Potência*Duração do Tratamento, Potência*Tempo e Duração do Tratamento*Tempo) e tripla (Potência*Duração do Tratamento*Tempo). No experimento 2 foi avaliado o efeito da melhor combinação potência X duração dos tratamentos utilizados no Experimento 1, para irradiar o sêmen utilizado para a produção in vitro de embriões. O laser de baixa potência apresentou efeito sobre diversos atributos relacionados à viabilidade espermática. Este efeito foi dependente da potência e da duração do tratamento. Nas condições experimentais, a potência de $5 \mathrm{~mW}$ com duração de 10 minutos de aplicação sugere efeitos positivos no aumento na viabilidade espermática. No entanto, o 
tratamento de espermatozóides nesta potência e duração do tratamento, não apresenta incremento nas taxas de produção nem na qualidade embrionária.

Palavras chave - Fotobioestimulação, LASER He-Ne, Citometria de fluxo, espermatozóide, fecundação in vitro 


\begin{abstract}
SIQUEIRA, A. F. P. Effect of low potency laser on sperm viability and in vitro production of bovine embryos. 2011. 124f. Dissertação (Mestrado em Ciências) - Faculdade de Medicina Veterinária e Zootecnia, Universidade de São Paulo, São Paulo, 2011.
\end{abstract}

Success of fertilization and the maintenance of subsequent embryo development rely on sperm attributes related to seminal quality. The in vitro production of bovine embryos is an essential tool for genetic gain in the herd. However, its commercial use directly depends on improvement of the production system at a low cost. Inexpensive techniques which provide an increase of seminal quality, allowing the increment of in vitro production of embryos are of great interest to cattle breeding. Low-power laser emits electromagnetic waves with biological effects. These effects are dependent of irradiation parameters and target cell type. Studies with seminal samples irradiated by low potency laser suggest its use to improve several sperm features and, therefore, in vitro production of embryos. This study aimed to evaluate the effect of low potency laser on sperm viability and fertilization ability of irradiated sperm. Briefly, in Experiment 1, samples of frozen/thawed commercial semen were subjected to He-NE laser irradiation. Laser potencies of $0,5,7.5$ or $10 \mathrm{~mW}$ were tested for 5 or $10 \mathrm{~min}$ of treatment. Samples were evaluated immediately and $30 \mathrm{~min}$ after irradiation. Double (Potency*Treatment length, Potency*Time and Treatment length*Time) and triple interactions (Potency*Treatment length*Time) were assessed. Afterwards, in Experiment 2, the effect of the best combination of potency and exposure length on in vitro production of embryos was verified. Low potency laser affected several semen attributes related to sperm viability. This effect was dependent on laser potency and the length of treatment. In the experimental conditions tested in this study, $5 \mathrm{~mW}$ potency combined to $10 \mathrm{~min}$ of exposure had appeared to have positive effect of increasing sperm viability. However, $5 \mathrm{~mW}$ potency laser for $10 \mathrm{~min}$ sperm irradiation did not improve in vitro embryo production rates and bovine embryo quality.

Keywords - photobiostimulation, He-Ne LASER, flow citometry, spermatozoa, in vitro fertilization 


\title{
LISTA DE ILUSTRAÇÕES
}

\author{
LISTA DE FIGURAS
}

Figura 1 Fotografia do sistema óptico em ambiente iluminado; B: Fotografia do sistema óptico em ambiente escuro - São Paulo - 2011

Figura 2 Análise da homogeneidade da distribuição das ondas eletromagnéticas no campo de irradiação. A e B fotografia do campo de irradiação. C, D, E e F gráfico 3D da distribuição de pixels - São Paulo 2011

Figura 3 Gráficos da análise pelo software FlowJo v8.7 para a análise da associação de sondas FITC-PSA/PI. A: histograma da fluorescência verde; B: histograma da fluorescência vermelha; C: gráfico das fluorescências verde/vermelha, no qual estão representadas as quatro populações e respectivas porcentagens - São Paulo - 2011

Figura 4 Gráficos das amostras coradas com JC-1 analisados no citômetro de fluxo. A: populções de alto e baixo potencial bem definidas; B: populações de potencial intermediário e baixo bem definidas; C: população de baixo potencial bem definida e populações de potencial intermediário e alto distribuídas gradualmente - São Paulo, 2011

Figura 5 Gráficos do ensaio SCSA. A: controle negativo; B: controle positivo; C mistura 1:1 controle positivo/controle negativo - São Paulo, 2011

Figura 6 Microscopia de epifluorescência do ensaio cometa alcalino (aumento de 200X coloração sonda fluorescente Syber Green). A: espermatozóides com DNA íntegro (ausência de cauda e cabeça 
intensa); B: espermatozóides com fragmentação discreta (presença de cauda discreta e cabeça intensa); C: espermatozóides com fragmentação moderada (presença de cauda expressiva e cabeça com intensidade moderada) D: espermatozóides com fragmentação elevada (presença de cauda expressiva, e cabeça com baixa intensidade) - São Paulo, 2011

Figura 7 Imagem ilustrativa dos parâmetros quantificados pelo software Comet ScoreTM.

Figura 8 Imagem de microscopia de epifluorescência submetida a quantificação no software Comet ScoreTM.

Figura 9 Microscopia de epifluorescência de embriões submetidos ao ensaio TUNEL. A: Controle Negativo (filtro DAPI); B: Controle Negativo (filtro FITC); C: Controle Positivo (filtro DAPI); D: Controle Positivo (filtro FITC); E: Embrião analisado (filtro DAPI); E: Embrião analisado (filtro FITC) - São Paulo, 2011 


\section{LISTA DE GRÁFICOS}

Gráfico 1 Média e erro padrão da média ( \pm EPM) da motilidade visual para interação Potência*Tempo. p0 - Potência 0 mW; p5 - Potência mW; p7.5 - Potência 7,5 mW; p10 - Potência $10 \mathrm{~mW}$; pós - análise tempo PÓS; final análise tempo FINAL - São Paulo, 2011

Gráfico 2 Média e erro padrão da média ( \pm EPM) do vigor para interação Potência*Tempo. p0 - Potência 0 mW; p5 Potência $5 \mathrm{~mW}$; p7.5 - Potência 7,5 mW; p10 Potência $10 \mathrm{~mW}$; pós - análise tempo PÓS; final análise tempo FINAL - São Paulo, 2011

Gráfico 3 Média e erro padrão da média ( \pm EPM) da aglutinação para efeito duração - São Paulo, 2011

Gráfico 4 Média e erro padrão da média $( \pm$ EPM) da motilidade progressiva para interação Potência*Duração. p0 Potência $0 \mathrm{~mW}$; p5 - Potência $5 \mathrm{~mW}$; p7.5 - Potência 7,5 mW; p10 - Potência $10 \mathrm{~mW}$; d5 - duração de tratamento de 5 minutos; d10 duração de tratamento de 10 mnutos - São Paulo, 2011

Gráfico 5 Média e erro padrão da média $( \pm$ EPM) da frequência de batimento flagelar cruzado (BCF) para efeito duração do tratamento - São Paulo, 2011

Gráfico 6 Média e erro padrão da média $( \pm$ EPM) da frequência de batimentro flagelar cruzado (BCF) para efeito Tempo - São Paulo, 2011 
Gráfico 7 Média e erro padrão da média ( \pm EPM) da amplitude de deslocamento lateral da cabeça para efeito pós análise tempo PÓS; final - análise tempo FINAL - São Paulo, 2011

Gráfico 8 Média e erro padrão da média ( \pm EPM) da velocidade de trajeto média (VAP) para interação Potência*Duração de tartamento p0 - Potência $0 \mathrm{~mW}$; p5 - Potência $5 \mathrm{~mW}$; p7,5 - Potência 7,5 mW; p10 Potência $10 \mathrm{~mW}$; d5 - duração de tratamento 5 minutos; d10 - duração de tratamento 10 minutos - São Paulo, 2011

Gráfico 9 Média e erro padrão da média ( \pm EPM) da velocidade linear progressiva (VSL) para interação Potência*Duração p0 - Potência 0 mW; p5 - Potência $5 \mathrm{~mW}$; p7.5 - Potência 7,5 mW; p10 - Potência 10 mW; d5 - duração de tratamento 5 minutos; d10 duração de tratamento 10 minutos - São Paulo, 2011

Gráfico 10 Média e erro padrão da média ( \pm EPM) da velocidade de curvilinea (VCL) para efeito Tempo. Pós - tempo de análise PÓS; FINAL - tempo de análise FINAL São Paulo, 2011

Gráfico 11 Média e erro padrão da média ( \pm EPM) da velocidade curvilínea (VCL) para interação Potência*Duração do tratamento. p0 - Potência 0 mW; p5 - Potência 5 mW; p7.5 - Potência 7,5 mW; p10 - Potência 10 mW; d5 duração de tratamento 5 minutos; d10 - duração de tratamento 10 minutos - São Paulo, 2011 
Gráfico 12 Média e erro padrão da média ( \pm EPM) da alongação das células (Elong) para efeito duração - São Paulo, 2011

Gráfico 13 Média e erro padrão da média ( \pm EPM) da alongação das células (Elong) para interação Potência*Tempo. p0 - Potência 0 mW; p5 - Potência 5 mW; p7.5 - Potência 7,5 mW; p10 - Potência $10 \mathrm{~mW}$; pós - análise tempo PÓS; final - análise tempo FINAL - São Paulo, 2011

Gráfico 14 Média e erro padrão da média $( \pm$ EPM) da lesão de membrana plasmática (PL) para efeito Tempo. Pós tempo de análise PÓS; FINAL - tempo de análise FINAL - São Paulo, 2011

Gráfico 15 Média e erro padrão da média ( \pm EPM) da integridade de membrana plasmática (PI) para efeito Tempo. Pós tempo de análise PÓS; FINAL - tempo de análise FINAL - São Paulo, 2011

Gráfico 16 Média e erro padrão da média $( \pm \mathrm{EPM})$ da lesão de acrossomo (AL) para efeito duração - São Paulo, 2011

Gráfico 17 Média e erro padrão da média ( \pm EPM) da integridade de acrossomo (AI) para efeito duração - São Paulo, 2011

Gráfico 18 Média e erro padrão da média ( \pm EPM $)$ das membranas acrossomal e plasmática lesadas (ALPL) para efeito duração - São Paulo, 2011

Gráfico 19 Média e erro padrão da média ( \pm EPM) das membranas acrossomal e plasmática íntegras (AIPI) 
Gráfico 20 Média e erro padrão da média ( \pm EPM) da população com alto potencial de membrana mitocondrial (Alto) para efeito Tempo. Pós - tempo de análise PÓS; FINAL - tempo de análise FINAL - São Paulo, 2011

Gráfico 21 Média e erro padrão da média ( \pm EPM) da população com alto potencial de membrana mitocondrial (Alto) para interação Potência*Duração do tratamento. p0 Potência 0 mW; p5 - Potência 5 mW; p7.5 - Potência 7,5 mW; p10 - Potência $10 \mathrm{~mW}$; d5 - duração de tratamento 5 minutos; d10 - duração de tratamento 10 minutos - São Paulo, 2011

Gráfico 22 Média e erro padrão da média ( \pm EPM) da população com potencial de membrana mitocondrial intermediário (Intermediário) para interação Potência*Duração. p0 Potência 0 mW; p5 - Potência 5 mW; p7.5 - Potência 7,5 mW; p10 - Potência $10 \mathrm{~mW}$; 5 - duração de tratamento 5 minutos; d10 - duração de tratamento 10 minutos - São Paulo, 2011

Gráfico 23 Média e erro padrão da média ( \pm EPM) das células positivas do ensaio da estrutura da cromatina (SCSA positivo) para efeito Duração do tratamento - São Paulo, 2011

Gráfico 24 Média e erro padrão da média ( \pm EPM) das células negativas do ensaio da estrutura da cromatina (SCSA negativo) para efeito Duração do tratamento - São Paulo, 2011 
Gráfico 25 Média e erro padrão da média ( \pm EPM) da potência 0 $\mathrm{mW}$ nas durações do tratamento de 5 e 10 minutos para a motilidade progressiva (Prog), velocidade média de trajeto (VAP), velocidade linear progressiva (VSL), velocidade curvilínea (VCL), população de alto potência de membrana mitocondrial (alto), população com potencial de membrana mitocondrial intermediário (inter) - São Paulo, 2011

Gráfico 26 Média e erro padrão da média $( \pm$ EPM) da potência 5 $\mathrm{mW}$ nas durações de 5 e 10 minutos de tratamento para a motilidade progressiva (Prog), velocidade média de trajeto (VAP), velocidade linear progressiva (VSL), velocidade curvilínea (VCL), população de alto potência de membrana mitocondrial (alto), população com potencial de membrana mitocondrial intermediário (inter) - São Paulo, 2011

Gráfico 27 Média e erro padrão da média ( \pm EPM) da potência 7,5 $\mathrm{mW}$ nas durações de 5 e 10 minutos de tratamento para a motilidade progressiva (Prog), velocidade média de trajeto (VAP), velocidade linear progressiva (VSL), velocidade curvilínea (VCL), população de alto potência de membrana mitocondrial (alto), população com potencial de membrana mitocondrial intermediário (inter) - São Paulo, 2011

Gráfico 28 Média e erro padrão da média ( \pm EPM) da potência 10 $\mathrm{mW}$ nas durações de 5 e 10 minutos de tratamento para a motilidade progressiva (Prog), velocidade média de trajeto (VAP), velocidade linear progressiva (VSL), velocidade curvilínea (VCL), população de alto potência de membrana mitocondrial (alto), população 
com potencial de membrana mitocondrial intermediário (inter) - São Paulo, 2011

Gráfico 29 Média e erro padrão da média ( \pm EPM) da potência 0 $\mathrm{mW}$, imediatamente após a aplicação do tratamento (PÓS) e após 30 minutos do início do tratamento para a motilidade visual (Mot), vigor e alongação das células (Elong) - São Paulo, 2011

Gráfico 30 Média e erro padrão da média ( \pm EPM) da potência 5 $\mathrm{mW}$, imediatamente após a aplicação do tratamento (PÓS) e após 30 minutos do início do tratamento para a motilidade visual (Mot), vigor e alongação das células (Elong) - São Paulo, 2011

Gráfico 31 Média e erro padrão da média ( \pm EPM) da potência 7,5 mW, imediatamente após a aplicação do tratamento (PÓS) e após 30 minutos do início do tratamento para a motilidade visual (Mot), vigor e alongação das células (Elong) - São Paulo, 2011

Gráfico 32 Média e erro padrão da média $( \pm$ EPM) da potência 10 $\mathrm{mW}$, imediatamente após a aplicação do tratamento (PÓS) e após 30 minutos do início do tratamento para a motilidade visual (Mot), vigor e alongação das células (Elong) - São Paulo, 2011 


\section{LISTA DE QUADROS}

Quadro 1 Potência, duração do tratamento e fluência dos grupos tratamento e controle - São Paulo - 2011

Quadro 2 Concentração espermática, concentração e volume das sondas fluorescentes, tempo e temperatura de incubação no preparo das amostras para a leitura no citômetro de fluxo - São Paulo - 2011 


\section{LISTA DE TABELAS}

Tabela 1 Valor de $\mathrm{p}$ do efeito, da potência, da duração do tratamento e do momento de análise, assim como as interações dos efeitos para cada variável estudada - São Paulo, 2011

Tabela 2 Valores de $\mathrm{P}$ para os efeitos tratamento, tempo e tratamento*tempo para os parâmetros espermáticos analisados - São Paulo, 2011

Tabela 3 Médias e erro padrão da média ( \pm EPM) dos grupos tratado e controle, nos atributos espermáticos analisados e respectivos valores de $\mathrm{P}$ para o efeito de tratamento São Paulo, 2011

Tabela 4 Média e erro padrão da média $( \pm$ EPM) dos três momentos de análise e valor de $\mathrm{P}$ para efeito tempo São Paulo, 2011

Tabela 5 Média e erro padrão da média ( \pm EPM) do grupo tratado e controle nos três momentos de análise e o valor de $\mathrm{P}$ para a interação Tratamento*Tempo - São Paulo, 2011

Tabela 6 Valores de $\mathrm{P}$ para os efeitos tratamento, tempo e tratamento*tempo para os parâmetros do ensaio cometa alcalino - São Paulo, 2011

Tabela 7 Média \pm EPM do grupo tratado e controle para o ensaio cometa alcalino e valores de $\mathrm{P}$ para o efeito de tratamento - São Paulo, 2011 - São Paulo, 2011 
Tabela 8 Média \pm EPM dos momentos de análise do ensaio cometa alcalino e valor de $\mathrm{P}$ para o efeito de tempo São Paulo, 2011

Tabela 9 Médias \pm EPM dos grupos tratado e controle, nos três momentos de análise (T0, T10 e T30) e valores de P para a interação Tratamento*Tempo - São Paulo, 2011

Tabela 10 Médias \pm EPM das taxas de produção in vitro de embriões dos grupos tratado (laser), controle e o valor de P - São Paulo, 2011

Tabela 11 Médias \pm EPM das avaliações embrionárias e o valor de P - São Paulo, 2011 


\section{LISTA DE ABREVIATURAS E SIGLAS}

$\begin{array}{cl}\boldsymbol{+ +} & \text { Três cruzes } \\ \boldsymbol{\mu g} & \text { Micrograma } \\ \boldsymbol{\mu l} & \text { Microlitro } \\ \boldsymbol{\mu m} & \text { Micrômetro } \\ \mathbf{3 D} & \text { Tridimensional } \\ \mathbf{A I} & \text { Acrossomo íntegro } \\ \mathbf{A L} & \text { Acrossomo lesado } \\ & \text { É o resultado da divisão da fluorescência vermelha pela } \\ & \text { Fluorescência total (vermelho + verde) da cromatina de }\end{array}$

AlfaTYlog cada espermatozóide.

Amplitude de deslocamento lateral da cabeça em

$\begin{array}{cl}\text { ALH } & \text { micrometros } \\ \text { ANOVA } & \text { Análise de variância } \\ \text { ATP } & \text { Adenosil trifosfato } \\ \text { BCF } & \text { Freqüência de batida cruzada } \\ \text { CASA } & \text { Computer-assisted sperm analysis } \\ \text { CCO } & \text { Complexos cumulus oophorus } \\ \text { CD46 } & \text { Cluster of differentiation 46 } \\ \text { Cels } & \text { Células } \\ \text { cm }{ }^{2} & \text { Centímetros quadrados } \\ \text { CO2 } & \text { Dióxido de carbono } \\ \text { CPCs } & \text { Centrais de Processamento e Colheita de Sêmen } \\ \text { DABCO } & \text { 1,4-Diazabicyclo [2.2.2] octane } \\ \text { DNA } & \text { Ácido desoxirribonucleico } \\ \text { dUTP } & \text { Deoxynucleotidyl transferase mediated } \\ \text { EDTA } & \text { Ethylenediamine tetraacetic acid } \\ \text { EPM } & \text { Erro padrão da média }\end{array}$




\begin{tabular}{|c|c|}
\hline \multirow[t]{2}{*}{ EROs } & Espécies reativas de oxigênio \\
\hline & Psium sativum conjugada ao fluoróforo isotiocionato de \\
\hline FITC-PSA & fluoresceína \\
\hline FIV & Fecundação in vitro \\
\hline $\mathbf{g}$ & Grama \\
\hline g & Força centrífuga \\
\hline $\mathbf{G}$ & Gauge \\
\hline GaAIAs & Gallium aluminium arsenide \\
\hline GaAs & Gallium arsenide \\
\hline $\mathbf{h}$ & Hora \\
\hline He-Ne & Helium néon \\
\hline Hoechst 33342 & Trihydrochloride, trihydrate \\
\hline ICSI & Injeção intra-citoplasmática de espermatozóides \\
\hline IP & Iodeto de propídio \\
\hline \multirow[t]{2}{*}{$\mathbf{J}$} & Jaule \\
\hline & 5,5',6,6'-tetrachloro-1,1',3,3' \\
\hline JC-1 & tetraethylbenzimidazolylcarbocyanine iodide \\
\hline $\mathbf{K}$ & Potássio \\
\hline $\mathbf{l}$ & Levógiro \\
\hline LASER & Light Amplification by Stimulated Emissions of Radiation \\
\hline LIN & Linearidade \\
\hline $\mathbf{L M}$ & Low melting \\
\hline $\mathbf{m A}$ & Miliampere \\
\hline Min & Minuto \\
\hline MIV & Maturação in vitro \\
\hline mg & Miligrama \\
\hline $\mathbf{m L}$ & Mililitro \\
\hline $\mathbf{m m}$ & Milimetro \\
\hline $\mathbf{m W}$ & Miliwatt \\
\hline $\mathbf{n}$ & Número \\
\hline $\mathbf{N a}$ & Sódio \\
\hline NADH & Dinucleotideo de nicotinamida e adenina \\
\hline Nd:YAG & Neodymium: yttrium aluminium garnet \\
\hline
\end{tabular}




\begin{tabular}{|c|c|}
\hline $\mathbf{n m}$ & Nanômetro \\
\hline NM & Normal melting \\
\hline${ }^{\circ} \mathbf{C}$ & Graus celsius \\
\hline $\mathbf{P}$ & $\mathrm{P}$ valor \\
\hline PBS & Solução salina fosfatada \\
\hline $\mathbf{p H}$ & Potencial hidrogeniônico \\
\hline $\mathbf{P I}$ & Membrana plasmática íntegra \\
\hline PIV & Produção in vitro \\
\hline PL & Membrana plasmática lesada \\
\hline PVP & Polivinilpirrolidona \\
\hline RNAm & Ácido ribonucléico mensageiro \\
\hline $\mathbf{S}$ & Segundo \\
\hline SAS & Statistic analysis system \\
\hline SCSA & Sperm chromatin struture assay \\
\hline SFB & Soro fetal bovino \\
\hline SOF & Synthetic oviduct fluid \\
\hline STR & Retidão \\
\hline T0 & Tempo zero \\
\hline T10 & Tempo 10 \\
\hline T30 & Tempo 30 \\
\hline TALP & Modified tyrode's albumin lactate pyruvate \\
\hline TCM & Tissue culture medium \\
\hline TBE & Tris-boric-EDTA \\
\hline TNE & Tris-NaCL-EDTA \\
\hline TUNEL & Terminal Transferase dutp Nick End Labeling \\
\hline $\mathbf{U V}$ & Luz ultravioleta \\
\hline VAP & Velocidade média de percurso \\
\hline VCL & Velocidade curvo-linear \\
\hline VSL & Velocidade linear \\
\hline $\mathbf{W}$ & Watt \\
\hline $\mathbf{X}$ & Vezes \\
\hline
\end{tabular}




\section{LISTA DE SÍMBOLOS}

\begin{tabular}{ll}
$\boldsymbol{\alpha}$ & Alfa \\
$*$ & interação \\
${ }^{\circledR}$ & Marca registrada \\
${ }^{\mathbf{O}}$ & Graus Celsius \\
$>$ & Maior que \\
+ & Mais \\
\pm & Mais ou menos \\
TM & Marca Registrada \\
$\leq$ & Menor ou igual \\
$<$ & Menor que \\
$=$ & Igual \\
$\geq$ & Maior ou igual \\
$>$ & Maior que \\
$\boldsymbol{\Psi}$ & Menos \\
- & Micro \\
\hline &
\end{tabular}




\section{SUMÁRIO}

1 INTRODUÇÃO

2 REVISÃO DE LITERATURA _............................................... 34

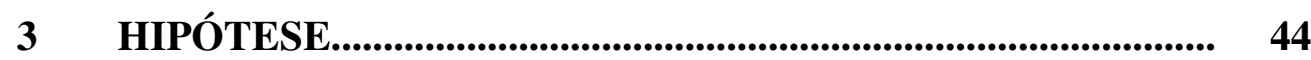

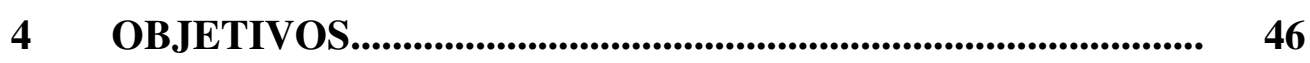

4.1 OBJETIVOS GERAIS................................................................. 46

4.2 OBJETIVOS ESPECÍFICOS........................................................ 46

5 MATERIAL E MÉTODO.................................................... 48

5.1 EXPERIMENTO 1....................................................................... 48

5.2 EXPERIMENTO 2............................................................ 58

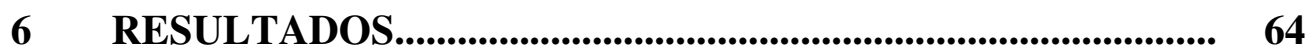

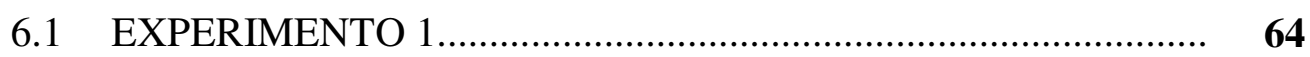

6.2 EXPERIMENTO 2.............................................................. 84

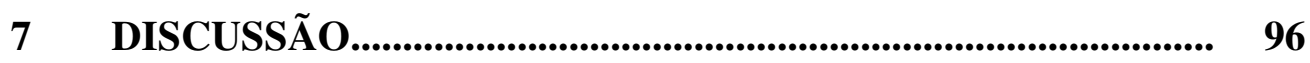

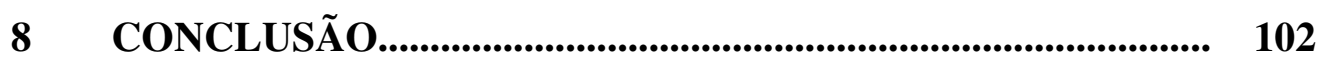

REFERÊNCIA BIBLIOGRÁFICA........................................... 104

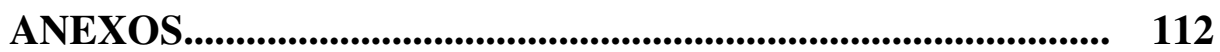


INTRODUÇÃO 


\section{INTRODUÇÃO}

A produção in vitro (PIV) de embriões bovinos é uma ferramenta de grande importância na reprodução, permitindo a utilização mais intensa de animais com alto potencial genético, além de permitir a utilização de animais jovens, gestantes ou lactantes e com infertilidade adquirida (TERVIT, 1996; TANEJA et al., 2000). O uso de animais jovens diminui o intervalo entre as gerações, acelerando com isso o ganho genético (LOHUIS, 1995; TANEJA et al., 2000). No âmbito acadêmico, esta técnica é amplamente utilizada na rotina de laboratórios que pesquisam transgenia, clonagem e outras diferentes áreas da biologia da reprodução (KRISSHER; BAVISTER, 1998; KHURANA; NIEMANN, 2000; BARD et al., 2006).

No entanto, apesar da grande aplicabilidade tanto comercial quanto acadêmica, a PIV ainda é considerada uma técnica com eficiência limitada pelo alto custo e pelas condições sub-ótimas de sobrevivência embrionária e fetal (HANSEN et al., 2006). Ao longo dos anos, muitos relatos descrevem que distintos fatores inerentes ao oócito (qualidade), aos diferentes sistemas de cultivo (co-cultura, meios de cultivo, densidade embrionária e diferentes atmosferas gasosas) afetam as taxas de implantação de embriões provenientes da PIV (KHURANA; NIEMANN, 2000). Apesar da importância destes fatores, a influência paterna não pode ser esquecia.

O espermatozóide carreia tanto o material genético haplóide quanto os fatores citoplasmáticos que são necessários para o desenvolvimento embrionário normal, sendo já estabelecido que alterações espermáticas reduzem as taxas de desenvolvimento embrionário (ERENPREISS et al., 2006). A influência paterna atua na fase pré-implantacional, pois apresenta fatores espermáticos importantes para a ativação oocitária (TESARIK, GRECO, MENDONZA, 2002). Em 2005, Tesarik e colaboradores verificaram que a influência paterna possui efeitos negativos no desenvolvimento embrionário mais tardio, quando as células espermáticas apresentam danos no DNA ou apresentam alterações da organização da cromatina espermática. Isso ocorre devido à modificação da expressão de genes paternos.

Apesar da motilidade, do potencial de membrana mitocondrial e da integridade das membranas plasmática e acrossomal estarem diretamente relacionadas à capacidade de fecundação dos espermatozóides, outras características seminais, que podem não prejudicar diretamente a fecundação, tem demonstrado alta relação com problemas de fertilidade 
(EVERSON; WIXON, 2006). Assim, a avaliação, tanto da integridade do DNA, quanto da conformação do empacotamento da cromatina são fatores relevantes a serem correlacionados da influência paterna no desenvolvimento embrionário.

Devido à importância que o gameta masculino desempenha no processo da PIV de embriões bovinos, o desenvolvimento de novas técnicas que incrementem a fertilidade de uma amostra de sêmen é de interesse para o setor produtivo. $\mathrm{O}$ efeito do laser de baixa potência no sêmen de diferentes espécies animais, demonstrado por diversos autores, sugere a aplicação desta ferramenta como uma possibilidade de aumentar o potencial de fecundação dos espermatozóides, a fim de aumentar os resultados na PIV. Apesar do uso do laser já estar de certo modo bem disseminado, os mecanismos de interação biológica, efeitos da aplicação deste em funções e atributos espermáticos, assim como a influência paterna na PIV, ainda não estão completamente elucidados. No entanto, sabe-se que a interação depende do tipo celular e das características do laser, o que dificulta a extrapolação dos efeitos entre tipos celulares e de laser (CORRAL-BAQUÉS et al., 2005), bem como entre diferentes espécies. O apelo deste trabalho é, portanto, estabelecer a melhor relação potência X duração do tratamento para a irradiação de espermatozóides bovinos com o intuito de aumentar a produção in vitro de embriões. 
REVISÃO DE LITERATURA

$\sim \cos x x^{2}$ 


\section{REVISÃO DE LITERATURA}

A eficiência reprodutiva dos animais domésticos é uma das maiores preocupações econômicas da pecuária mundial. Segundo Screenan e Diskinn (1983), aproximadamente 90\% do sucesso produtivo pode estar relacionado às taxas de fecundação e de desenvolvimento embrionário inicial. A produção in vitro (PIV) de embriões (que consiste na maturação, fecundação de oócitos imaturos e cultivo in vitro de embriões) é uma poderosa ferramenta no melhoramento animal. No Brasil, esta técnica é amplamente usada na espécie bovina, sendo mais de 255.000 embriões produzidos in vitro em 2009, o que representa $85,8 \%$ do total de embriões produzidos (VIANA et al., 2010). Porém, o incremento do uso comercial da PIV depende diretamente da melhoria da produção de embriões, com redução do custo.

A PIV é, ainda hoje, considerada uma biotecnologia de baixa eficiência (VIANA et al., 2010), sendo classificada como um sistema de produção subótimo (RIZOS et al., 2002). Isto se deve ao fato desta biotécnica apresentar menor taxa de prenhez (33,52\%) quando comparada à produção in vivo (41,52\%) (PONTES et al., 2009). Contudo, Hansen et al. (2006) consideram que a maioria dos problemas técnicos associados à produção in vitro de embriões, pode ser superada por meio de pesquisas inovadoras.

Portanto, técnicas de baixo custo que proporcionem melhorias na qualidade seminal, possibilitando assim, um incremento na produtividade de embriões é de grande interesse para a pecuária nacional.

A influência paterna no desenvolvimento embrionário ocorre já nas primeiras etapas da fecundação (TESARIK; GRECO; MENDONZA, 2004). Defeitos nos espermatozóides podem levar à falha imediata ou em ciclos celulares subseqüientes (MÉNÉZO, 2006). Embriões bovinos produzidos por espermatozóides submetidos a danos no DNA, induzido por radiação UV, por exemplo, falham no desenvolvimento a partir de duas células, sugerindo que estes espermatozóides são capazes de ativar o oócito, no entanto podendo haver falha na primeira mitose (BORDIGNON; SMITH, 1999). Fatehi et al. (2006) demonstraram que alguns espermatozóides resistiam à irradiação UV e que atributos como motilidade, atividade mitocondrial, integridade das membranas plasmática e acrossomal desses espermatozóides não diferem quando comparadas aos espermatozóides não irradiados. Porém, uma relação logarítimica altamente significativa entre a dose de irradiação e os danos no DNA espermático foi relatada. Utilizando os espermatozóides irradiados na fecundação in vitro, os autores 
observaram que não houve redução da capacidade de fecundação dos espermatozóides e nem da taxa de clivagem. Contudo, observaram que quando utilizavam espermatozóides irradiados, ocorria bloqueio do desenvolvimento embrionário após as primeiras clivagens, sinais específicos de apoptose nos embriões e esporádicas formações de blastocistos.

A qualidade seminal é fundamental para a obtenção de altos índices reprodutivos (SAACKE et al., 1994). No entanto, durante a manipulação do sêmen, as células espermáticas são expostas a uma série de fatores deletérios como, diluição, incubação, centrifugação, congelação e descongelação que possuem uma reconhecida capacidade de afetar a sobrevivência e o potencial de fecundação (BOE-HANSEN et al., 2005), além de poder causar danos à qualidade genética do sêmen (HAMMADEH et al., 1999;KRZYZOSIAK et al., 2000).

O espermatozóide é responsável por carrear o material genético até o oócito durante a fecundação (KNOBIL; NEILL, 1994), assim a motilidade é muito importante, sendo a movimentação flagelar do espermatozóide sensível às alterações externas ou internas a célula. Para um espermatozóide fecundar um oócito, precisa manter, no mínimo, quatro atributos: a) metabolismo para produção de energia; b) motilidade progressiva; c) enzimas, situadas dentro do acrossoma, essenciais para a aderência e a penetração do espermatozóide no oócito; d) proteínas na membrana plasmática importante para a sobrevivência do espermatozóide dentro do sistema reprodutor feminino (AMANN; PICKETT, 1987).

A análise de sêmen computadorizada (do inglês "Computer-Assisted Sperm Analysis" - CASA) permite uma avaliação objetiva de diferentes características celulares como: movimento, velocidade e morfologia. Dentre as características analisadas estão: velocidade curvo-linear (VCL); amplitude de deslocamento lateral da cabeça em micrometros (ALH), que esta correlacionada com a capacidade do espermatozóide vencer a barreira do muco cervical e penetrar no oócito; freqüência de batida cruzada $(\mathrm{BCF})$, que é a frequência na qual a cabeça do espermatozóide cruza o caminho médio do espermatozóide; velocidade média de percurso (VAP), que corresponde à velocidade média do trajeto em $\mu \mathrm{m} / \mathrm{s}$; velocidade linear (VSL), que é a velocidade média, em linha reta, do início ao fim do trajeto em $\mu \mathrm{m} / \mathrm{s}$; retidão (STR), que é o valor médio da relação percentual entre VSL e VAP (estima quão próximo é o trajeto realizado pela célula a uma reta, sendo $100 \%$ o ideal de retidão) e, finalmente, a linearidade (LIN) que é o valor médio da relação percentual entre VSL e VCL (a linearidade é a estimativa da proximidade do percurso da célula com a linha reta) (VERSTEGEN, 2002). 
Contudo, maiores evidências que correlacionem os parâmetros analisados pelo CASA com a fertilidade, ainda precisam ser aprofundados.

O espermatozóide é essencial para a fecundação, pois além de carrear o DNA paterno é o responsável em ativar o oócito após a penetração, além de possuir RNAm essenciais para sustentar as primeiras clivagens. Por ser uma célula tão importante, a morfologia, a estrutura, os mecanismos de ação e de sinalização celular são particulares. Por ser uma célula de grande importância na preservação das espécies, possui distintos domínios de membrana, que conferem a cada segmento uma função e uma ação determinadas (KNOBIL; NEILL, 1994). Devido a estas características dos espermatozóides, uma análise detalhada dos diferentes atributos espermáticos é essencial.

A integridade da membrana espermática é fundamental para a sobrevivência do espermatozóide, sendo responsável pelo equilíbrio osmótico celular, funcionando como barreira entre o meio intra e extracelular. Danos na membrana plasmática podem levar à perda da homeostasia e consequente morte celular (AMANN; PICKETT, 1987; AMANN; GRAHAM, 1993). Além disto, a membrana plasmática possui proteínas específicas que facilitam o transporte de glicose e de frutose do ambiente extracelular. Estes substratos são fonte de energia indispensável para a sobrevivência da célula (SILVA; GADELLA, 2006). A integridade da membrana pode ser avaliada com o uso de corantes impermeáveis, assim células que não estiverem coradas indicam que a membrana plasmática está intacta. Sondas fluorescentes impermeáveis à membrana com afinidade pelo DNA também são usadas com este propósito. O iodeto de propídio (IP) é um exemplo destas sondas (SILVA; GADELLA, 2006).

O acrossoma é uma vesícula grande que contém enzimas hidrolíticas, sendo originado pela união de vesículas geradas do complexo de Golgi da espermátide e transportadas por uma rede de microtúbulos e actina (KIERZENBAUM, A. L., 2008). Durante a reação acrossômica, ocorre a liberação destas enzimas, que são responsáveis pela digestão das células do cumulus do oócito, e a exposição de receptores de membrana que são responsáveis pela penetração do espermatozóide na zona pelúcida e conseqüente fusão com a membrana plasmática (DIAZ-PEREZ, E; THOMAS, P.; MEIZEL, S., 1988).

A integridade do acrossoma pode ser avaliada com o uso de lecitinas conjugadas aos fluoróforos (marcadores de lisossomos) ou de anticorpos anti-proteína intra-acrossomal (antiCD46). As lecitinas conjugadas se ligam às cadeias de carboidratos glicoprotéicos presentes no acrossoma (SILVA; GADELLA, 2006). A lecitina Psium sativum conjugada ao fluoróforo 
isotiocionato de fluoresceína (FITC-PSA) é uma das mais utilizadas (CELEGHINI et al., 2007)

As mitocôndrias são organelas responsáveis pela produção de ATP através de respiração aeróbia (TUNER, 2006). Muitos relatos indicam relação direta entre a motilidade e a atividade mitocondrial (TROIANO et al., 1998), porém o mecanismo pelo qual esta relação é estabelecida não está bem compreendido (EDDY; O`BRIEN, 1994). Segundo Ford (2006), a glicólise local pode fornecer energia para o flagelo distal, mas, as evidências de que esta é necessária são fracas, sendo provável que a difusão reforçada pela adenilato quinase e outros transportadores seja suficiente para a troca de ATP, ADP e Pi entre o flagelo e as mitocôndrias presentes na peça intermediária na taxa necessária para sustentar a motilidade espermática.

Há consenso, no entanto, que a integridade da mitocôndria é fundamental para a sobrevivência do espermatozóide no trato genital da fêmea ou em técnicas de reprodução assistida (SILVA; GADELLA, 2006).

Para a determinação do potencial de membrana das mitocôndrias, dentre as sondas mais utilizadas está 5,5',6,6'-tetrachloro-1,1',3,3'-tetraethylbenzimidazolylcarbocyanine iodide (JC-1) (SILVA; GADELLA, 2006). O JC-1 é uma carbocianina catiônica lipofílica que é internalizada por todas as mitocôndrias funcionantes fluorescendo em verde. Em mitocôndrias altamente funcionais há um aumento na concentração do JC-1 formando agregados que fluorescem em laranja (GILLAN, EVANS, MAXWELL, 2005).

Apesar da utilização de sondas fluorescentes permitirem uma avaliação rigorosa de muitos atributos seminais, o método de avaliação em microscopia é laborioso limitando o número de células avaliadas. A utilização de sondas fluorescentes, associadas à citometria de fluxo, permite avaliar 200 vezes mais células do que a avaliação por microscopia em menos de 1 minuto, aumentando o tamanho da amostra analisada e diminuindo o tempo requerido (ARRUDA, 2000).

O espermatozóide é uma célula altamente diferenciada, sendo a cromatina organizada de forma única, o que a difere quando comparada a uma célula somática (ROCHA et al., 2002; McLAY; CLARKE, 2003). No final da espermiogênese, as histonas, conjunto de proteínas compactadoras de duplas fitas de DNA, são substituídas por nucleoproteínas específicas chamadas de protaminas (processo denominado de protaminação). Após a ligação com esta proteína, a cromatina se apresenta inerte e altamente condensada pela interação de resíduos amina da protamina com os grupos fosfatos do DNA, neutralizando o esqueleto 
fosfodiéster (ROCHA et al., 2002). Aproximadamente $85 \%$ do DNA espermático estão associados às protaminas e apenas $15 \%$ se mantém associados às histonas (SINGH et al, 2003). Defeitos no DNA, como a quebra da fita que pode afetar uma ou as duas cadeias da molécula de DNA, podem resultar na alteração da sequência original e desencadear efeitos indesejáveis ao embrião (TESARIK et al., 2005).

Uma das técnicas utilizadas para analisar a conformação do material genético espermático é o ensaio de estrutura de cromatina do espermatozóide (do inglês "Sperm Chromatin Struture Assay - SCSA), sendo a correlação deste com a fertilidade de touros a campo, relatada por Saacke et al. (1987). O SCSA baseia-se na marcação do DNA com laranja de acridina, assim tanto a estrutura quanto a estabilidade da cromatina podem ser avaliadas pela técnica da citometria de fluxo.

O SCSA é uma técnica que avalia a susceptibilidade do espermatozóide a sofrer denaturação ácida. Já o ensaio cometa baseia-se na detecção de quebras nas fitas de DNA em célula única, utilizando lâmina de microscopia. A técnica consiste na mistura de sêmen com agarose derretida, sendo esta depositada sobre a lâmina. As células são previamente lisadas, expostas a um $\mathrm{pH}$ elevado e as lâminas submetidas à eletroforese horizontal. $\mathrm{O}$ alto peso molecular do DNA íntegro é responsável pela manutenção do DNA na cabeça do espermatozóide, enquanto que os pedaços menores do DNA fragmentado migram formando a cauda do cometa, justificando o nome da técnica. Esta técnica já foi utilizada em sêmen de garanhões para detectar danos no DNA em resposta a crio-injúria (LINFOR; MEYERS, 2002); em sêmen suíno foi usada para detectar danos no DNA durante o armazenamento refrigerado (FRASER; STRZEZEK, 2004) e em sêmen bovino usado em estudos com sêmen sexado e após a congelação/descongelação. O ensaio cometa é uma técnica quantitativa, rápida e simples que tem provado ser muito sensível para a detecção de quebras nas fitas de DNA no sêmen humano (HUGHES et al., 1996; IRVINE et al., 2000).

De acordo com Slowinska et al. (2008), ao realizar o ensaio Cometa Alcalino em amostras de sêmen congelados/descongelados, relataram por métodos computadorizados, diminuição de 3,8\% de DNA na cabeça do cometa e um aumento de 5,3\% no comprimento da cauda. Por serem alterações sutis, os autores recomendam a utilização de métodos computadorizados para esta análise.

Sabendo que um dos principais fatores que pode alterar tanto a fecundação como o desenvolvimento embrionário é a qualidade seminal, o laser de baixa potência tem sido 
sugerido como uma possibilidade de aumentar o potencial de fecundação dos espermatozóides, a fim de aumentar os resultados obtidos na PIV.

Light Amplification by Stimulated Emissions of Radiation (LASER) são aparelhos que pela geração de uma descarga elétrica, estimulam elétrons de uma substância radioativa a absorverem energia e a mudarem para uma órbita em um nível mais alto de energia. Porém, por ser instável, este elétron retorna à órbita original, sendo que durante o retorno ocorre um fenômeno denominado emissão espontânea. Este fenômeno compreende a liberação da energia excedente em forma de fóton, uma partícula de transmissão de um tipo de energia eletromagnética (BAXTER, 1994; BAGNATO, 2001).

O fóton oriundo da emissão espontânea vai perturbar outros átomos com elétrons excitados, estimulando o decaimento do elétron excitado e este, ao passar para um estado de mais baixa energia, emite outro fóton que emerge do sistema juntamente com aquele que causou a transição (emissão estimulada). Deste modo, na emissão estimulada, o causador do efeito sai intacto e o fóton gerado, possui a mesma energia e propaga-se na mesma direção. Os dois fótons gerados vão novamente perturbar outros átomos com elétrons excitados, havendo emissão de mais fótons que se juntam aos iniciais. Todos estes fótons, que emergem do sistema são novamente jogados sobre ele por meio de espelhos, fazendo com que os fótons emitidos interajam mais com os átomos. Desta forma, há multiplicação do número de fótons emitidos pelo processo de emissão estimulada, amplificando a quantidade de luz que sairá do sistema. Após vários passos, os fótons que se movimentam através do meio que forma o laser, constituirão um feixe que apresenta alta intensidade. Uma abertura no sistema em uma das extremidades do espelho permite que uma fração desta luz deixe o sistema continuamente. A luz laser tem como propriedades serem monocromáticas, atingirem altas intensidades, ter feixe unidirecional e possuir coerência, esta última propriedade significa que as ondas eletromagnéticas possuem mesma direção e comprimento de onda (BAGNATO, 2001).

Características do laser, como potência e propriedades terapêuticas são definidas pelo comprimento de onda que por sua vez depende da substância radioativa que o compõe. Quanto menor o comprimento de onda, maior a ação e o poder de penetração (ROCHA JÚNIOR et al., 2007). A substância radioativa ou meio ativo, pode estar na forma de cristais sólidos, como o ruby sintético (neodymium: yttrium aluminium garnet - Nd:YAG), de gases, como o helium néon (He-Ne) e o dióxido de carbono $\left(\mathrm{CO}_{2}\right)$ ou de semicondutores diodos, como o gallium arsenide (GaAs) e o gallium aluminium arsenide (GaAIAs) (ENWEMEKA, 1988). 
O laser de baixa potência emite uma energia com efeitos fotobiológicos, fotofísicos, fotoquímicos e não-térmicos (ROCHA JÚNIOR et al., 2007). A utilização terapêutica depende se o efeito biológico, o qual o laser pode apresentar, é estimulador ou inibidor (KANEPS et al., 1983).

A reatividade de átomos e moléculas depende da estrutura eletrônica, dos níveis de energia e das possíveis transições, fundamentais para as interações intra-átomos ou intramolecular (PASSARELA; DECHECCHI; QUAGLIARIELLO, 1981). Estes autores demonstraram que a irradiação com potência de $13 \mathrm{~mW}$, de laser $\mathrm{He}-\mathrm{Ne}$, em soluções de $\mathrm{NADH}$ induz alterações no comportamento bioquímico desta coenzima. Experimentos alterando co-fatores e enzimas demonstraram que o NADH é sensível a irradiação laser e pode estar envolvido no mecanismo de alteração da atividade intracelular, causada por este.

Assim como o NADH, acredita-se que existam outros fotoaceptores celulares, sensíveis a determinados comprimentos de onda, que absorvem os fótons desencadeando reações químicas, como por exemplo, a glicólise e a oxidação fosforilativa, resultando na aceleração da síntese, da transcrição e da replicação de DNA, em longo prazo (KARU, 1987).

A utilização do laser como terapia analgésica e antiinflamatória foi eficazmente demonstrada por Ozdemir et al. (2001) e Porter et al. (2005), respectivamente, sendo utilizada efetivamente em áreas como a fisioterapia, a dermatologia e a odontologia.

Peplow et al. (2010) realizaram uma extensa revisão avaliando o efeito do laser de baixa potência na proliferação e na viabilidade celular in vitro de diversos tipos celulares de humanos e de animais. Dentre eles células-tronco, células endoteliais, células da musculatura lisa, queratinócitos, monócitos, fibroblastos e linhagens celulares foram estudados. Os parâmetros avaliados incluíam número de células, viabilidade celular, dano de DNA, integridade de membrana, síntese e liberação de proteínas, morfologia celular, organelas celulares e características ultraestruturais. Em decorrência da aplicação de laser foi demonstrada proliferação celular incluindo medidas como número de célula, viabilidade celular, integridade de membrana e dano de DNA e diferenciação de células-tronco em tipos celulares específicos. Os achados demonstram a habilidade do laser em modular a proliferação celular (geralmente estimulação). Entre os mecanismos moleculares relacionados observou-se ativação da cadeia respiratória mitocondrial e início da sinalização celular como a indução da fosforilação do receptor da proteína tirosina quinase. Os efeitos diretos do laser puderam ser detectados 1 a 3 horas após a irradiação, enquanto que os efeitos indiretos (proliferação e expressão de proteínas) necessitam de um período superior à 24h. Deste modo, 
a efetividade do laser em aumentar ou diminuir a proliferação celular em diversos tipos celulares e a dependência dos parâmetros de irradiação como comprimento de onda, potência, fluência, número de exposições e intervalo entre exposições estão bem consolidadas.

$\mathrm{Na}$ área de reprodução, utilizando-se um comprimento de onda de $780 \mathrm{~nm}(13 \mathrm{~mW}$ e $40 \mathrm{~mW}$ ) do laser diodo e laser de gás He-Ne (10 mW e $35 \mathrm{~mW})$, com um comprimento de $633 \mathrm{~nm}$ em baixa potência foi verificado aceleração do transporte de cálcio em espermatozóides irradiados. Tal resultado indica que o laser pode causar alterações na concentração de cálcio intracelular, o que em se tratando de espermatozóide, tem papel regulatório no controle da motilidade e na reação acrossomal (LUBART et al., 1992).

O laser He-Ne $(10 \mathrm{~mW})$ foi utilizado como alternativa para a indução da capacitação espermática, sendo também eficiente em induzir a reação acrossomal, o que resultou numa diminuição da mortalidade espermática quando comparado com outros agentes capacitantes, como o cálcio ionóforo e a heparina (OCAÑA-QUERO, 1997).

Lubart et al. (2000) observaram que ao irradiar amostras de sêmen bovino com laser com comprimentos de onda de 360, 630, 660 e 830nm, a produção de radicais hidroxilas foi estimulada. Tal produção é baseada na hipótese de que os fotoaceptores (porfirinas endógenas, os citocromos de membrana e as mitocôndrias) responsáveis pela fotobioestimulação são foto-sensibilizadores, e, portanto geram EROs (espécies reativas de oxigênio) após a irradiação. Lavi et al. (2011) demonstraram a indução da produção de EROs em membrana espermática isolada quando irradiada com comprimentos de onda de 400 a $800 \mathrm{~nm}$ e potências de 40 ou $130 \mathrm{~mW} / \mathrm{cm}^{2}$.

O laser diodo com comprimento de $1,48 \mu \mathrm{m}$ induziu imobilização e permeabilização da membrana plasmática em espermatozóides humanos (MONTAG et al., 2000). Quando utilizado para a imobilização de espermatozóide para a injeção intra-citoplasmática de espermatozóides (ICSI) na reprodução humana, apresentou bons resultados de fecundação, de desenvolvimento embrionário e de formação de blastocisto in vitro (EBNER et al., 2002). Em reprodução humana também foi demonstrado aumento significativo na motilidade de espermatozóides humanos, após 30 minutos de tratamento laser de $905 \mathrm{~nm}\left(50 \mathrm{~mW} / \mathrm{cm}^{2}\right)$, sem haver aumento significativo do dano ao DNA (FIRESTONE et al., 2011).

Corral-Baqués et al. (2005) relataram aumento significativo na motilidade espermática de cães, 15 a 45 minutos após a irradiação, com comprimento de onda de 655nm de laser diodo $(21,7 \mathrm{~mW})$ e queda na produção de L-lactato. Esta relação inversa entre a motilidade e a produção de lactato, indica uma alteração no metabolismo aeróbico, para a produção de 
energia e um provável aumento na eficiência energética. Em sêmen canino também foi avaliado o efeito da aplicação laser $(655 \mathrm{~nm})$ em diferentes potências $(6.8 \mathrm{~mW}, 14.5 \mathrm{~mW}, 33.1$ $\mathrm{mW}$ e $49.7 \mathrm{~mW}$ ) na motilidade de espermatozóides. Este estudo relatou efeitos mais intensos, proporcionais ao aumento da potência (CORRAL- BAQUÉS et al., 2009).

Em outros animais, como o peru, com a utilização de laser de gás He-Ne $(6 \mathrm{~mW})$ também foi demonstrado aumento de motilidade e de qualidade seminal após armazenamento de até 60 horas, após irradiação (IAFFALDANO et al., 2005). Na espécie eqüina, Brandão (2008) obteve aumento da freqüência de batimento flagelar em sêmen fresco e observou melhor proteção às membranas plasmática e acrossomal após $2 \mathrm{~h}$ de incubação, utilizando laser diodo $(50 \mathrm{~mW})$ com $650 \mathrm{~nm}$ de comprimento de onda. Já em sêmen de coelhos, a aplicação de laser He-Ne $(6 \mathrm{~mW})$ proporcionou efeito de proteção na motilidade, viabilidade e integridade de acrossomo durante o armazenamento do sêmen (IAFFALDANO, 2010).

Apesar do uso do laser estar de certo modo disseminado, os mecanismos de interação biológica, ainda não estão completamente elucidados. O efeito do laser depende dos parâmetros de irradiação e do tipo celular. A falta de informação sobre a irradiação utilizada, assim como uma minuciosa avaliação da potência, do tempo, da área a ser irradiada e da fluência do estímulo utilizados nos trabalhos disponíveis sobre o assunto, dificultam a repetibilidade e a reprodução dos resultados. $\mathrm{Na}$ área da reprodução animal existem relatos da utilização do laser em diversas espécies, com resultados positivos sobre as características seminais. Porém, há escassez de trabalhos que testem o potencial de fecundação destas amostras, corroborando para a hipótese de a que utilização do laser é uma ferramenta de incremento da fertilidade e permite a avaliação deste efeito melhorando o desenvolvimento embrionário subseqüente. 
HIPÓTESE

$\sim 3.7 x^{x}$ 


\section{HIPÓTESE}

A onda eletromagnética (LASER) tem efeito sobre a viabilidade espermática, sendo esse efeito dependente da duração do tratamento e da potência aplicada. As ondas eletromagnéticas apresentam efeito positivo sobre a viabilidade espermática resultando numa melhora na produtividade in vitro de embriões bovinos 


\section{OBJETIVOS}

Os objetivos desta dissertação foram divididos em geral e específicos.

\subsection{GERAL}

Verificar o efeito do laser de baixa potência sobre a viabilidade espermática e a produção in vitro de embriões

\subsection{ESPECÍFICOS}

1) Avaliar o efeito da duração do tratamento, da potência e da interação Duração do tratamento*Potência das ondas eletromagnéticas sobre a viabilidade espermática, imediato e 30 minutos após a aplicação.

2) Determinar a melhor combinação duração do tratamento $X$ potência das ondas eletromagnéticas sobre a viabilidade espermática.

3) Avaliar o efeito da combinação duração do tratamento $X$ potência das ondas eletromagnéticas sobre a produção in vitro de embriões 


\section{MATERIAL E MÉTODO}

O presente estudo foi realizado nos Laboratórios de Fecundação in vitro, Clonagem e Transgenia Animal e no Laboratório de Andrologia, ambos nas dependências do Departamento de Reprodução Animal da Faculdade de Medicina Veterinária e Zootecnia da Universidade de São Paulo, campus São Paulo - Cidade Universitária.

\subsection{EXPERIMENTO 1}

O experimento 1 teve como objetivo avaliar o efeito da duração do tratamento, da potência e da interação Duração do tratamento*Potência de ondas eletromagnéticas sobre a viabilidade espermática. Para tanto, palhetas de sêmen congelado de touros $(n=9)$, doados de Centrais de Processamento e Colheita de Sêmen (CPCs) foram utilizadas. As potências das ondas eletromagnéticas utilizadas foram de $0,5,7,5$ ou $10 \mathrm{~mW}$ e a duração do tratamento de 5 ou 10 minutos. As combinação das potências e a duração dos tratamentos resultaram na formação de 6 grupos tratados e respectivos controles (Quadro 1).

\begin{tabular}{|c|c|c|c|c|c|c|c|}
\hline Grupo & $\begin{array}{c}\text { Potência } \\
(\mathbf{m W})\end{array}$ & $\begin{array}{c}\text { Duração } \\
(\mathbf{m i n})\end{array}$ & $\begin{array}{c}\text { Fluência } \\
\left(\mathbf{J} / \mathbf{c m}^{2}\right)\end{array}$ & Grupo & $\begin{array}{c}\text { Potência } \\
(\mathbf{m W})\end{array}$ & $\begin{array}{c}\text { Duração } \\
(\mathbf{m i n})\end{array}$ & $\begin{array}{c}\text { Fluência } \\
\left(\mathbf{J} / \mathbf{c m}^{2}\right)\end{array}$ \\
\hline $\mathbf{1}$ & 5 & 5 & 0.156 & $\mathbf{1 C}$ & 0 & 5 & 0 \\
\hline $\mathbf{2}$ & 5 & 10 & 0.312 & $\mathbf{2 C}$ & 0 & 10 & 0 \\
\hline $\mathbf{3}$ & 7,5 & 5 & 0.234 & $\mathbf{3 C}$ & 0 & 5 & 0 \\
\hline $\mathbf{4}$ & 7,5 & 10 & 0.468 & $\mathbf{4 C}$ & 0 & 10 & 0 \\
\hline $\mathbf{5}$ & 10 & 5 & 0.312 & $\mathbf{5 C}$ & 0 & 5 & 0 \\
\hline $\mathbf{6}$ & 10 & 10 & 0.624 & $\mathbf{6 C}$ & 0 & 10 & 0 \\
\hline
\end{tabular}

Quadro 1- Potência, duração do tratamento e fluência dos grupos tratamento e controle - São Paulo - 2011 


\section{Amostras e irradiação:}

Três palhetas do mesmo touro foram descongeladas em água a $37^{\circ} \mathrm{C}$, durante 30 segundos. O conteúdo foi centrifugado em $6 \mathrm{~mL}$ de meio TALP sem Phenol Red (ANEXO A), em tubo cônico de $15 \mathrm{~mL}$ a 200 x g por 6 minutos, para a retirada do diluidor e do plasma seminal. O sobrenadante foi descartado e $600 \mu \mathrm{l}$ do sedimento contendo os espermatozóides foram re-suspendidos em meio TALP sem Phenol Red, para a concentração final de $7 \times 10^{6}$ espermatozóides/mL. A concentração espermática foi calculada utilizando-se câmara de Neubauer, em diluições de 10 a 20X, em água. Após a preparação dos espermatozóides, uma alíquota foi retirada para a realização das análises imediatamente anterior à exposição dos espermatozóides às ondas eletromagnéticas (tempo pré). Posteriormente, a amostra foi dividida em grupo controle (não submetida às ondas eletromagnéticas - incubadas) e grupo tratado (submetida às ondas eletromagnéticas - irradiadas).

O procedimento foi repetido para cada tratamento e o respectivo controle. Foram utilizadas palhetas de mesma partida ou da mesma combinação de partidas, para todos os grupos, tratado e controle.

O equipamento utilizado para a produção destas ondas eletromagnéticas (LASER) foi o sistema da Unilaser projetado e desenvolvido na UNICAMP, o qual possui fonte de luz de $633 \mathrm{~nm}$ de comprimento de onda de laser He-Ne, com potência máxima de 24,5mW. Para garantir a repetibilidade do experimento e a precisão dos dados fornecidos, utilizou-se um sistema óptico com lentes e filtro espacial. O aparelho foi calibrado para que o feixe de ondas eletromagnéticas fosse amplo o suficiente para abranger toda a amostra, para que as características das ondas eletromagnéticas (coerência) fossem mantidas e que a frente de onda fosse uniforme. O tratamento foi realizado em local escuro e o sistema óptico montado dentro de um aparato constituído por duas caixas de isopor, para impedir entrada de luz externa (Figura 1). 


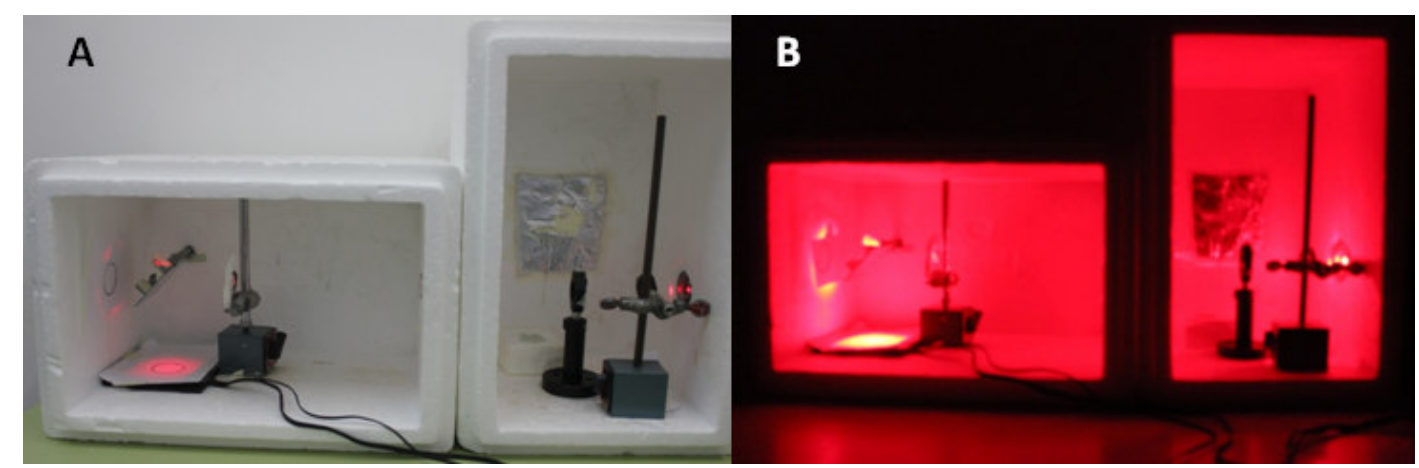

Figura 1 - A: Fotografia do sistema óptico em ambiente iluminado; B: Fotografia do sistema óptico em ambiente escuro - São Paulo - 2011

O campo de irradiação foi fotografado, a imagem digitalizada (Figura 2 - A e B) e analisada em software de análise de imagens IMAGE $\mathrm{J}^{\mathrm{TM}}$, disponível gratuitamente na internet. Analisou-se a homogeneidade das ondas eletromagnéticas no campo de irradiação pela distribuição de pixels da imagem transformada em um gráfico em três dimensões (Figura 2 - C, D, E e F). A potência das ondas do campo de irradiação foi verificada utilizando-se um medidor de potência óptica (U.S. Laser Corp. N.1034-2).

O sistema óptico foi emprestado do Centro de Ciências Naturais e Humanas da Universidade Federal do ABC. A montagem e a calibração foram realizadas pela física Taciana Deprá Magrini, mestre em Nanociências e Materiais Avançados da área de Biossistemas e Biofotônica e pelo físico em medicina Thiago Dreyer, aluno de mestrado em Nanociências e Materiais Avançados na área de Biossistemas e Biofotônica, sob orientação dos professores doutores Herculano Martinho da Silva e Marcella Pecora Milazzotto, respectivamente.

O sistema foi desenvolvido com a utilização de duas lentes, fenda circular, filtro óptico e espelho defletor. As diferentes potências foram obtidas pela utilização de filtros ópticos distintos e a potência desejada foi confirmada utilizando-se um medidor de potência óptica. Uma variação de até $30 \%$ para mais ou para menos foi adotada na potência média, pois flutuações na corrente elétrica influenciam a potência de saída gerada pelo equipamento. Há ainda diferença da intensidade de ondas entre o centro e a borda da placa e o próprio erro intrínseco da técnica de medição de potência foram considerados para estabelecer a potência empregada. 

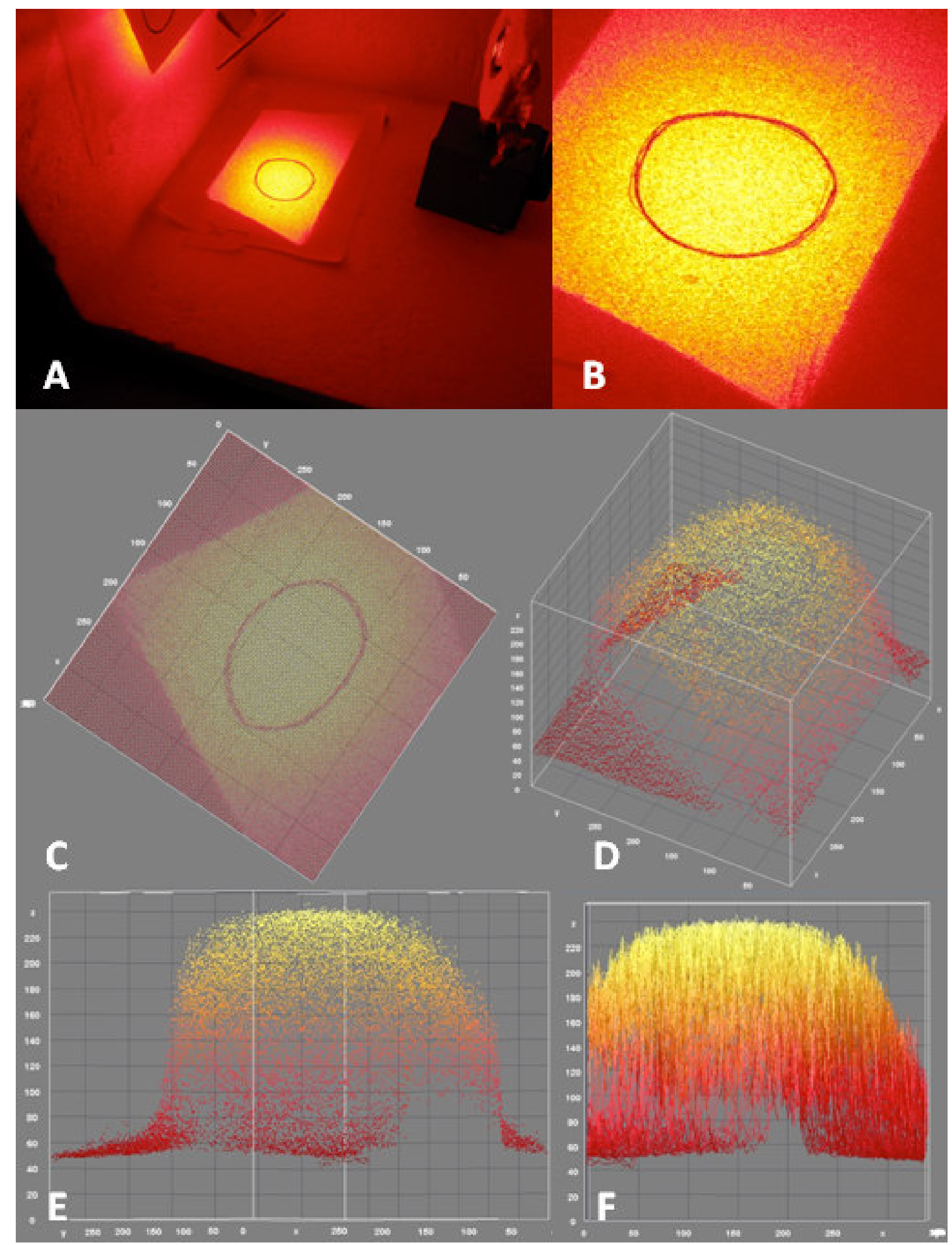

Figura 2 - Análise da homogeneidade da distribuição das ondas eletromagnéticas no campo de irradiação. A e B fotografia do campo de irradiação. C, D, E e F gráfico 3D da distribuição de pixels - São Paulo 2011 
A amostra ( $3 \mathrm{~mL}$ do grupo tratado) foi distribuída por toda a superfície da placa de Petri pequena $($ diâmetro $=35 \mathrm{~mm}$ ), sendo posicionada sob o campo de incidência de ondas eletromagnéticas sobre placa aquecida, de modo que o campo abrangesse toda a amostra. A placa contendo os $3 \mathrm{ml}$ da amostra do grupo controle correspondente foi posicionada sob a mesma placa aquecida, porém coberta por um aparato para bloquear completamente a incidência das ondas eletromagnéticas.

Metade do volume da amostras (1,5mL), de cada grupo foi retirada para análise, imediatamente após a duração do tratamento (irradiação ou incubação) de cada grupo (tempo pós) e a metade restante $(1,5 \mathrm{~mL})$, mantida em incubação a $37^{\circ} \mathrm{C}$. Após trinta minutos do início do tratamento, o restante da amostra foi submetido às análises finais (tempo final).

\section{Análises Espermáticas}

\section{Motilidade Espermática Visual:}

A porcentagem de espermatozóides com movimento progressivo em escala de 0 a $100 \%$ e vigor, o qual representa a força de propulsão do espermatozóide classificado de 0 a 5 , sendo 0 - sem movimento e 5 - movimento vigoroso. Estas análises foram realizadas em microscópio óptico de luz, em aumento de $200 \mathrm{X}$, entre lâmina e lamínula a $37^{\circ} \mathrm{C}$, utilizandose gotas de $10 \mu \mathrm{L}$ da amostra.

Durante a avaliação da motilidade foi também avaliada a presença ou a ausência e a intensidade de aglutinação das células espermáticas, comumente encontrada após o processo de centrifugação. Esta foi caracterizada pela aderência das células na lâmina ou lamínula, no qual se observam células sem movimento de progressão, apesar de intenso batimento flagelar. Padrão de aglutinação cabeça-cabeça, as quais cabeças de duas ou mais células espermáticas se apresentam unidas, também podem ser observadas e avaliadas. Em todas as avaliações de motilidade este padrão de movimento foi classificado utilizando-se escala de cruzes (no qual nenhuma cruz indicou ausência de aglutinação e +++ alto grau de aglutinação). A aderência das células à lâmina ou lamínula pode causar uma subestimativa da motilidade, devendo ser avaliada conjuntamente. 
Análise de Motilidade Espermática Computadorizada:

A análise computadorizada foi realizada utilizando-se o sistema Computer Assisted Sperm Analysis (CASA) da Hamilton Thorne IVOS, do Laboratório de Andrologia do Departamento de Reprodução Animal da FMVZ/USP, sob responsabilidade da Profa. Dra. Valquiria Hypollito Barnabe.

As câmaras aquecidas à $37^{\circ} \mathrm{C}$ foram preenchidas com $5 \mu \mathrm{L}$ de amostra e 10 campos foram selecionados para análise, os parâmetros utilizados para a seleção dos campos foram ausência de grumos e ausência de aglutinações.

Citometria de Fluxo:

A integridade da membrana acrossomal, a integridade da membrana plasmática e o potencial de membrana mitocondrial, dos grupos tratado e controle foi analisado em citômetro de fluxo. O preparo das amostras para a leitura no citômetro de Fluxo está sumarizado no Quadro 2. O preparo das soluções de PI, FITC-PSA e JC-1 estão descritas no ANEXO B.

\begin{tabular}{|c|c|c|c|c|}
\hline Sonda & $\begin{array}{c}\text { Quantidade } \\
\text { espermática (cels) }\end{array}$ & $\begin{array}{c}\text { Volume da } \\
\text { Sonda }(\boldsymbol{\mu L})\end{array}$ & $\begin{array}{c}\text { Tempo de } \\
\text { Incubação (min) }\end{array}$ & $\begin{array}{c}\text { Temperatura de } \\
\text { Incubação }\left({ }^{\circ} \mathbf{C}\right)\end{array}$ \\
\hline PI $(\mathbf{6} \boldsymbol{\mu M})$ & 750.000 & 3 & 5 & 37 \\
\hline $\begin{array}{c}\text { FITC-PSA } \\
(\mathbf{1 0 0} \boldsymbol{\mu} \mathbf{g} / \mathbf{m L})\end{array}$ & 750.000 & 50 & 5 & 37 \\
\hline $\begin{array}{c}\mathbf{J C}-\mathbf{1} \\
(\mathbf{5 0} \boldsymbol{\mu g} / \mathbf{m L})\end{array}$ & 750.000 & 2 & 5 & 37 \\
\hline
\end{tabular}

Quadro 2 - Concentração espermática, concentração e volume das sondas fluorescentes, tempo e b temperatura de incubação no preparo das amostras para a leitura no citômetro de fluxo - São Paulo - 2011

As sondas PI e FITC-PSA foram adicionadas na mesma amostra seminal, obtendo-se assim o resultado combinado entre a integridade das membranas plasmática e acrossomal, da mesma população de células.

Os gráficos destes ensaios foram analisados utilizando-se o software FlowJo v8.7 (Flow Cytometry Analysis Software - Tree Star INc., Ashland, Oregon, USA). Para a análise dos gráficos, a população de interesse foi identificada e selecionada segundo o tamanho e a fluorescência das mesmas. Esta etapa foi necessária, pois partículas muito grandes e com alta fluorescência costumam representar células aglutinadas e partículas muito pequenas com 
fluorescência média a baixa, costumam ser sujidades ou partículas de sonda livres. Após a determinação e a seleção da população de interesse, as análises foram realizadas.

FITC-PSA/PI: observou-se a distribuição da população de interesse em duas subpopulações de acordo com a intensidade de fluorescência verde. O gráfico foi transformado em histograma (Figura 3 - A) e o ponto de encontro da queda da população de baixa fluorescência e do aumento da população de alta fluorescência foi utilizado como ponto de corte. Células que apresentaram fluorescência superior a este ponto foram consideradas verdes positivas (acrossomo íntegro - AI) e as que apresentaram fluorescência inferior a este foram consideradas verdes negativas (acrossomo lesado - AL). A mesma metodologia foi adotada para a fluorescência vermelha (Figura 3 - B), fluorescência superior ao corte, vermelha positiva (membrana plasmática lesada - PL) e fluorescência inferior ao corte, células vermelhas negativas (membrana plasmática íntegra - PI). Os cortes para as duas fluorescências, quando simultâneos e aplicados à mesma população (Figura 3 - C) originaram quatro populações (AIPI, AIPL, ALPI E ALPL).
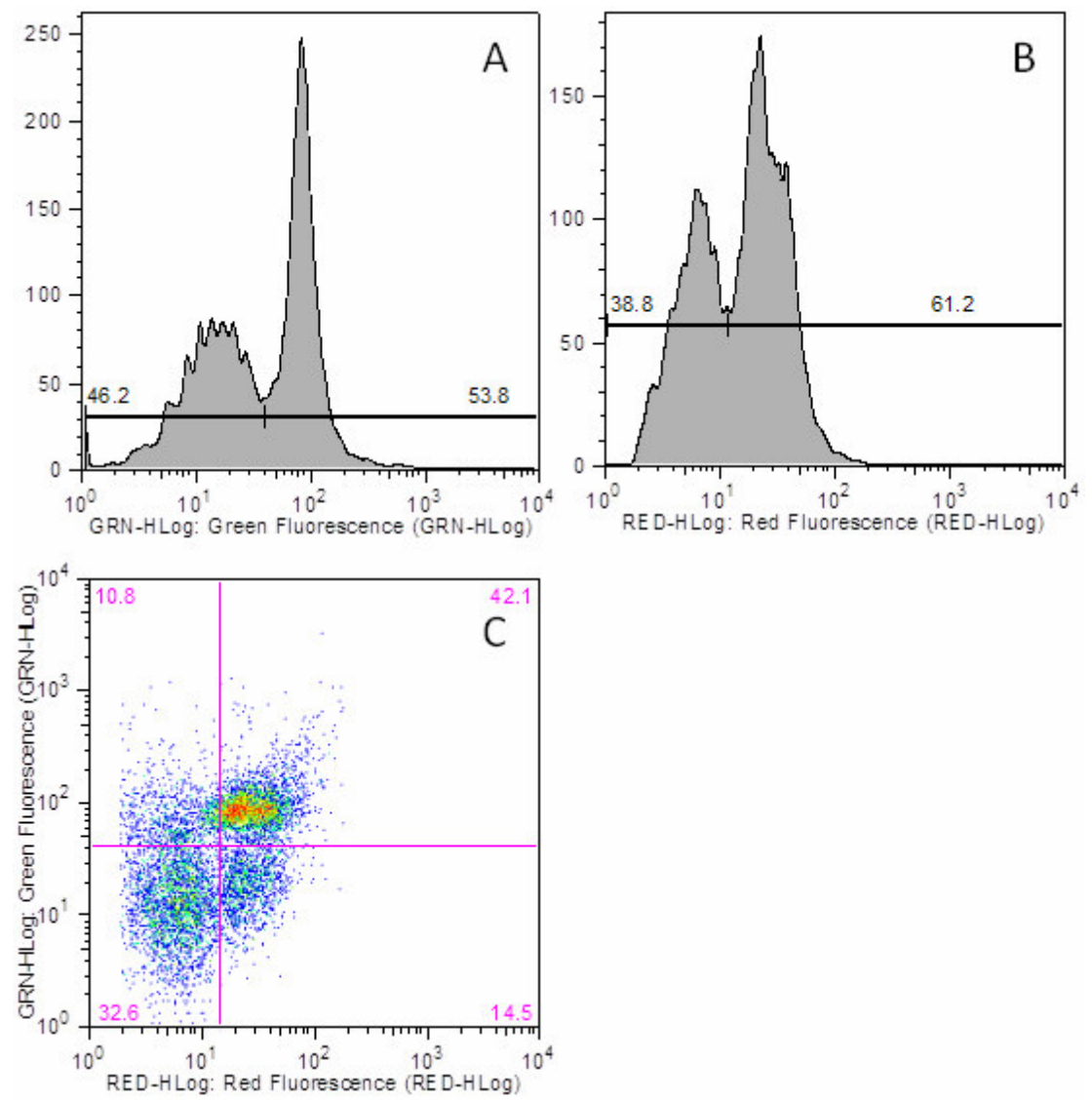

Figura 3 - Gráficos da análise pelo software FlowJo v8.7 para a análise da associação de sondas FITC- PSA/PI. A: histograma da fluorescência verde; B: histograma da fluorescência vermelha; C: gráfico das fluorescências verde/vermelha, no qual estão representadas as quatro populações e respectivas porcentagens - São Paulo - 2011 
JC1: a sonda JC-1 determina o potencial de membrana mitocondrial. Fluoresce em verde quando a membrana mitocondrial apresenta alto potencial e em vermelho quando apresenta baixo potencial. Como as células espermáticas podem apresentar graduações do potencial de membrana mitocondrial, é comum detectar fluorescências que vão desde o verde, passando pelo alaranjado até o vermelho. Portanto, para captar todos os possíveis espectros de fluorescência, a análise do potencial de membrana mitocondrial foi realizada empregando a fluorescência amarela (figura 4). A população que fluoresce intensamente em amarelo, representa células com alto potencial de membrana mitocondrial, pois a excitação e a emissão desta fluorescência são cruzadas com as da fluorescência verde. Já a população que apresenta baixo potencial de membrana mitocondrial será representada na baixa intensidade de fluorescência amarela. Isso porque, no comprimento de onda da fluorescência amarela, células que emitiriam fluorescência vermelha serão pouco excitadas por este comprimento de onda. Em algumas amostras analisadas, as células foram divididas em subpopulações, delimitadas pelas diferentes intensidades de fluorescência, variando entre duas a três subpopulações (Figura 4 - A e B). Já em outras, as células estavam distribuídas gradualmente de acordo com a intensidade de fluorescência, sem a divisão em subpopulações definidas (Figura 4 - C). Por este motivo foi estabelecido dois pontos de corte ao longo da intensidade de fluorescência com base na distribuição das células. A população que apresentava fluorescência superior a nota de corte mais alta foi definida como população de alto potencial de membrana mitocondrial, a população que se localizava entre os dois pontos de corte foi definida com potencial de membrana mitocondrial intermediário e a população com fluorescência inferior ao ponto de corte mais baixo, definida como população com baixo potencial de membrana mitocondrial.

Os dois pontos de corte estabelecidos foram mantidos para todas as amostras analisadas. 

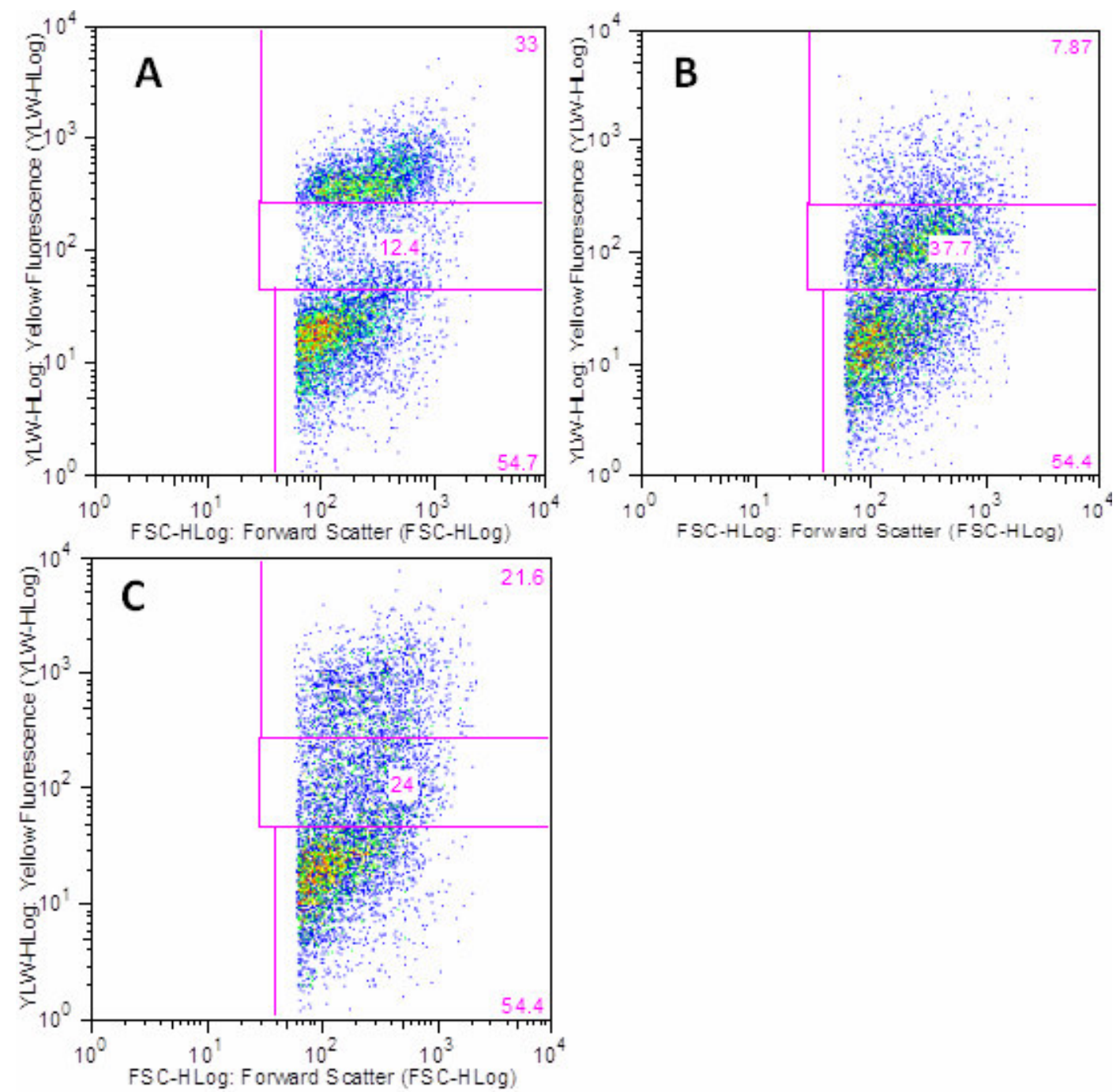

Figura 4 - Gráficos das amostras coradas com JC-1 analisados no citômetro de fluxo. A: populções de alto e baixo potencial bem definidas; B: populações de potencial intermediário e baixo bem definidas; C: população de baixo potencial bem definida e populações de potencial intermediário e alto distribuídas gradualmente

Sperm Chromatin Structure Assay (SCSA): este ensaio foi adaptado (Anexo C) do protocolo descrito por BoeHansen et al. (2005). O procedimento foi realizado em sala escura, sendo adicionadas 200.000 células em $50 \mu \mathrm{L}$ de tampão TNE, acrescido de $100 \mu \mathrm{L}$ de detergente ácido. Após 30 segundos foram acrescentados $300 \mu \mathrm{L}$ de solução de Laranja de Acridina, sendo as amostras então avaliadas após 3-5 minutos. As leituras foram realizadas em citômetro de fluxo Guava EasyCyte ${ }^{\mathrm{TM}}$ Mini System (Guava ${ }^{\square}$ Technologies) do Departamento de Reprodução Animal da Faculdade de Medicina Veterinária e Zootecnia da Universidade de São Paulo.

Para a validação do SCSA e a caracterização das populações a serem analisadas, o controle da população de células negativas (não suscetíveis à ação do detergente ácido -

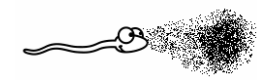


fluorescência verde) e o de células positivas (suscetíveis à ação do detergente ácido fluorescência vermelha) foram determinados. Para isto, uma amostra de sêmen de um animal aleatório foi submetida à incubação por duas horas com peróxido de hidrogênio $30 \%$ na proporção 1:2 de volume de amostra e de peróxido de hidrogênio, respectivamente, sendo este considerado o controle positivo (Figura 5-B). Uma amostra de mesma partida, do mesmo animal foi apenas descongelada e lavada para o controle negativo (Figura 5-A). Realizou-se o SCSA no controle negativo obtendo-se um histograma com pico único, analisou-se a amostra positiva, obtendo-se também um pico único, porém deslocado á direita no histograma de AlfaTYlog. A amostra formada foi analisada com a mistura em mesma proporção (50\%) dos dois controles, obtendo-se dois picos (Figura 5-C). O ponto médio entre os dois picos foi estabelecido como ponto de corte para a consideração das células positivas ou negativas para o SCSA.

O AlfaTYlog é o resultado da divisão da fluorescência vermelha pela fluorescência total (vermelho + verde) e serve para quantificar a extensão da denaturação da estrutura da cromatina de cada espermatozóide.
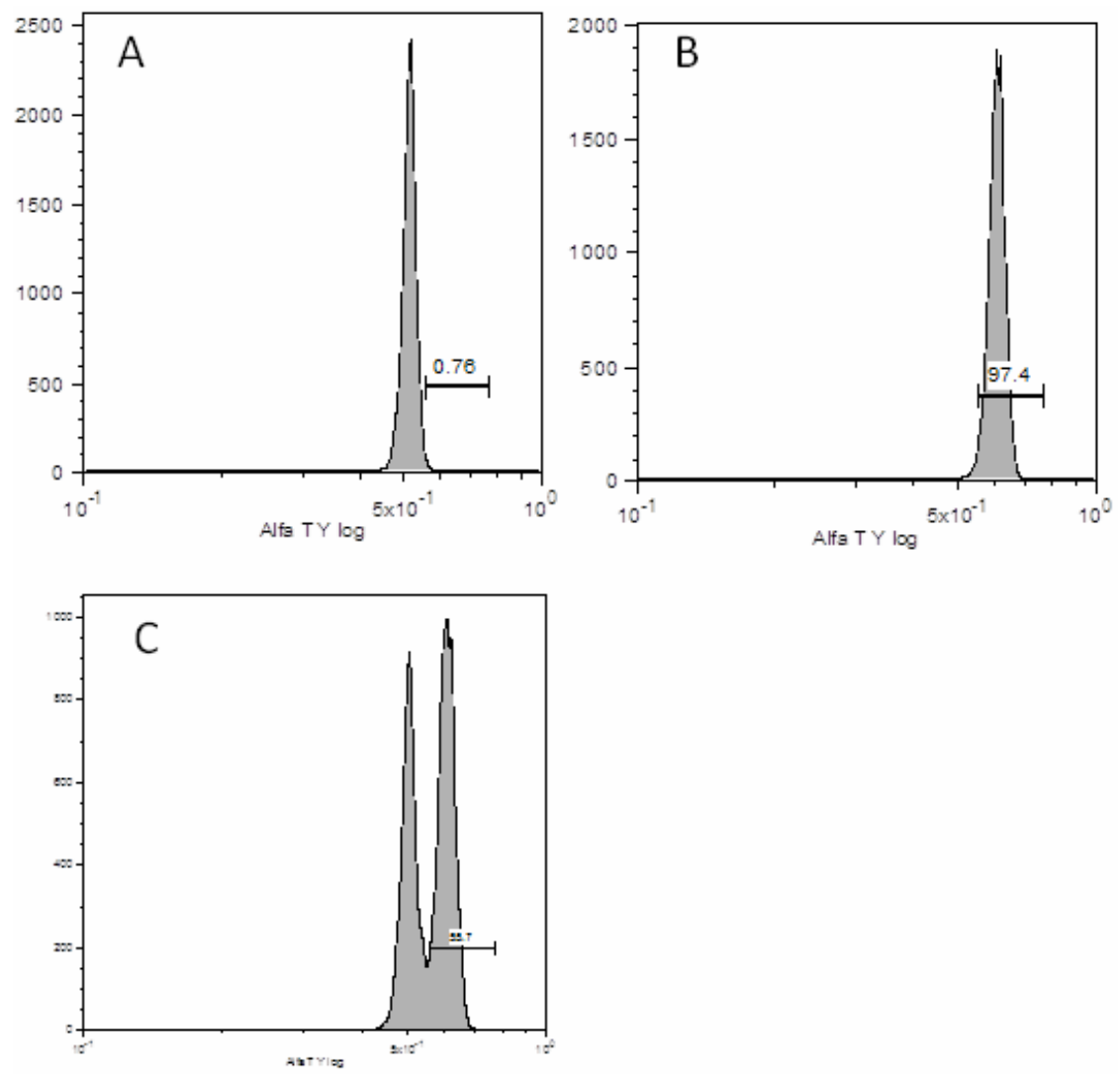

Figura 5 - Gráficos do ensaio SCSA. A: controle negativo; B: controle positivo; C mistura 1:1 controle positivo/controle negativo 


\section{Análise Estatística:}

As amostras foram analisadas em um arranjo fatorial $4 \times 2$ (4 potências 0, 5, 7,5 ou 10 mW x 2 períodos duração do tratamento 5 ou 10 minutos). Em cada combinação foram avaliadas as variáveis motilidade visual; vigor; aglutinação; motilidade computadorizada; motilidade progressiva; STR; lineariadade; BCF; VCL; VSL; ALH; VAP; elongação; lesão/integridade de membranas plasmática, acrossomal e respectivas associações; potencial de membrana mitocondrial alta, intermediária e baixa e positividade/negatividade ao SCSA. Os efeitos de potência, duração do tratamento, tempo e todas as interações duplas e triplas sobre cada variável dependente foram analisados por análise de variância com medidas repetidas no tempo (split-plot ANOVA). O momento PÓS foi o tempo imediatamente pósirradiação e o FINAL, trinta minutos após o início da irradiação. Utilizou-se PROC MIXED do software SAS, versão 9.2. Considerou-se o efeito de touro como um efeito aleatório. Para cada variável, as médias e erros padrão da média, referentes a cada efeito testado foram calculadas pelo método dos quadrados mínimos (LSmeans). Os efeitos foram considerados significativos quando $\mathrm{P} \leq 0,05$.

\subsection{EXPERIMENTO 2}

\section{Produção in vitro de Embriões:}

Ovários de vacas destinadas ao abatedouro comercial foram colhidos no matadouro e transportados em recipiente térmico, contendo solução salina estéril, aquecida a $30^{\circ} \mathrm{C}$. No laboratório, os ovários foram lavados $2 \mathrm{X}$ em solução salina aquecida a $30^{\circ} \mathrm{C}$, e os folículos com diâmetro entre 2 e $8 \mathrm{~mm}$ cortados com auxílio de bisturi em Becker, contendo 50mL de meio de fatiamento (Anexo D). Após todos os folículos terem sido cortados, o ovário foi mergulhado e agitado com movimentos circulares, auxiliando na recuperação dos complexos cumulus oophorus (CCO). Posteriormente, a solução contendo o meio de fatiamento, o líquido folicular e os CCOs foi depositada em tubo cônico de $50 \mathrm{~mL}$, permanecendo em repouso por 10 minutos em água à $37^{\circ} \mathrm{C}$. Após este período, o sedimento de cada tubo foi removido com auxílio de pipeta pasteur e depositado sobre um filtro de células de $100 \mu \mathrm{m}$ (Cell strainer, BD Falcon ${ }^{\mathrm{TM}}$ ). O conteúdo retido no filtro foi recuperado e colocado em tubo cônico de $50 \mathrm{~mL}$ e o filtro lavado com meio de fatiamento, sendo aplicado um suave jato de meio, com auxílio de seringa de $20 \mathrm{ml}$ e agulha $21 \mathrm{G}$. A solução recuperada foi depositada em 
placa de Petri (90mm) para rastreamento dos complexos cumulus oophorus e posterior seleção, em estereomicroscópio. Apenas oócitos apresentando camada de células do cumulus oophorus íntegra, espessa e compacta, assim como citoplasma homogêneo foram selecionados para maturação in vitro (MIV). Após o rastreamento, os CCOs foram depositados em placa de Petri pequena (35mm) contendo meio de lavagem MIV (Anexo D) e após a seleção foram lavados em meio de maturação (Anexo D). A lavagem foi realizada, colocando-se os CCOs em gotas de $100 \mu \mathrm{l}$ de meio e fazendo 3 passagens sequências para outras gotas de $100 \mu 1$ de meio. Em seguida, os oócitos foram colocados para a MIV, sendo colocados 20 a 30 oócitos em gotas de $90 \mu 1$ do meio de maturação, sob óleo mineral. A maturação foi realizada em incubadora a $38,5^{\circ} \mathrm{C} ; 5 \%$ de $\mathrm{CO}_{2} \mathrm{em}$ ar e alta umidade por 22 a 24 horas.

Após o período de maturação, os oócitos foram avaliados quanto à expansão das células do cumulus, indicação da maturação oocitária. Os oócitos maturados foram lavados em meio de lavagem FIV (Anexo E) e em seguida em meio FIV Gota (PARRISH et al., 1988 - Anexo E). Para a fecundação in vitro, o mesmo procedimento de descongelação, lavagem, análise e diluição final, descrito para os espermatozóides no experimento 1 foram utilizados. A potência de $5 \mathrm{~mW}$ e o período de 10 minutos de incidência das ondas eletromagnéticas foram escolhidos, pois no experimento 1 foi a relação Duração do tratamento*Potência que apresentou melhor efeito sobre a viabilidade espermática.

Os espermatozóides $\left(7 \times 10^{6} / \mathrm{mL}\right)$ foram submetidos às ondas eletromagnéticas na potência de $5 \mathrm{~mW}$ por 10 minutos de exposição (grupo tratado) ou apenas incubados durante 10 minutos (grupo controle). Imediatamente após o término do tratamento (tempo pós), gotas de 150uL do meio FIV-gota, contendo 20-30, sob óleo mineral foram inseminadas com um total de 10,5 X $10^{4}$ espermatozóides (15ul). A FIV foi realizada em atmosfera controlada, com $5 \%$ de $\mathrm{CO}_{2} \mathrm{em}$ ar, $38,5^{\circ} \mathrm{C}$ e alta umidade por 18 horas.

Após a fecundação, os presumíveis zigotos foram lavados, sendo o excesso de células do cumulus removido mecanicamente em meio de lavagem FIV (Anexo E). Em seguida, os prováveis zigotos foram lavados em meio SOF (Anexo F) e cultivados por 12 dias neste meio, com co-cultivo de células do cumulus em estufa a $38,5^{\circ} \mathrm{C}, 5 \%$ de $\mathrm{CO}_{2}$ em ar e alta umidade.

$\mathrm{O}$ índice de clivagem foi determinado no terceiro dia de cultivo, e o de blastocisto no sexto, nono e décimo segundo dia de cultivo. Estes índices foram calculados com base no número total de estruturas colocadas para a MIV. No terceiro dia de cultivo, juntamente com 
avaliação do índice de clivagem, $45 \mu 1$ de meio SOF foram acrescidos às gotas de cultivo. No quinto dia, $90 \mu 1$ de meio foram retirados das gotas de cultivo, sendo reposto por meio novo.

No nono dia de cultivo, todos os embriões que atingiram o estágio de blastocisto com morfologia compatível a estruturas viáveis foram fixados em paraformaldeído 4\% por 1 hora em temperatura ambiente e armazenados em PBS-PVP (Anexo G) à $4^{\circ} \mathrm{C}$ até o dia da realização do ensaio TUNEL.

TUNEL: no dia do ensaio, os embriões foram colocados em solução de permeabilização (Anexo G) à temperatura ambiente, por duas horas e em seguida, lavados em PBS-PVP. Os embriões foram então incubados com $25 \mu \mathrm{L}$ de mistura de reação de TUNEL (contendo dUTP conjugado com isothiocyanate de fluoresceína e a enzima desoxinucreotidil transferase terminal preparados segundo instruções do fabricante (In situ cell death detection kit fluorescence, ROCHE) por uma hora à $37^{\circ} \mathrm{C}$, em câmara úmida e escura.

Posteriormente à incubação, os embriões foram lavados em PBS-PVP e corados com Hoechst $33342(5 \mu \mathrm{g} / \mathrm{mL})$ por 15 minutos, em temperatura ambiente. Os embriões foram novamente lavados e colocados entre lâmina e lamínula com 1,4-Diazabicyclo [2.2.2] octane (DABCO - Sigma ST.Lous, MO, USA) para avaliação em microscópio de epifluorescência IX80 (Tóquio, Japão). Cada embrião foi analisado individualmente, sendo o número total de células (núcleo azuis coradas pelo Hoechst) e o número de células embrionárias com fragmentação de DNA (núcleos verdes) visualizados pelos filtros DAPI e FITC, respectivamente.

Para os grupos controle positivo e negativo do ensaio TUNEL, embriões produzidos pela mesma técnica foram incubados durante 1 hora em câmara úmida e escura à $37^{\circ} \mathrm{C}$, com DNase I (ANEXO G). Após a permeabilização e a incubação com DNase I, metade destes embriões foram incubados com a mistura de reação TUNEL formando o controle positivo e a outra metade incubada apenas com os dUTPs conjugados formando o controle negativo. Os embriões foram corados com Hoechst, colocados entre lâmina e lamínula com 1,4Diazabicyclo [2.2.2] octane (DABCO - Sigma ST. Lous, MO, USA) e avaliados para verificar a eficiência do ensaio de TUNEL.

Alíquotas do sêmen irradiado (grupo tratado) e do grupo controle de cada manipulação foram congeladas a $-20^{\circ} \mathrm{C}$, para realizar o ensaio do cometa alcalino, objetivando avaliar a fragmentação do DNA espermático. 


\section{Ensaio Cometa Alcalino:}

O protocolo utilizado foi adaptado de Donnelly et al (2000) e as soluções utilizadas encontram-se descritas no Anexo H. Lâminas de microscopia foram previamente preparadas com uma fina camada $(1 \mathrm{~mL})$ de agarose normal melting (NM) $1 \%$ em TBE, e deixadas secar em temperatura ambiente. Sobre a camada de agarose NM seca foi adicionado $100 \mu \mathrm{da}$ amostra de sêmen diluído ( 5 X $10^{5}$ espermatozóides $/ \mathrm{mL}$ ) em agarose low melting (LM) 0,75\% em TBE e coberto por lamínula. As lâminas foram acondicionadas à $4^{\circ} \mathrm{C}$ para solidificação do gel. Após a solidificação do gel de agarose LM, a lamínula foi cuidadosamente removida, sendo acrescidos mais $300 \mu \mathrm{L}$ de agarose LM, e esta novamente coberta com lamínula e acondicionada à $4^{\circ} \mathrm{C}$, para solidificação do gel. Posteriormente à solidificação, a lamínula foi novamente retirada, sendo adicionado $1 \mathrm{ml}$ da solução de lise I. As lâminas foram incubadas em câmara úmida a $55^{\circ} \mathrm{C}$, por uma hora. Em seguida, as lâminas foram lavadas três vezes com intervalos de 5 minutos entre cada lavagem, utilizando-se uma piceta com água ultrapura $\left(\mathrm{H}_{2} \mathrm{O}\right.$ MilliQ $\left.{ }^{\mathrm{TM}}\right)$ para a remoção da solução de lise I, procedido pelo acréscimo de $1 \mathrm{~mL}$ da solução de lise II. Após a adição da solução de lise II, as lâminas foram acondicionadas à $4^{\circ} \mathrm{C}$, por duas horas. Após as etapas de lise, as lâminas foram lavadas, posicionadas na cuba de eletroforese e imersas na solução de corrida (Anexo H), gelada por 20 minutos. A eletroforese foi realizada a $3 \mathrm{~V} / \mathrm{cm}$ e $270 \mathrm{~mA}$, por 20 minutos. Após a eletroforese, as lâminas foram lavadas com TBE, desidratadas e secas a temperatura ambiente.

No dia da leitura, as lâminas foram reidratadas com água ultrapura por uma hora e coradas com $1 \mathrm{~mL}$ de Syber Green (Anexo H) diluído 5.000X, também por uma hora em câmara escura. Ao término deste período, as lâminas foram lavadas com água ultrapura, secas e cobertas por lamínulas.

As imagens foram visualizadas em microscópio de epifluorescência Olympus IX80 (Tóquio, Japão) com filtro de excitação de 515-560nm e filtro de barreira de 600nm, equipado com câmera OLYMPUS Q-Color ${ }^{\mathrm{TM}}$ de 5 megapixels, em aumento de 200X. As imagens de 50 a 70 células foram selecionadas aleatoriamente e analisadas com o software de imagens Comet Score ${ }^{\mathrm{TM}}$, disponibilizado gratuitamente na internet pela empresa Tritek-Corp (http:// autocomet.com/producs_cometscore.php).

O programa fornece um quadro de mensuração retangular para a avaliação dos cometas. As células foram avaliadas quanto às variáveis: comprimento do cometa, altura do cometa, área do cometa, intensidade do cometa, intensidade média do cometa, diâmetro da cabeça, área da cabeça, intensidade da cabeça, intensidade média da cabeça, porcentagem de 
DNA na cabeça, comprimento da cauda, área da cauda, intensidade da cauda, intensidade média da cauda e porcentagem de DNA na cauda.

Análise Estatística:

As amostras seminais foram analisadas em um arranjo fatorial 2 × 3 (2 tratamentos: irradiado e controle em três momentos de análise T0, T10 e T30). Em cada combinação foram avaliadas as variáveis motilidade visual; vigor; aglutinação; lesão/integridade de membranas plasmática, acrossômica e associação; potencial de membrana mitocondrial alta, intermediária e baixa; positividade/negatividade ao SCSA; comprimento do cometa; altura do cometa; área do cometa; intensidade do cometa; intensidade média do cometa; diâmetro da cabeça; área da cabeça; intensidade da cabeça; intensidade média da cabeça; DNA na cabeça; comprimento cauda; área da cauda, intensidade da cauda, intensidade média da cauda e DNA na cauda.

Os efeitos de tratamento, tempo e interação Tratamento*Tempo de cada variável dependente foram avaliados por análise de variância com medidas repetidas no tempo (splitplot ANOVA), O tempo T0 foi considerado a análise antes do tratamento, T10 imediatamente após o tratamento e o T30, trinta minutos após o início do tratamento. Utilizou-se PROC MIXED do software SAS, versão 9.2. Considerou-se o efeito de touro como um efeito aleatório. Para cada variável, as médias e erros padrão da média, referentes a cada efeito testado foram calculadas pelo método dos quadrados mínimos (LSmeans).

Os resultados foram analisados pelo programa SAS System for Windows (versão 9.2) e testados quanto à normalidade dos resíduos e homogeneidade das variâncias, sendo obedecidas as premissas estatísticas utilizou-se o teste $t$ de Student para comparação de média de dois tratamentos (PROC TTEST) para as variáveis dependentes relacionadas à características embrionária e taxas da produção de embriões in vitro. O nível de significância considerado foi de 0,05 para rejeitar a hipótese de nulidade 
RESULTADOS

$\sim 3.6 x^{x}$ 


\section{RESULTADOS}

\subsection{EXPERIMENTO 1}

Os resultados da análise de variância encontrados no experimento 1 estão apresentados sumarizados na tabela 1, contendo o valor de $\mathrm{p}$ do efeito da potência, da duração do tratamento e do momento de análise, assim como as interações dos efeitos para cada parâmetro analisado.

Para os efeitos ou interações que apresentaram significância, com $p<0,05$ ou tendência $0,05 \leq \mathrm{P}<0,10$, os valores da média e o respectivo erro padrão da média, para cada grupo estão apresentados em forma de gráfico de colunas. 
Tabela 1 - Valor de p do efeito, da potência, da duração do tratamento e do momento de análise, assim como as interações dos efeitos para cada parâmetro estudado. São Paulo, 2011

\begin{tabular}{|c|c|c|c|c|c|c|c|}
\hline Parâmetro\Efeito & Potência & Duração & Tempo & Pot*Dur & Pot*Tem & Dur*Tem & Pot*Dur*Tem \\
\hline Motilidade & 0,0533 & 0,1965 & 0,5587 & 0,7785 & 0,0164 & 0,1526 & 0,6124 \\
\hline Motilidade Casa & 0,2782 & 0,6586 & 0,4792 & 0,1985 & 0,2620 & 0,3111 & 0,5629 \\
\hline Vigor & 0,9967 & 0,7281 & 0,1427 & 0,8178 & 0,0620 & 0,1094 & 0,8483 \\
\hline Aglutinação & 0,7877 & 0,0061 & 0,1056 & 0,4753 & 0,6477 & 0,9767 & 0,5291 \\
\hline Progressiva & 0,2452 & 0,9517 & 0,2812 & 0,0780 & 0,3065 & 0,1796 & 0,4215 \\
\hline STR & 0,6590 & 0,4931 & 0,6902 & 0,5858 & 0,1312 & 0,7490 & 0,6862 \\
\hline Linea & 0,2254 & 0,3818 & 0,1926 & 0,9666 & 0,2188 & 0,8369 & 0,9311 \\
\hline BCF & 0,4275 & 0,0245 & 0,0602 & 0,3970 & 0,8596 & 0,4090 & 0,6223 \\
\hline ALH & 0,5425 & 0,9558 & 0,0004 & 0,3135 & 0,1782 & 0,7772 & 0,1398 \\
\hline VAP & 0,8436 & 0,2389 & 0,7630 & 0,0591 & 0,9799 & 0,7613 & 0,2404 \\
\hline VSL & 0,7500 & 0,2026 & 0,9267 & 0,0745 & 0,8613 & 0,8425 & 0,3742 \\
\hline VCL & 0,4944 & 0,4494 & 0,0068 & 0,0101 & 0,8850 & 0,4736 & 0,1885 \\
\hline Elong & 0,7432 & 0,0232 & 0,3844 & 0,9018 & 0,0758 & 0,2435 & 0,9801 \\
\hline PL & 0,2050 & 0,1355 & 0,0718 & 0,5181 & 0,5294 & 0,4411 & 0,496 \\
\hline PI & 0,2057 & 0,1362 & 0,0737 & 0,5157 & 0,5253 & 0,4460 & 0,4434 \\
\hline $\mathbf{A L}$ & 0,3961 & $\mathbf{0 , 0 3 7 7}$ & 0,1472 & 0,5441 & 0,6925 & 0,5550 & 0,2748 \\
\hline AI & 0,3960 & 0,0378 & 0,1504 & 0,5392 & 0,6854 & 0,5498 & 0,2756 \\
\hline AIPI & 0,1120 & 0,1153 & 0,0444 & 0,8855 & 0,7715 & 0,9044 & 0,4434 \\
\hline AIPL & 0,4238 & 0,3999 & 0,2388 & 0,4986 & 0,7941 & 0,3800 & 0,7695 \\
\hline ALPI & 0,7726 & 0,9583 & 0,8969 & 0,3603 & 0,6923 & 0,1801 & 0,7663 \\
\hline ALPL & 0,2319 & 0,0134 & 0,1120 & 0,2830 & 0,2175 & 0,6557 & 0,1776 \\
\hline Potencial alto & 0,0469 & 0,7688 & 0,0102 & 0,0371 & 0,5126 & 0,6638 & 0,2515 \\
\hline Potencial inter & 0,0003 & 0,7666 & 0,2162 & 0,0058 & 0,4221 & 0,7784 & 0,5432 \\
\hline Potencial baixo & 0,4705 & 0,5938 & 0,5516 & 0,6765 & 0,7835 & 0,6756 & 0,6100 \\
\hline SCSA + & 0,5259 & 0,0556 & 0,4036 & 0,5229 & 0,9459 & 0,5817 & 0,9856 \\
\hline SCSA - & 0,5259 & 0,0556 & 0,4036 & 0,5229 & 0,9459 & 0,5817 & 0,9856 \\
\hline
\end{tabular}

Pot*Dur - Interação Potência*Duração; Pot*Tem - Interação Potênica*Tempo; Dur*Temp - Interação Duração*Tempo; Pot*Dur*Temp - Interação Potência*Duração*Tempo; STR - retilinearidade; Linea linearidade; BCF - frequência de batimento flagelar cruzado; ALH - amplitude do deslocamento lateral da cabeça; VAP - velocidade de trajeto média; VSL - velocidade linear progressiva; VCL - velocidade curvilinea; Elong. - alongação; PL - membrana plasmática lesada; PI - membrana plasmática íntegra; AL - acrossomo lesado; AI - acrossomo íntegro; AIPI - acrossomo íntegro e plasmática íntegra; AIPL - acrossomo íntegro e plasmática lesada; ALPI - acrossomo lesado e plasmática íntegra; ALPL - acrossomo lesado e plasmática lesada; Potencial Inter - potencial intermediário; SCSA+ - positivo ao ensaio da estrutura da cromatina; SCSA- negativo ao ensaio da estrutura da cromatina

A motilidade visual (Gráfico 1) e o vigor (Gráfico 2) apresentaram interação Potência*Tempo, ou seja, efeito da potência do laser relacionado aos diferentes tempos de análise (PÓS ou FINAL). 
Foi observada uma diminuição da motilidade na potência $10 \mathrm{~mW}$ ao longo da incubação $(p=0,0074)$. Sendo que nas demais potências, inclusive no controle, não houve diferença da motilidade durante a incubação. A motilidade no tempo FINAL nas potências 0 , 5 e 7,5 foram superiores à potência $10 \mathrm{~mW}(\mathrm{p}<0,05)$.

\section{Média \pm EPM Motilidade/Pot ${ }^{\star} T e m$}

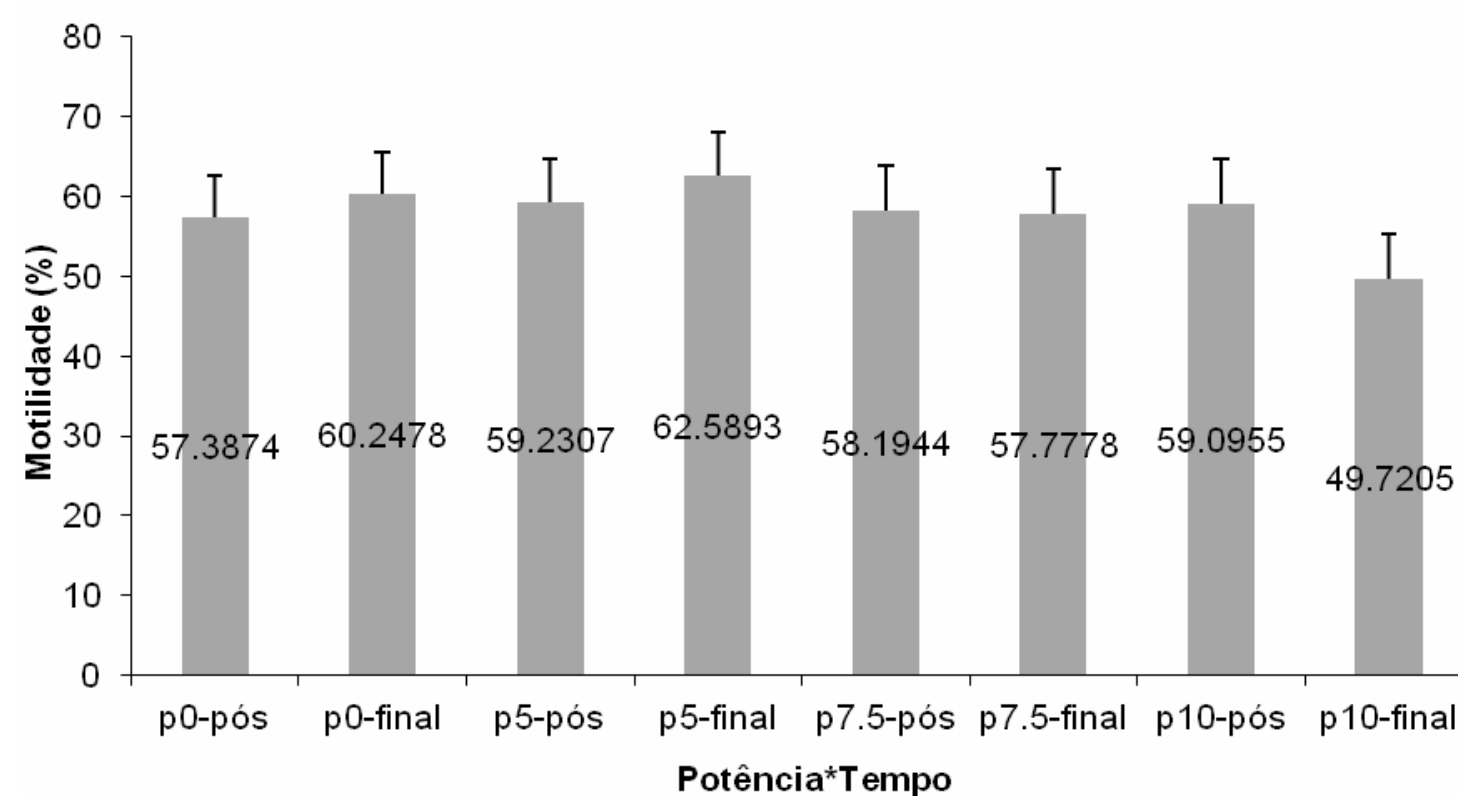

Gráfico 1 - Média e erro padrão da média $( \pm$ EPM) da motilidade visual para interação Potência*Tempo. p0 Potência $0 \mathrm{~mW}$; 5 - Potência $5 \mathrm{~mW}$; p7.5 - Potência 7,5 mW; p10 - Potência $10 \mathrm{~mW}$; pós - análise tempo PÓS; final - análise tempo FINAL - São Paulo - 2011

$\mathrm{O}$ vigor apresentou aumento após a incubação no grupo controle $(\mathrm{p}=0,002)$, no entanto, o vigor no grupo controle apresentou uma tendência a ser inferior à potência $10 \mathrm{~mW}$ imediatamente após o tratamento $(\mathrm{p}=0,06)$. 


\section{Média \pm EPM Vigor/Pot*Tem}

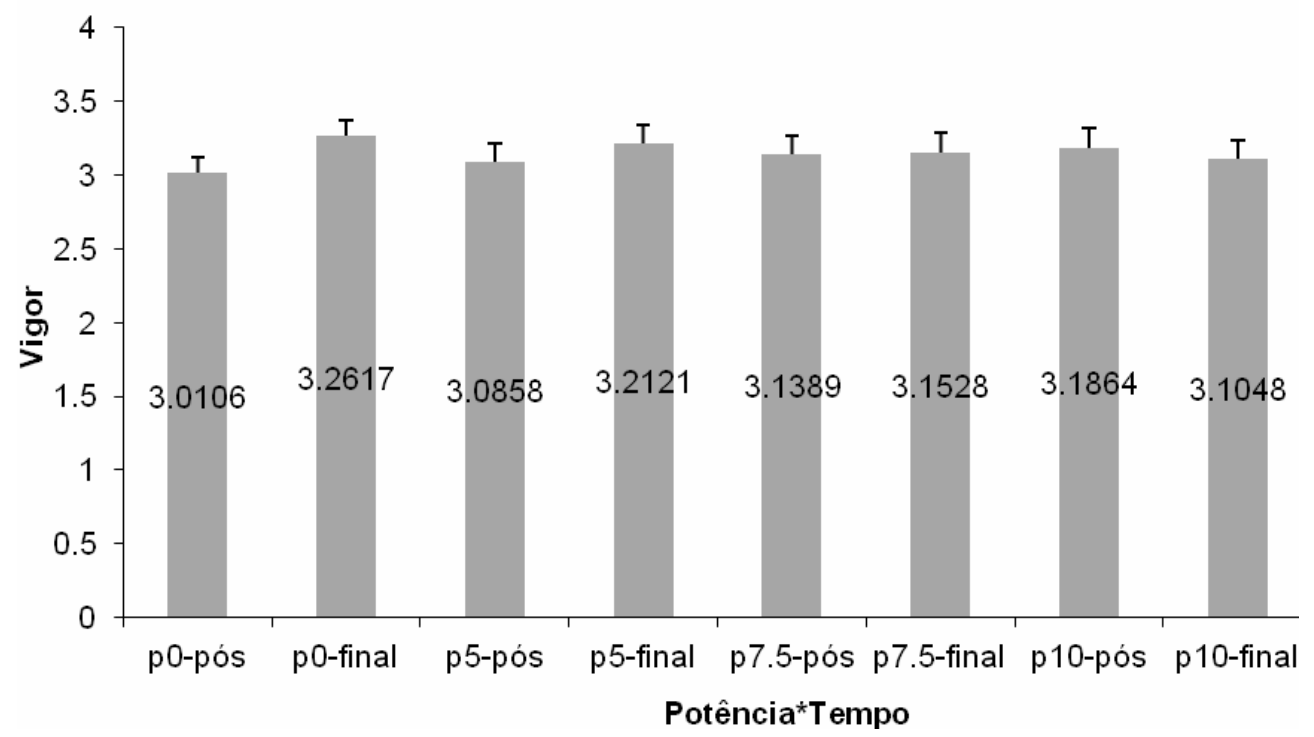

Gráfico 2 - Média e erro padrão da média ( \pm EPM) do vigor para interação Potência*Tempo. p0 - Potência 0 $\mathrm{mW}$; p5 - Potência $5 \mathrm{~mW}$; p7.5 - Potência 7,5 mW; p10 - Potência $10 \mathrm{~mW}$; pós - análise tempo PÓS; final - análise tempo FINAL - São Paulo - 2011

O parâmetro aglutinação apresentou efeito apenas de duração (Gráfico 3), ou seja, as amostras do grupo duração de tratamento 5 minutos apresentaram maior aglutinação espermática do que as amostras do grupo duração de tratamento 10 minutos, independentemente da potência ou do momento de análise (PÓS ou FINAL).

Média \pm EPM Aglutinação/Duração

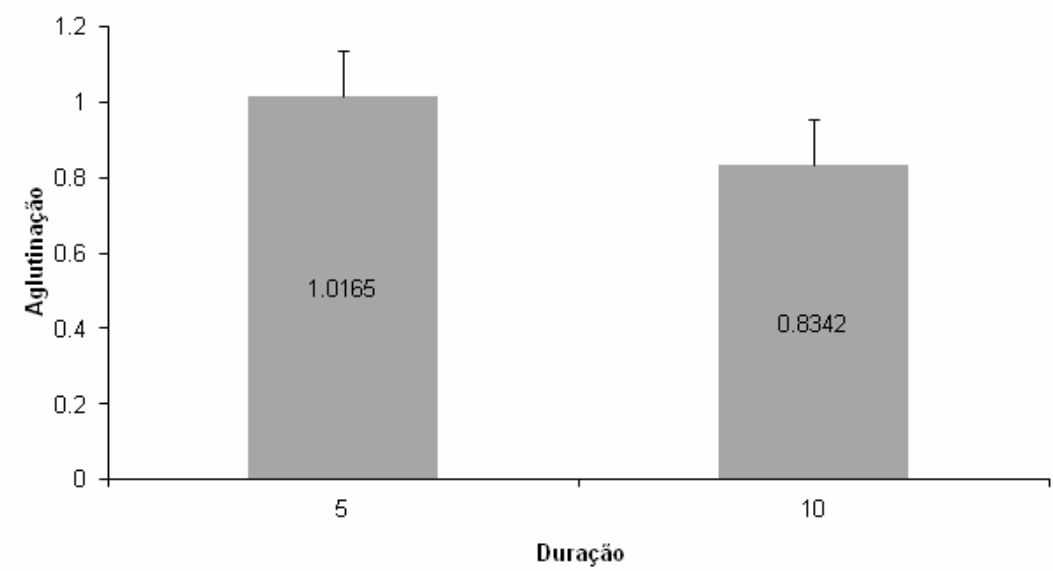

Gráfico 3 - Média e erro padrão da média ( Ł EPM) da aglutinação para efeito duração - São Paulo - 2011 
Com relação à motilidade progressiva (Gráfico 4), que representa a porcentagem de espermatozoides com movimento progressivo houve tendência para interação Potência*Duração do Tratamento.

A motilidade progressiva no grupo controle apresentou tendência a ser superior com 5 minutos de duração quando comparada ao tratamento de mesma duração na potência 7,5 mW (p=0,084). No entanto, o tratamento com 7,5 $\mathrm{mW}$ por 5 minutos de duração apresentou motilidade inferior no tratamento nas potências $5 \mathrm{~mW}$ ou 7,5 $\mathrm{mW}$ por 10 minutos de duração ( $\mathrm{p}=0,034$ e $\mathrm{p}=0,0318$, respectivamente).

\section{Média — EPM Progressiva/Pot*Duração}

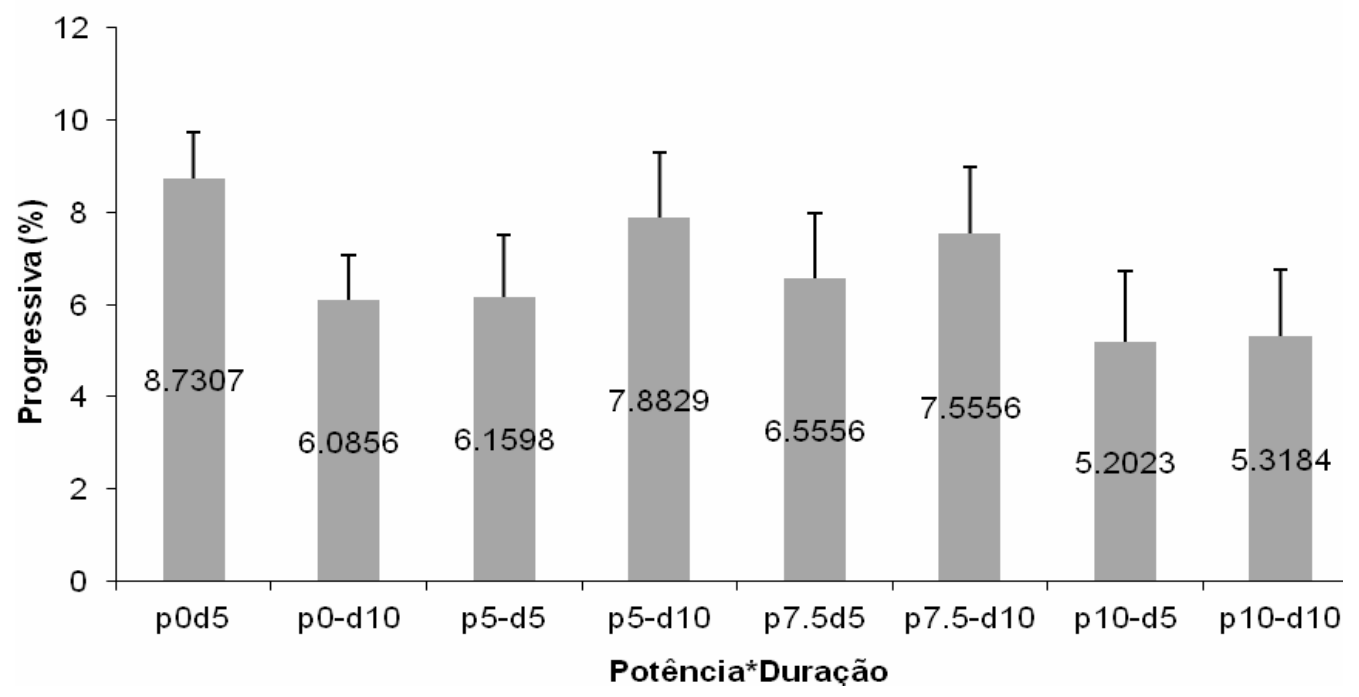

Gráfico 4 - Média e erro padrão da média ( \pm EPM) da motilidade progressiva para interação Potência*Duração. p0 - Potência 0 mW; p5 - Potência 5 mW; p7,5 - Potência 7,5 mW; p10 - Potência $10 \mathrm{~mW}$; d5 duração de tratamento de 5 minutos; d10 duração de tratamento de 10 mnutos - São Paulo - 2011

$\mathrm{Na}$ análise espermática computadorizada, a BCF (frequência de batimento flagelar cruzado), que corresponde ao número de vezes que a cabeça do espermatozóide cruza a direção do movimento, apresentou efeito de duração de tratamento e uma tendência para tempo (Gráficos 5 e 6). Sendo maior no grupo duração do tratamento 5 minutos e no tempo FINAL de análise. No entanto, os valores de BCF foram independentes da potência do laser aplicada. 


\section{Média — EPM BCFIDuração}

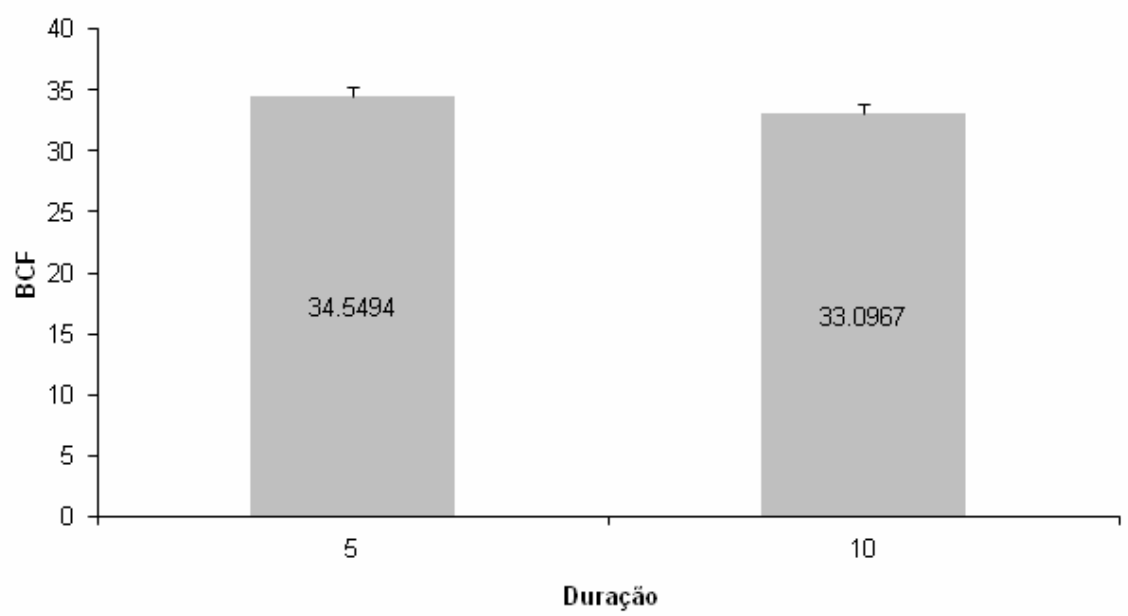

Gráfico 5 - Média e erro padrão da média ( \pm EPM) da frequência de batimento flagelar cruzado (BCF) para efeito duração do tratamento - São Paulo - 2011

\section{Média \pm EPM BCF/Tempo}

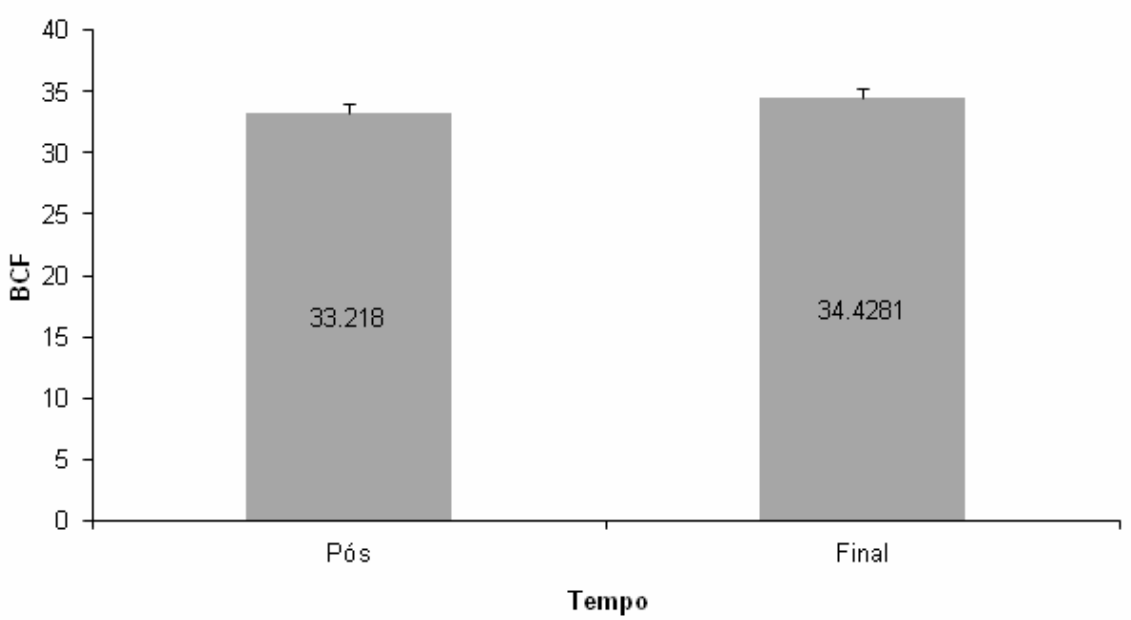

Gráfico 6 - Média e erro padrão da média ( \pm EPM) da frequência de batimentro flagelar cruzado $(\mathrm{BCF})$ para efeito Tempo - São Paulo - 2011

O parâmetro ALH (amplitude de deslocamento lateral de cabeça) apresentou efeito de tempo (Gráfico 7), sendo inferior na avaliação do tempo pós-incubação (PÓS). 


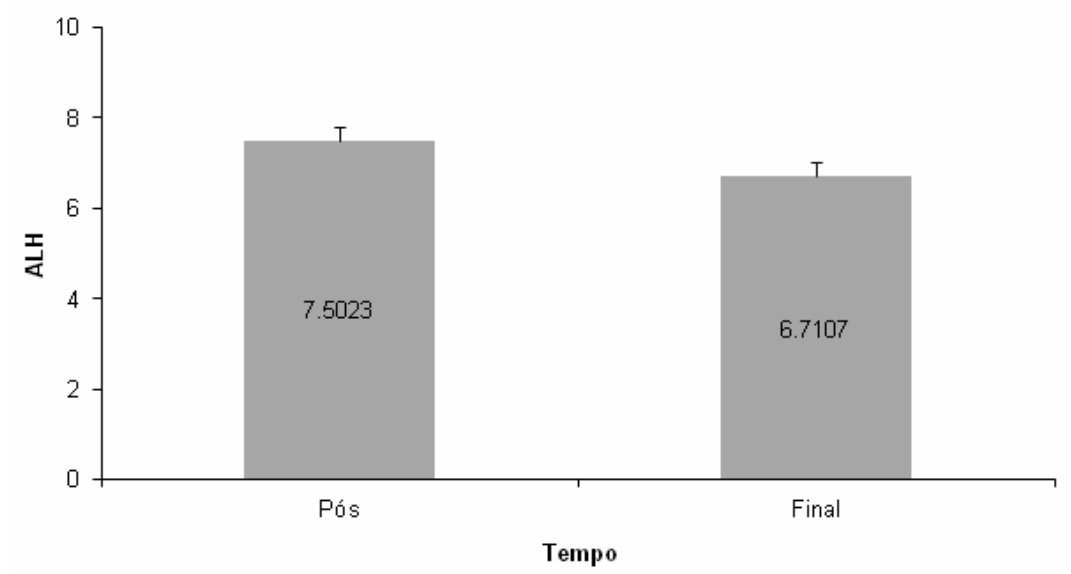

Gráfico 7 - Média e erro padrão da média ( \pm EPM) da amplitude de deslocamento lateral da cabeça para o efeito Tempo pós - análise tempo PÓS; final - análise tempo FINAL - São Paulo - 2011

Os parâmetros VAP (velocidade de trajeto média) (Gráfico 8) e VSL (velocidade linear progressiva) apresentaram tendência, para a interação Potência*Duração do tratamento (Gráfico 9). Estas tendências demonstram, no grupo controle com 10 minutos de duração, médias inferiores ao tratamento potência $7,5 \mathrm{~mW}$ por 5 minutos de duração ( $\mathrm{p}=0,0714)$, porém superiores ao tratamento potência $10 \mathrm{~mW}$ por 5 minutos de duração $(\mathrm{p}=0,097)$. Já a potência $5 \mathrm{~mW}$ por 5 minutos foi inferior à de $7,5 \mathrm{~mW}$ por 5 minutos $(\mathrm{p}=0,089)$.

\section{Média \pm EPM VAP/Pot*Duração}

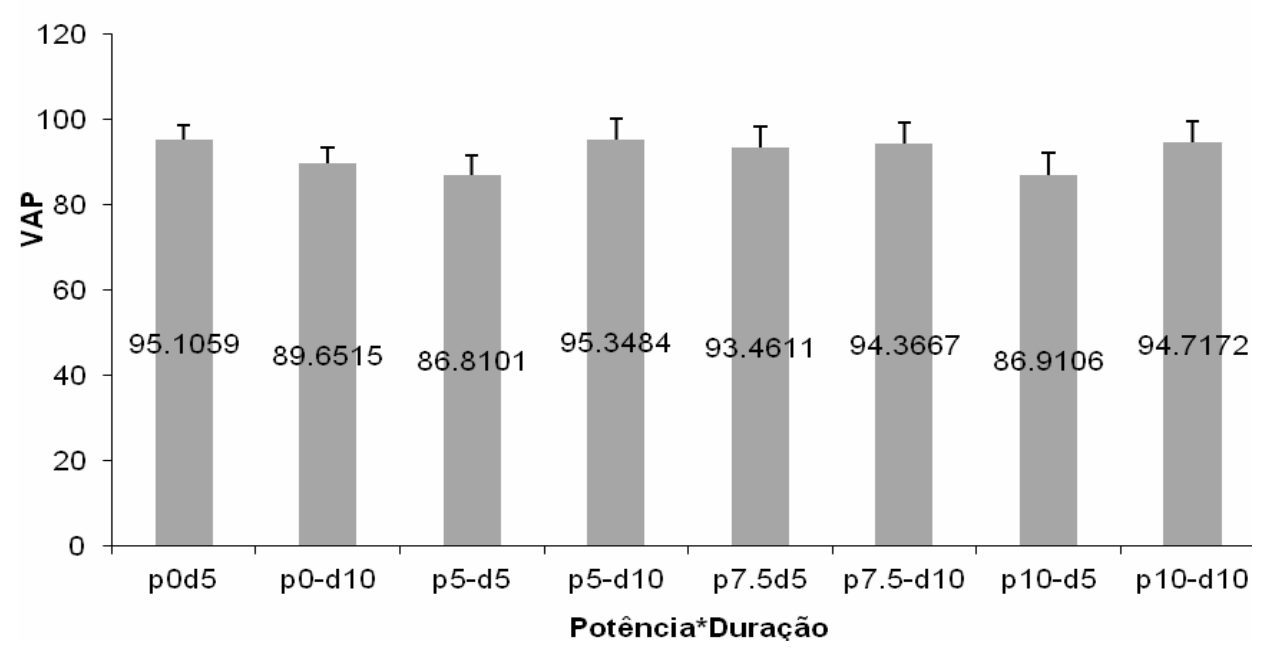

Gráfico 8 - Média e erro padrão da média $( \pm$ EPM) da velocidade de trajeto média $(\mathrm{VAP})$ para interação Potência*Duração de tartamento. p0 - Potência 0 mW; p5 - Potência 5 mW; p7,5 - Potência 7,5 $\mathrm{mW}$; p10 - Potência $10 \mathrm{~mW}$; d5 - duração de tratamento 5 minutos; d10 - duração de tratamento 10 minutos - São Paulo - 2011 


\section{Média \pm EPM VSL/Pot*Dur}

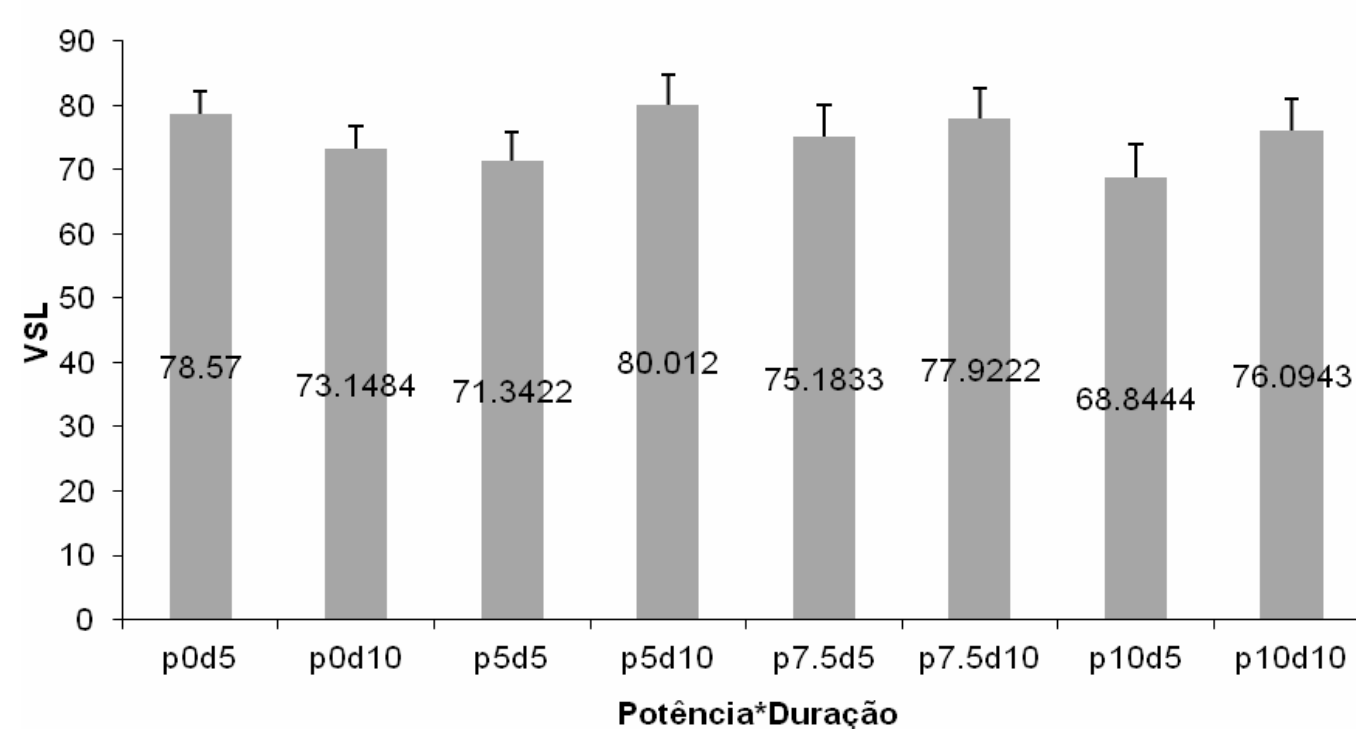

Gráfico 9 - Média e erro padrão da média ( \pm EPM) da velocidade linear progressiva (VSL) para interação Potência*Duração. p0 - Potência 0 mW; p5 - Potência $5 \mathrm{~mW}$; p7,5 - Potência 7,5 mW; p10 Potência $10 \mathrm{~mW}$; d5 - duração de tratamento 5 minutos; d10 - duração de tratamento 10 minutos São Paulo - 2011

A VCL (velocidade curvilínea) apresentou efeito de tempo (Gráfico 10) e interação Potência*Duração (Gráfico 11). Esta velocidade apresentou diminuição entre o tempo PÓS de análise e o tempo FINAL, independente da potência. Na interação Potência*Duração apresentou diminuição também conforme o aumento da duração do tratamento no grupo controle $(\mathrm{p}=0,014)$. A VCL no grupo controle com 5 minutos de tratamento apresentou tendência a ser superior a VCL com $10 \mathrm{~mW}$ de potência e 5 minutos de duração de tratamento $(\mathrm{p}=0,058)$. No entanto, tratamento laser por 10 minutos com $10 \mathrm{~mW}$ de potência foi superior à 5 minutos no grupo controle $(\mathrm{p}=0,014)$. 


\section{Média \pm EPM VCLITempo}

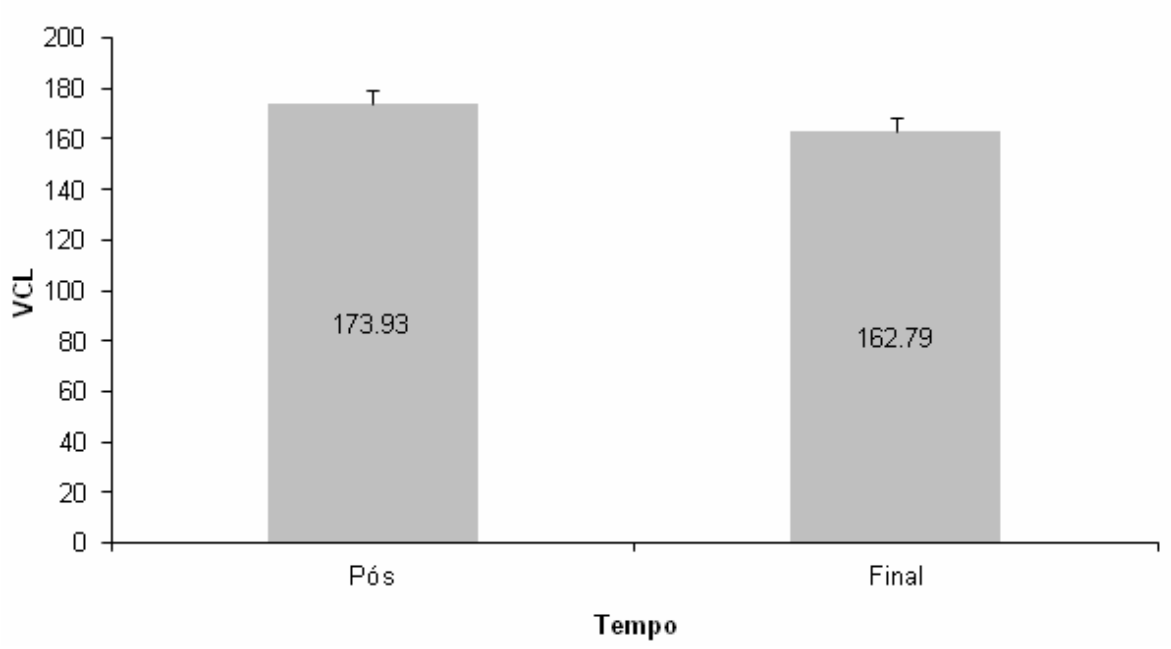

Gráfico 10 - Média e erro padrão da média (Ł EPM) da velocidade de curvilinea (VCL) para efeito Tempo. Pós tempo de análise PÓS; Final - tempo de análise FINAL - São Paulo - 2011

\section{Média \pm EPM VCL/Pot*Dur}

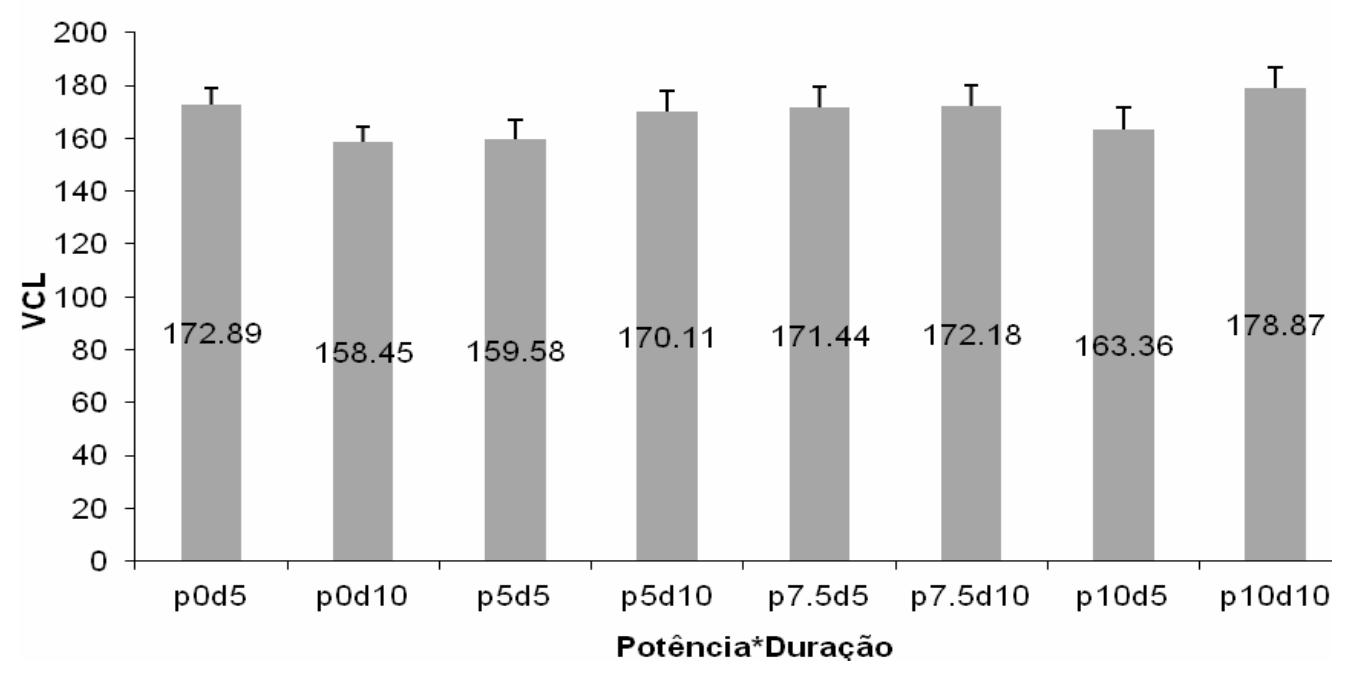

Gráfico 11 - Média e erro padrão da média ( \pm EPM) da velocidade curvilínea (VCL) para interação Potência*Duração do tratamento. p0 - Potência $0 \mathrm{~mW}$; p5 - Potência $5 \mathrm{~mW}$; p7,5 - Potência 7,5 $\mathrm{mW}$; p10 - Potência $10 \mathrm{~mW}$; d5 - duração de tratamento 5 minutos; d10 - duração de tratamento 10 minutos - São Paulo - 2011

Observou-se efeito de duração e tendência para interação Potência*Tempo no formato da cabeça dos espermatozóides, representado por Elong. Em relação à duração do 
tratamento (Gráfico 12), as células espermáticas apresentaram-se menos alongadas no grupo com 10 minutos de tratamento.

\section{Média \pm EPM Elong/Duração}

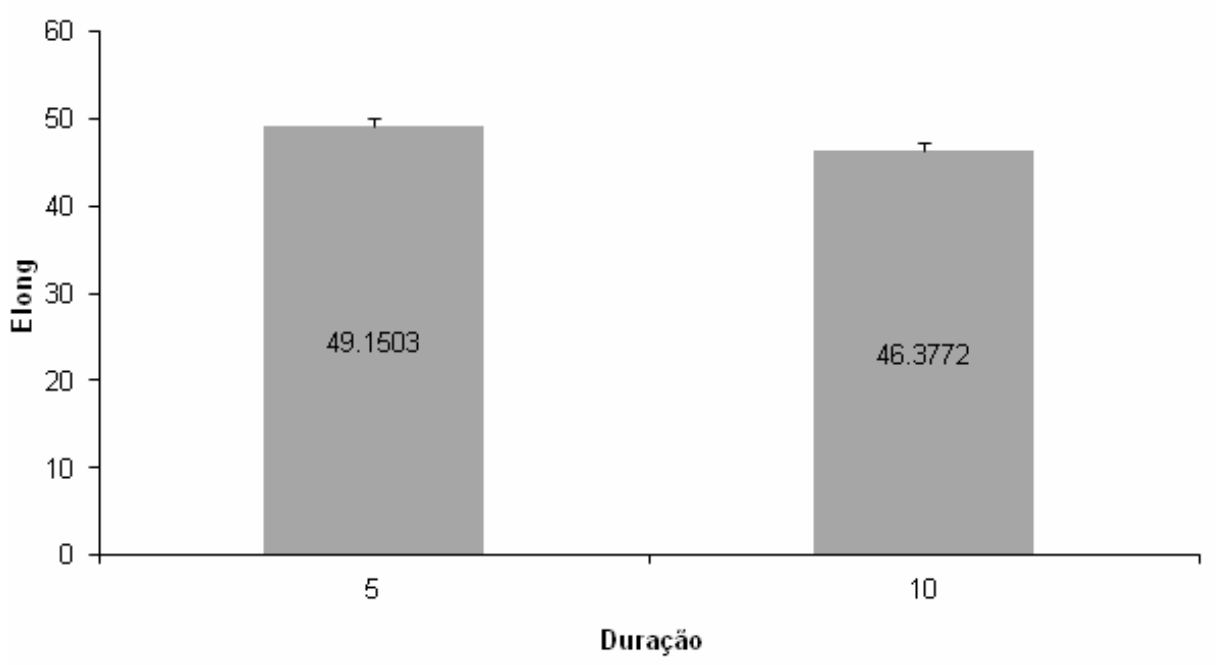

Gráfico 12 - Média e erro padrão da média ( \pm EPM) da alongação das células (Elong) para efeito duração - São Paulo - 2011

Com relação à interação Potência*Tempo (Gráfico 13), o grupo controle apresentou alongamento da cabeça dos espermatozóides (Elong) durante a incubação ( $\mathrm{p}<0,001)$, no entanto, a potência $10 \mathrm{~mW}$ apresentou diminuição desta característica durante o período $(\mathrm{p}=0,018)$ e a potência $5 \mathrm{~mW}$ uma tendência a apresentá-la $(\mathrm{p}=0,0798)$. $\mathrm{O}$ padrão de alongamento da cabeça dos espermatozóides do tempo FINAL de análise foi superior com $7,5 \mathrm{~mW}$ de potência quando comparado ao tempo FINAL do grupo controle $(\mathrm{p}=0,040)$. 


\section{Média \pm EPM Elong/Pot*Tem}

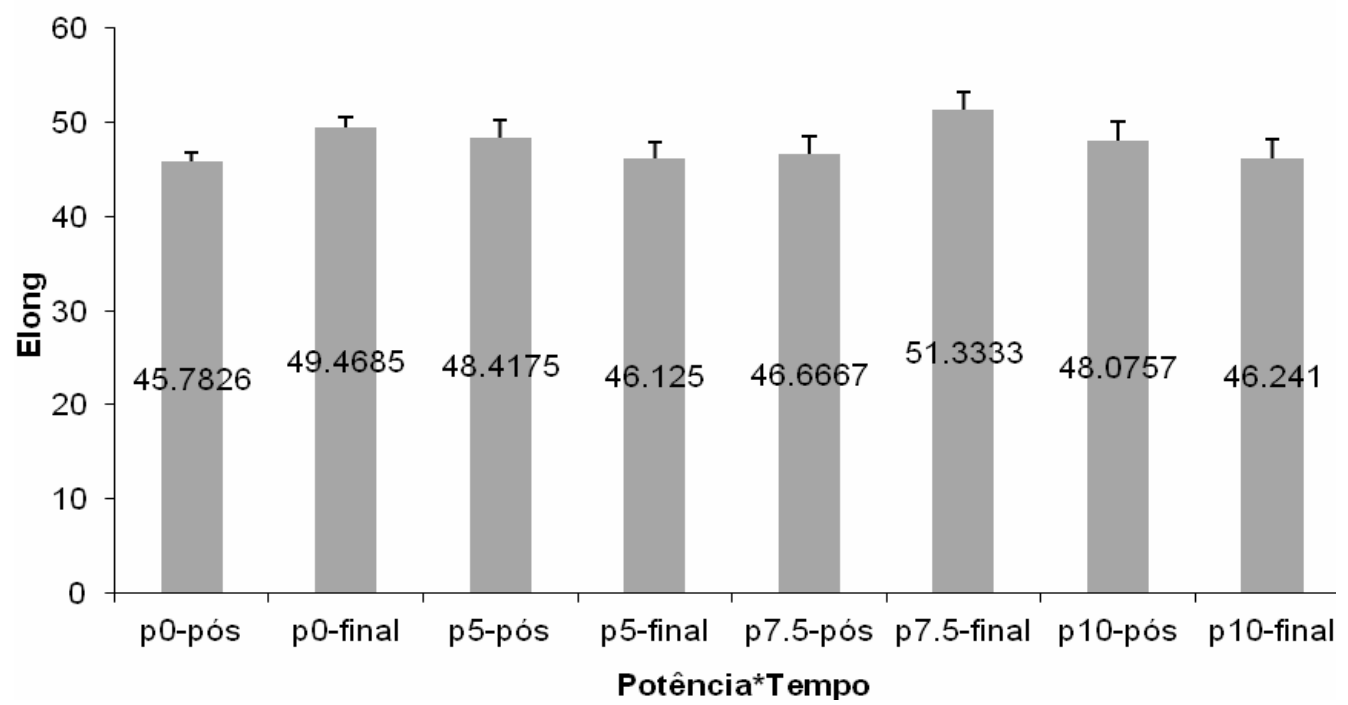

Gráfico 13 - Média e erro padrão da média ( \pm EPM) da alongação das células (Elong) para interação Potência*Tempo. p0 - Potência 0 mW; p5 - Potência 5 mW; p7.5 - Potência 7,5 mW; p10 Potência $10 \mathrm{~mW}$; pós - análise tempo PÓS; final - análise tempo FINAL - São Paulo - 2011

A integridade/lesão da membrana plasmática demonstrou tendência para efeito de tempo (Gráfico 14), com diminuição da integridade de membrana no tempo FINAL (Gráfico 15), independente da aplicação ou não do laser

Média \pm EPM PL/Tempo

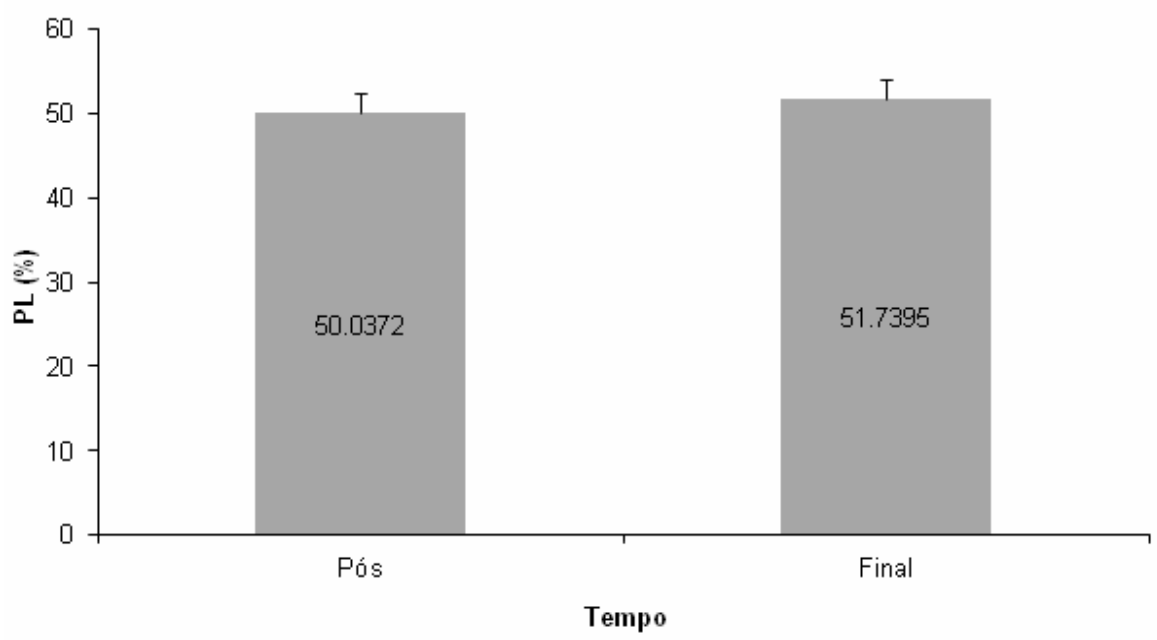

Gráfico 14 - Média e erro padrão da média ( \pm EPM) da lesão de membrana plasmática (PL) para efeito Tempo. Pós - tempo de análise PÓS; Final - tempo de análise FINAL - São Paulo - 2011 


\section{Média \pm EPM PIITempo}

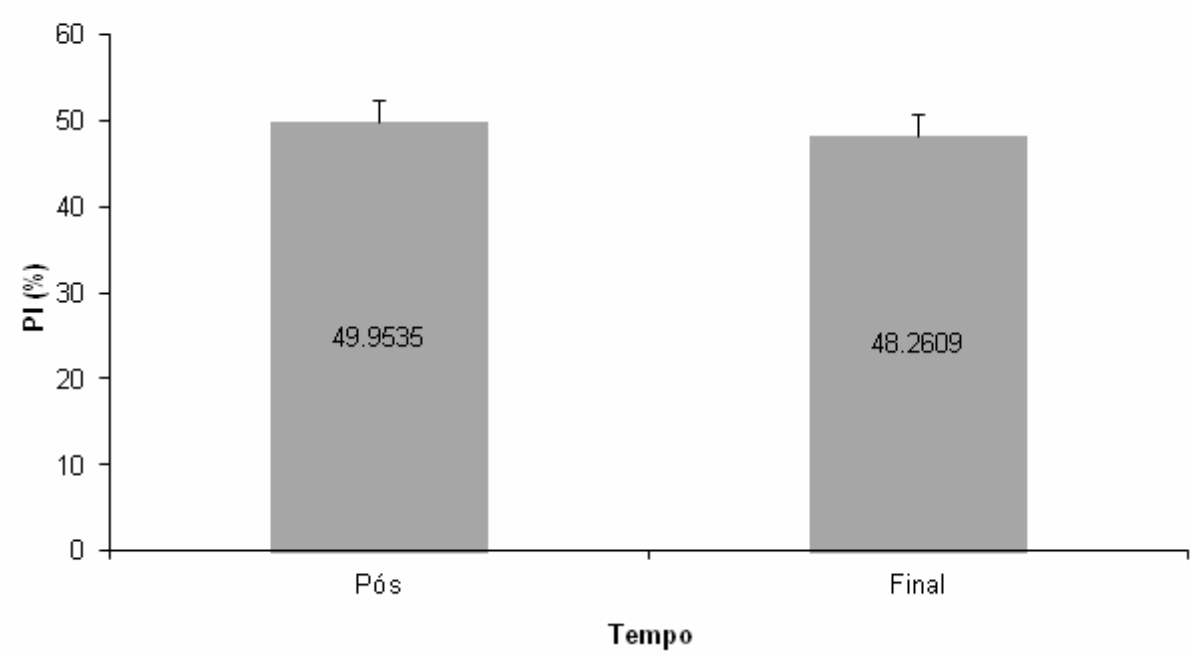

Gráfico 15 - Média e erro padrão da média ( \pm EPM) da integridade de membrana plasmática (PI) para efeito Tempo. Pós - tempo de análise PÓS; Final - tempo de análise FINAL - São Paulo - 2011

Houve efeito da duração do tratamento na integridade de membrana acrossomal (Gráfico 16 e 17), no qual o grupo 10 minutos de tratamento apresentou maior integridade com relação aos 5 minutos, independente da aplicação do laser.

\section{Média \pm EPM AL/Duração}

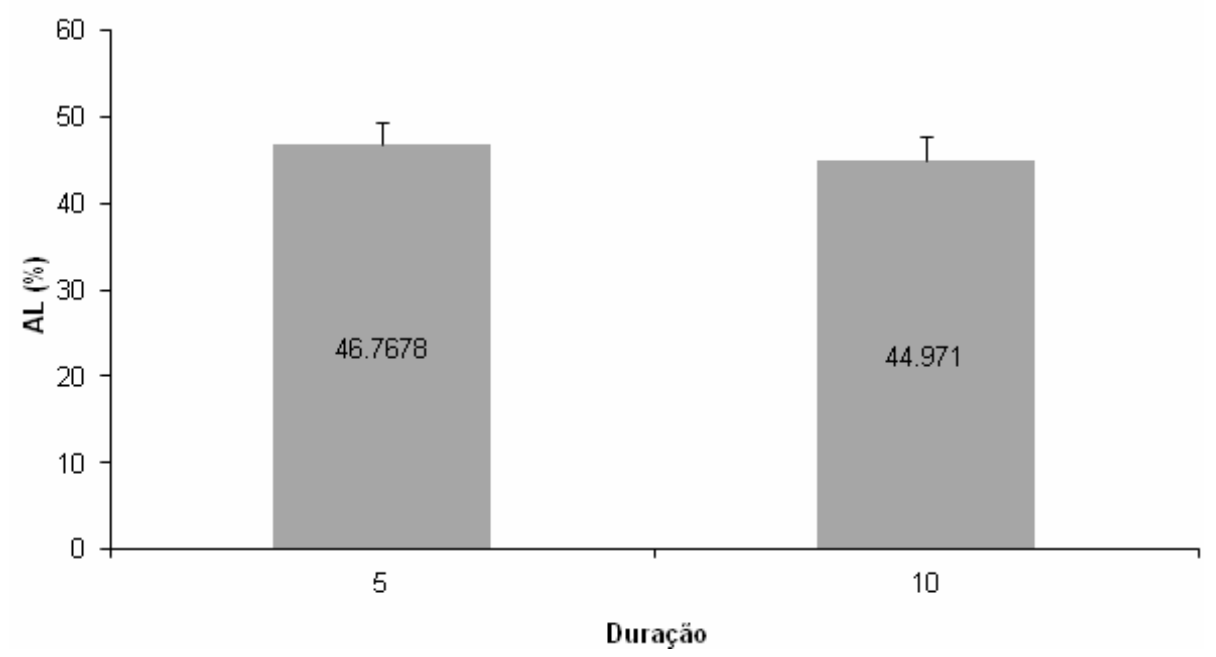

Gráfico 16- Média e erro padrão da média ( \pm EPM) da lesão de acrossomo (AL) para efeito duração - São Paulo $-2011$ 


\section{Média £ EPM Al/Duração}

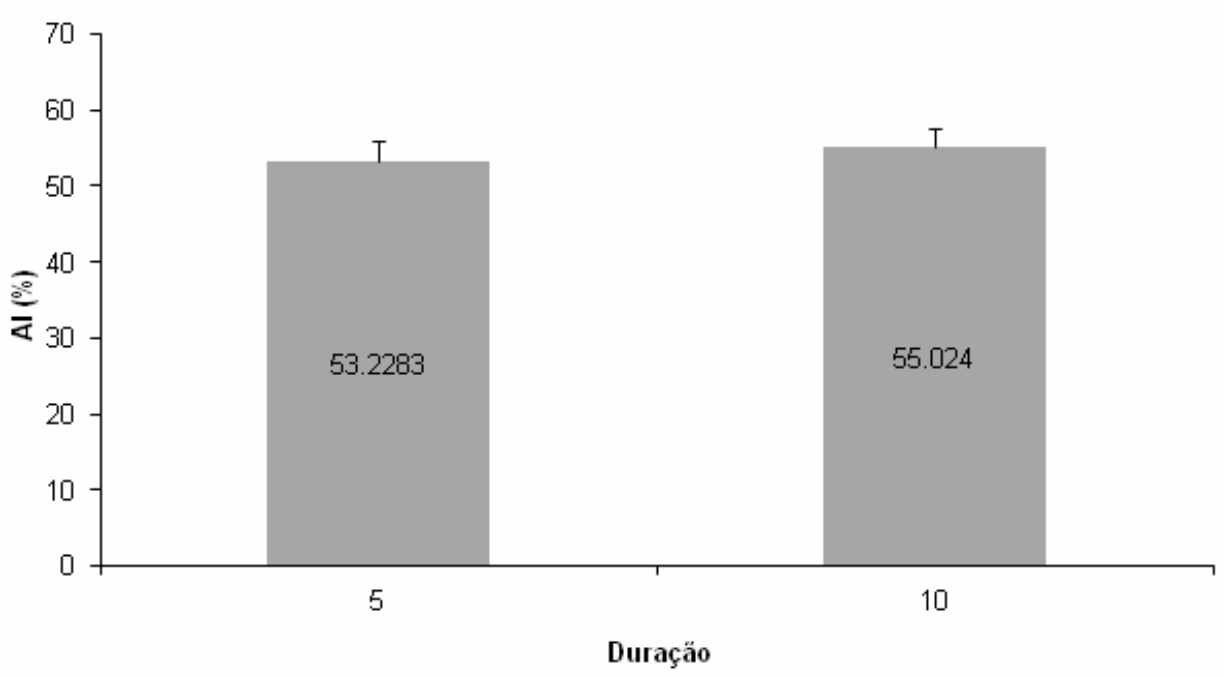

Gráfico 17 - Média e erro padrão da média ( \pm EPM) da integridade de acrossomo (AI) para efeito duração - São Paulo - 2011

$\mathrm{Na}$ análise associada (Gráfico 18 e 19), maior porcentagem de células com membranas plasmática e acrossomal íntegras também foi observada no grupo com 10 minutos tratamento. No entanto, todas estas alterações ocorreram independentemente da aplicação e da potência do laser.

\section{Média \pm EPM ALPLIDuração}

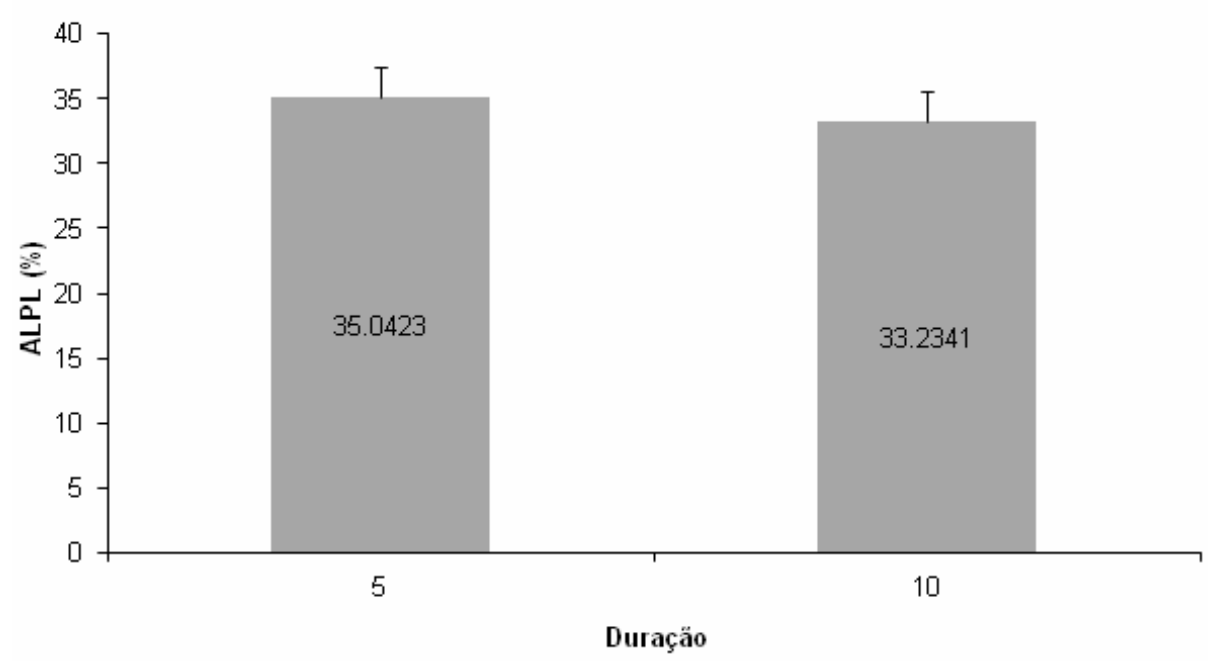

Gráfico 18 - Média e erro padrão da média ( \pm EPM) das membranas acrossomal e plasmática lesadas (ALPL) para efeito duração - São Paulo - 2011 
Média — EPM AIPI/Duração

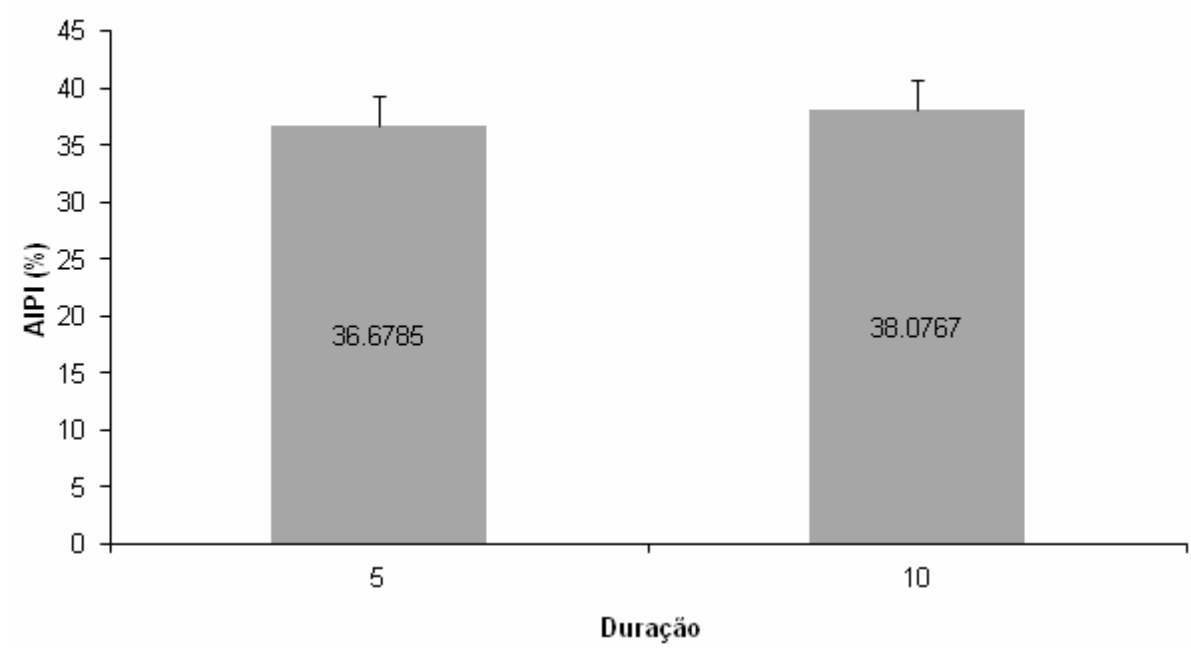

Gráfico 19 - Média e erro padrão da média ( \pm EPM) das membranas acrossomal e plasmática íntegras (AIPI) para efeito duração - São Paulo - 2011

$\mathrm{Na}$ análise de potencial de membrana mitocondrial, que avalia o metabolismo energético do espermatozóide, foi observado efeito do tempo, demonstrado pelo aumento da população de alto potencial de membrana mitocondrial, após o tratamento (incubação/irradiação) (Gráfico 20).

\section{Média \pm EPM Alto/Tempo}

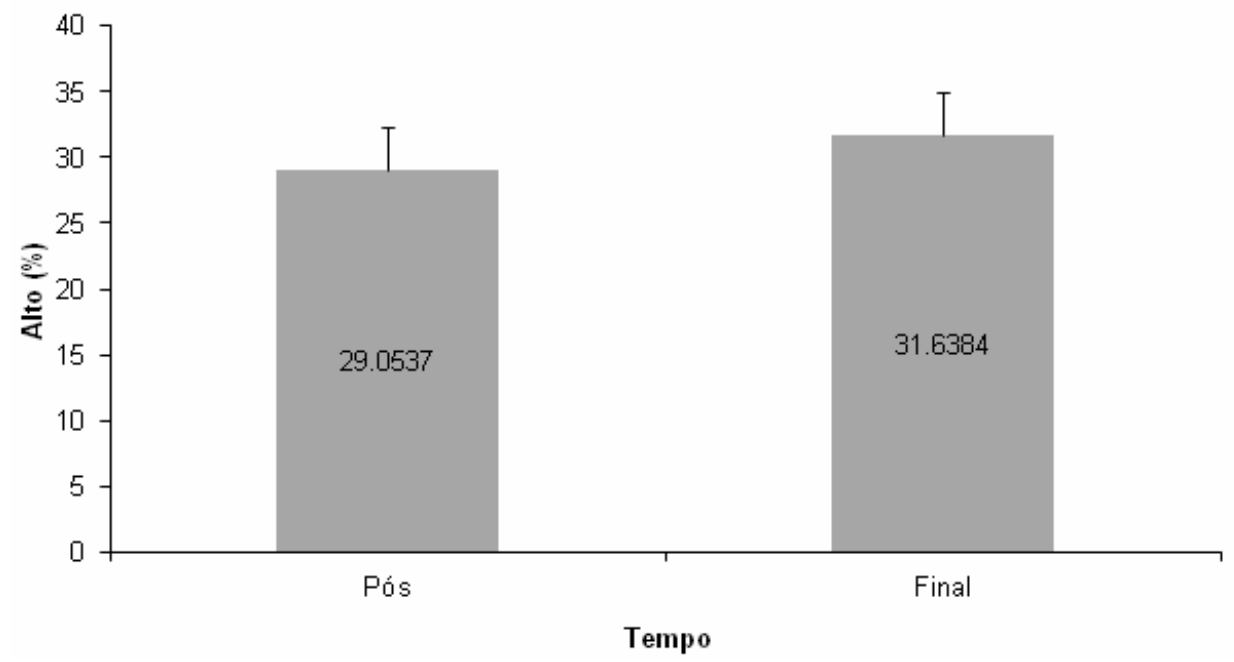

Gráfico 20 - Média e erro padrão da média ( \pm EPM) da população com alto potencial de membrana mitocondrial (Alto) para efeito Tempo. Pós - tempo de análise PÓS; FINAL - tempo de análise FINAL - São Paulo - 2011 
Observou-se também que esta mesma população (alto potencial), apresentou interação Potência*Duração de tratamento (Gráfico 21), sendo que na potência de $10 \mathrm{~mW}$ a duração de 10 minutos apresentou resultados inferiores ao10mW por 5 minutos de duração $(\mathrm{p}=0,035)$. A potência de $10 \mathrm{~mW}$ por 5 minutos de duração também apresentou tendência a ser superior à potência 7,5 mW na duração de 5 minutos $(\mathrm{p}=0,0699)$ e foi inferior à duração de 10 minutos de tratamento com a potência 7,5 $\mathrm{mW}(\mathrm{p}=0,034)$. A duração do tratamento por 10 minutos no grupo controle apresentou tendência a ser superior na duração do tratamento por 5 minutos de tratamento com $5 \mathrm{~mW}$ de potência $(\mathrm{p}=0,0947)$.

\section{Média \pm EPM Alto/Pot*Dur}

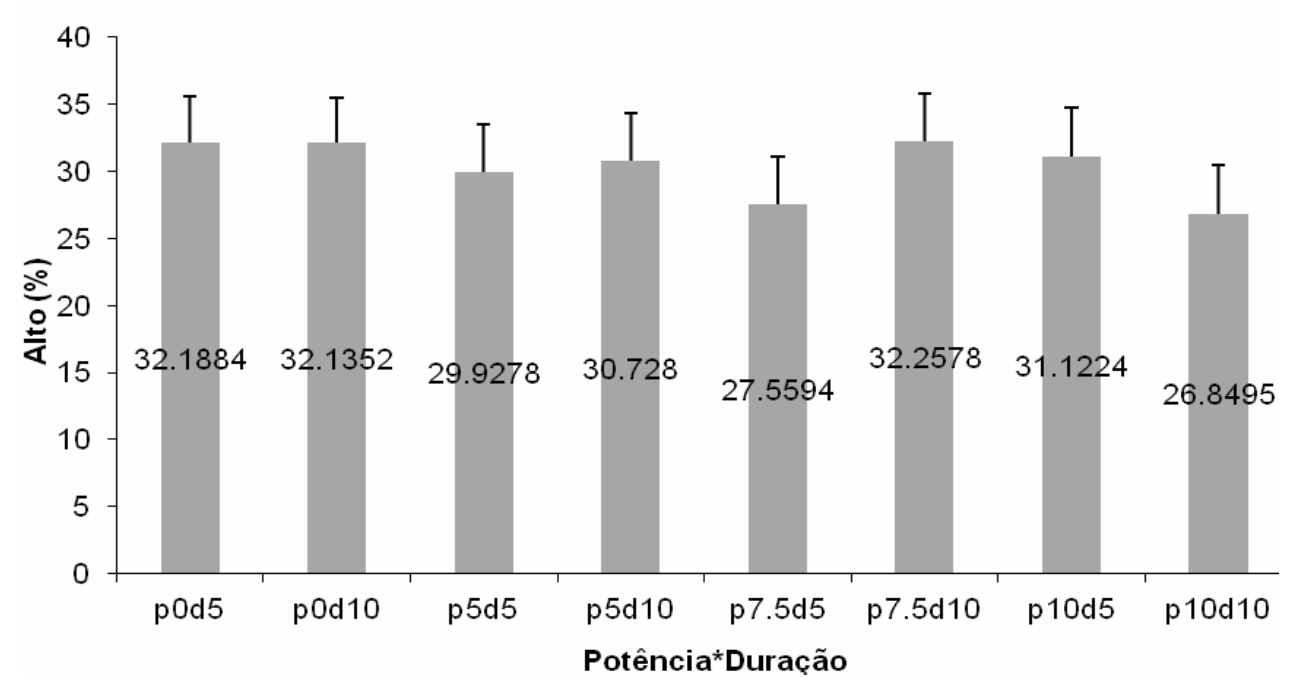

Gráfico 21 - Média e erro padrão da média ( \pm EPM) da população com alto potencial de membrana mitocondrial (Alto) para interação Potência*Duração do tratamento. p0 - Potência $0 \mathrm{~mW}$; p5 - Potência $5 \mathrm{~mW}$; p7.5 - Potência 7,5 mW; p10 - Potência $10 \mathrm{~mW}$; d5 - duração de tratamento 5 minutos; d10 duração de tratamento 10 minutos - São Paulo - 2011

Na população com potencial intermediário foi observada a mesma interação de Potência*Duração do tratamento (Gráfico 22). O grupo controle (incubação) com 10 minutos de tratamento apresentou tendência a ser inferior ao grupo tratado com $5 \mathrm{~mW}$ por 5 minutos $(\mathrm{p}=0,0947)$ e foi também inferior ao grupo tratado com $10 \mathrm{~mW}$ por 10 minutos $(\mathrm{p}=0,0235)$. $\mathrm{O}$ grupo tratado por 5 minutos com potência de $10 \mathrm{~mW}$ foi inferior ao grupo tratado por 5 minutos com potência de $7,5 \mathrm{~mW}(\mathrm{p}=0,033)$, apresentando tendência a ser inferior ao tratado por 10 minutos com potência de 7,5 $\mathrm{mW}$ (p=0,0699). 


\section{Média \pm EPM Intermediário /Pot*Dur}

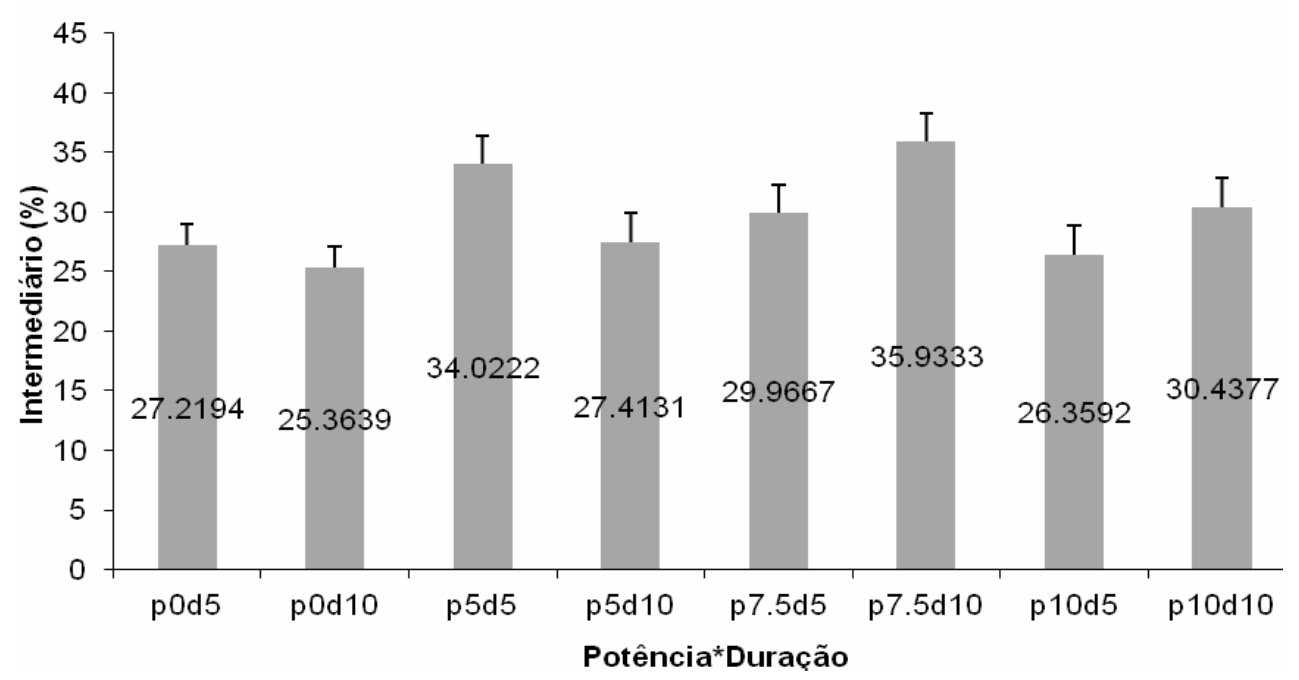

Gráfico 22 - Média e erro padrão da média ( \pm EPM) da população com potencial de membrana mitocondrial intermediário (Intermediário) para interação Potência*Duração. p0 - Potência $0 \mathrm{~mW}$; p5 - Potência $5 \mathrm{~mW}$; p7.5 - Potência 7,5 mW; p10 - Potência $10 \mathrm{~mW}$; d5 - duração de tratamento 5 minutos; d10 - duração de tratamento 10 minutos - São Paulo - 2011

A análise do SCSA apresentou efeito de duração do tratamento (Gráfico 23 e 24), na qual o grupo 10 minutos apresentou menor positividade, ou seja, menor alteração de cromatina quando comparado ao grupo 5 minutos de tratamento. Porém este efeito de duração de tratamento foi independente da potência.

Média \pm EPM SCSAPositivolDuração

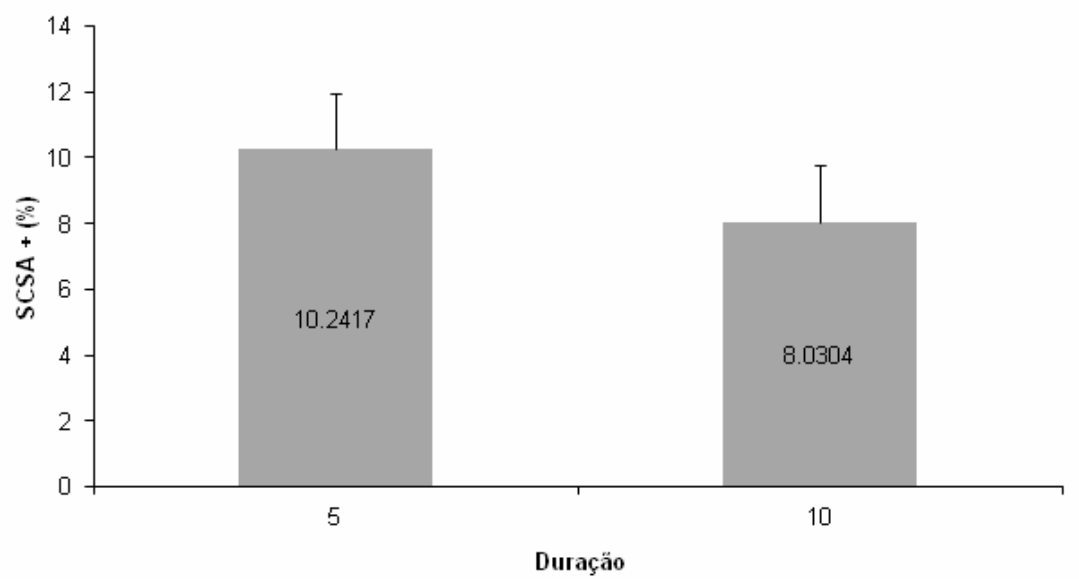

Gráfico 23 - Média e erro padrão da média ( \pm EPM) das células positivas do ensaio da estrutura da cromatina (SCSA positivo) para efeito duração do tratamento. - São Paulo - 2011 
Média \pm EPM SCSA Negativo/Duração

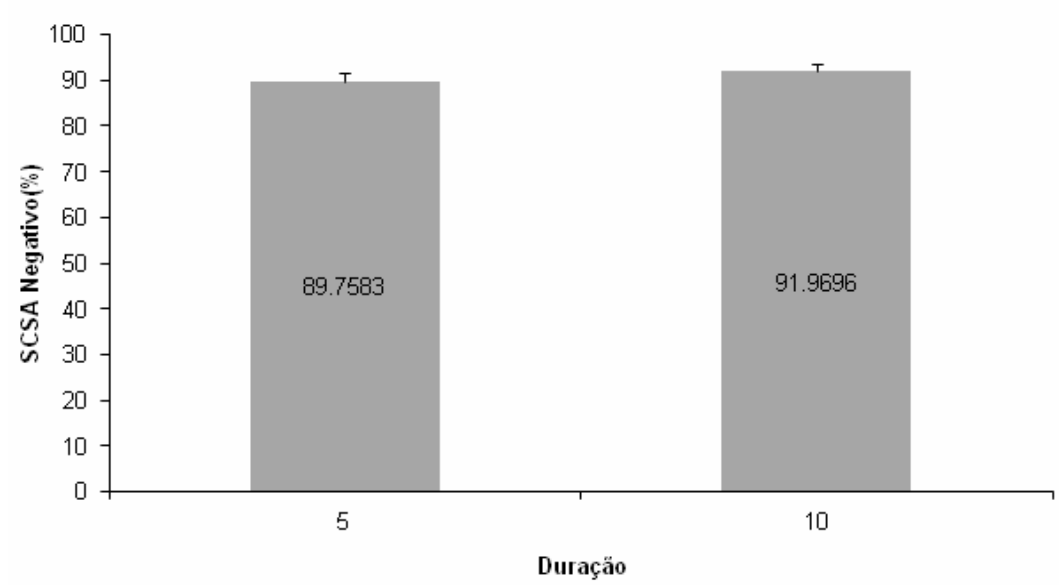

Gráfico 24 - Média e erro padrão da média ( \pm EPM) das células negativas do ensaio da estrutura da cromatina (SCSA negativo) para efeito duração do tratamento

Para melhor compreensão dos eventos biológicos ocorridos, o comportamento das amostras nos parâmetros espermáticos que apresentaram mesma interação, foi estudado agrupadamente. As médias e erro padrão das médias (†EPM) dos atributos espermáticos que apresentaram interação estão apresentados agrupadas por potência dentro de cada interação nos gráficos 25, 26, 27, 28, 29, 30, 31 e 32 .

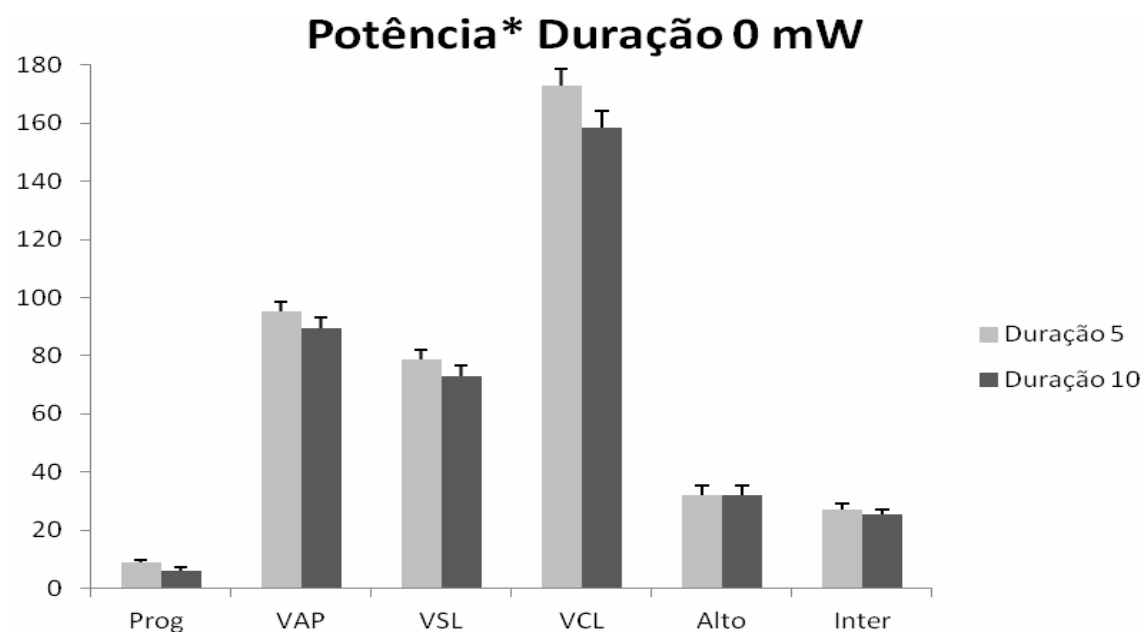

Gráfico 25 - Média e erro padrão da média ( \pm EPM) da potência $0 \mathrm{~mW}$ nas durações do tratamento de 5 e 10 minutos para a motilidade progressiva (Prog), velocidade média de trajeto (VAP), velocidade linear progressiva (VSL), velocidade curvilínea (VCL), população de alto potência de membrana mitocondrial (alto), população com potencial de membrana mitocondrial intermediário (inter) - São Paulo - 2011 


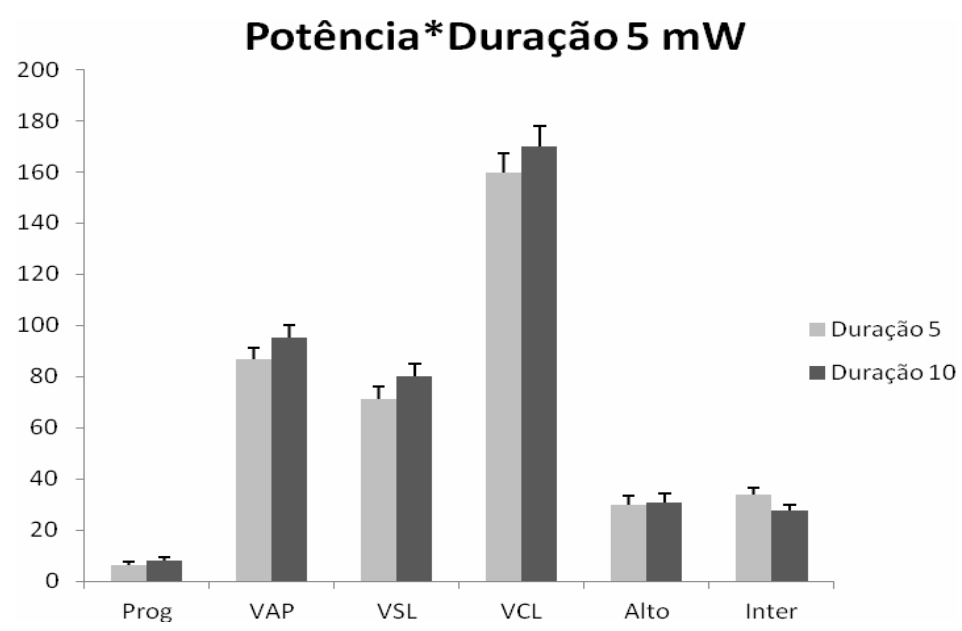

Gráfico 26 - Média e erro padrão da média ( \pm EPM) da potência $5 \mathrm{~mW}$ nas durações de 5 e 10 minutos de tratamento para a motilidade progressiva (Prog), velocidade média de trajeto (VAP), velocidade linear progressiva (VSL), velocidade curvilínea (VCL), população de alto potência de membrana mitocondrial (alto), população com potencial de membrana mitocondrial intermediário (inter) - São Paulo - 2011

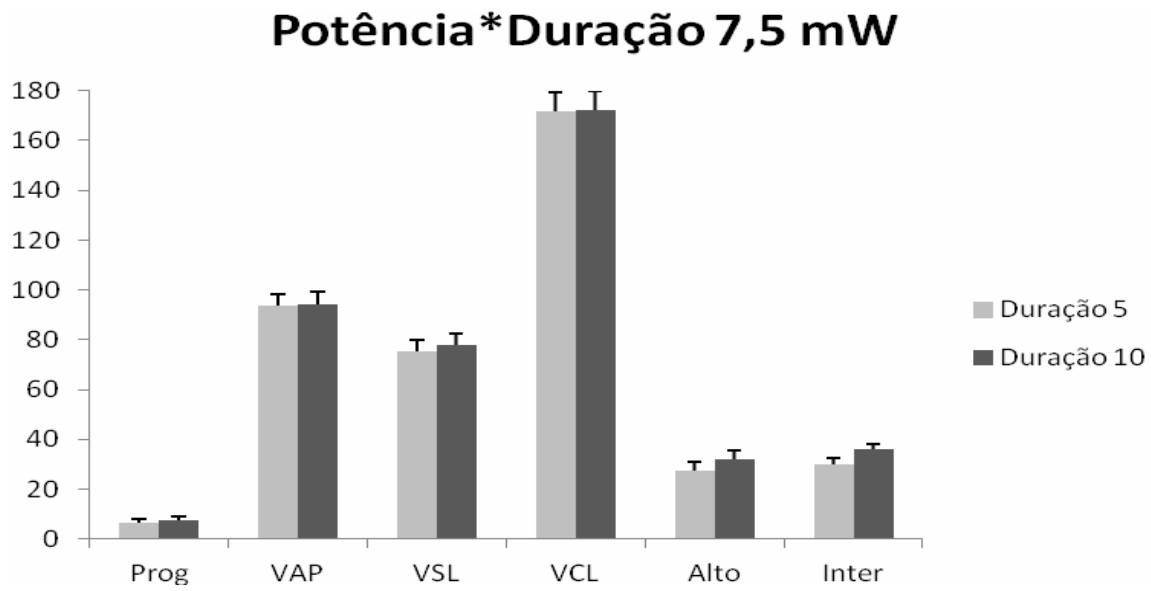

Gráfico 27 - Média e erro padrão da média ( \pm EPM) da potência 7,5 mW nas durações de 5 e 10 minutos de tratamento para a motilidade progressiva (Prog), velocidade média de trajeto (VAP), velocidade linear progressiva (VSL), velocidade curvilínea (VCL), população de alto potência de membrana mitocondrial (alto), população com potencial de membrana mitocondrial intermediário (inter) - São Paulo - 2011 


\section{Potência*Duração $10 \mathrm{~mW}$}

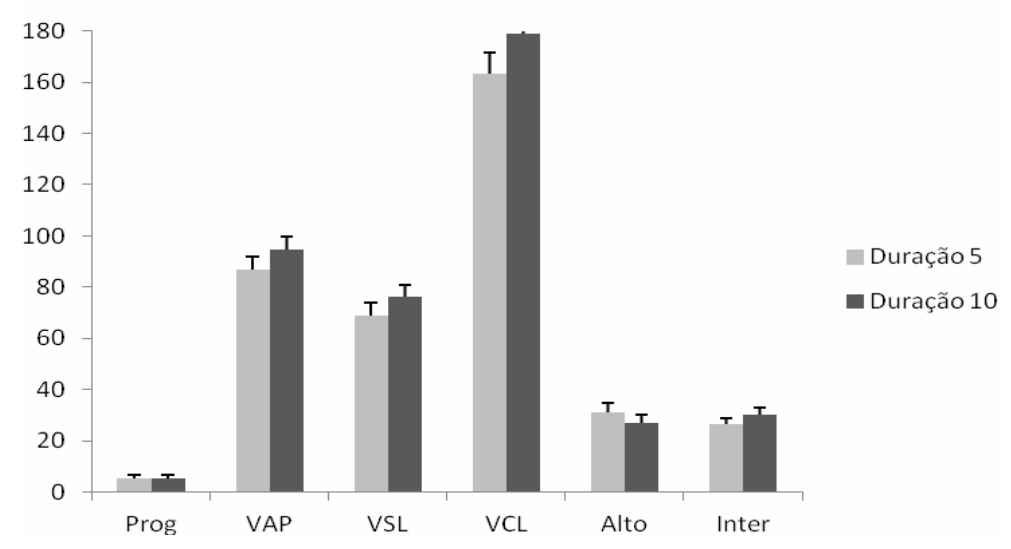

Gráfico 28 - Média e erro padrão da média ( \pm EPM) da potência $10 \mathrm{~mW}$ nas durações de 5 e 10 minutos de tratamento para a motilidade progressiva (Prog), velocidade média de trajeto (VAP), velocidade linear progressiva (VSL), velocidade curvilínea (VCL), população de alto potência de membrana mitocondrial (alto), população com potencial de membrana mitocondrial intermediário (inter) - São Paulo - 2011

\section{Potência *Tempo $0 \mathrm{~mW}$}

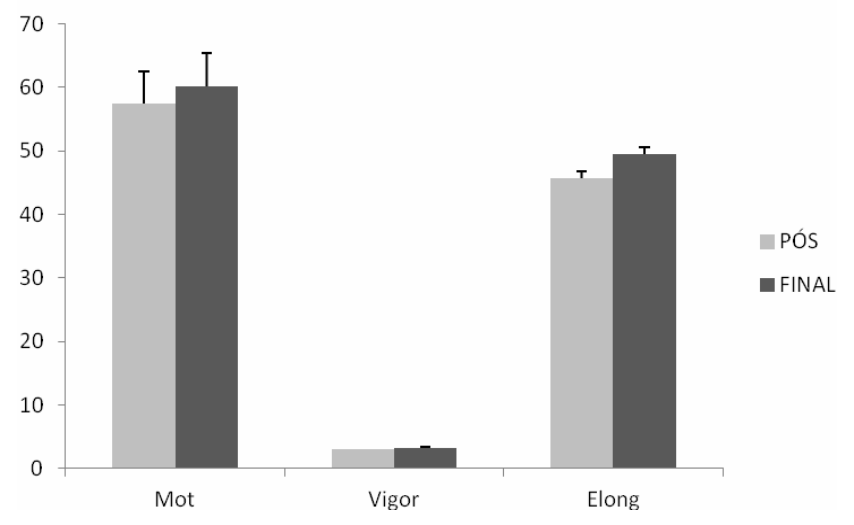

Gráfico 29 - Média e erro padrão da média ( \pm EPM) da potência $0 \mathrm{~mW}$, imediatamente após a aplicação do tratamento (PÓS) e após 30 minutos do início do tratamento para a motilidade visual (Mot), vigor e alongação das células (Elong) - São Paulo - 2011 


\section{Potência*Tempo $5 \mathrm{~mW}$}

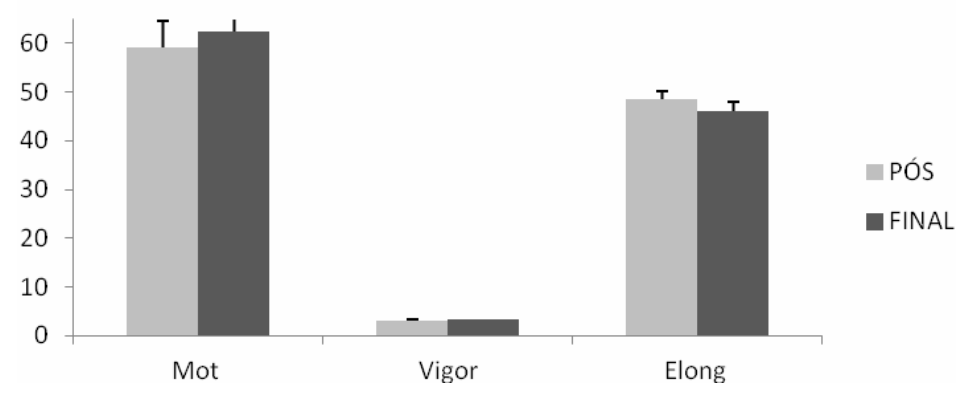

Gráfico 30 - Média e erro padrão da média ( \pm EPM) da potência $5 \mathrm{~mW}$, imediatamente após a aplicação do tratamento (PÓS) e após 30 minutos do início do tratamento para a motilidade visual (Mot), vigor e alongação das células (Elong) - São Paulo - 2011

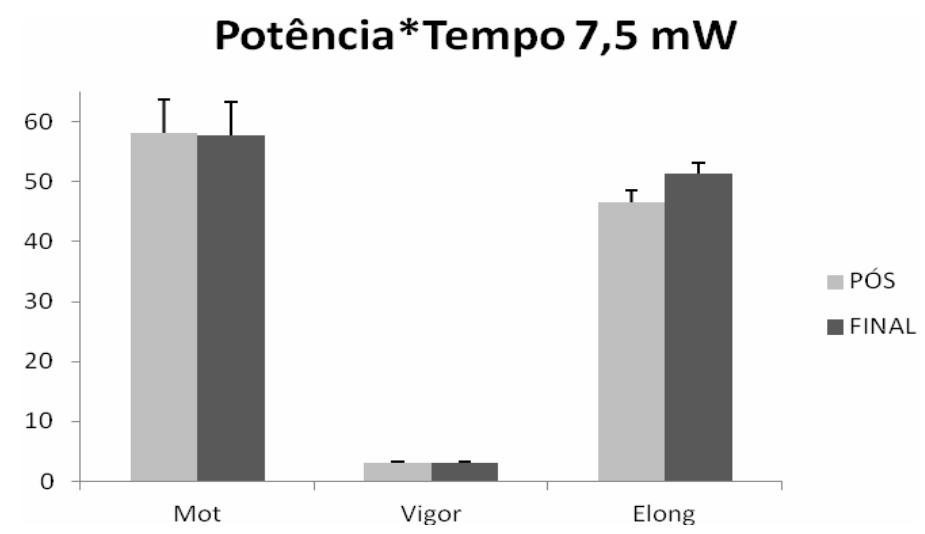

Gráfico 31 - Média e erro padrão da média ( + EPM) da potência 7,5 mW, imediatamente após a aplicação do tratamento (PÓS) e após 30 minutos do início do tratamento para a motilidade visual (Mot), vigor e alongação das células (Elong) - São Paulo - 2011

\section{Potência*Tempo $10 \mathrm{~mW}$}

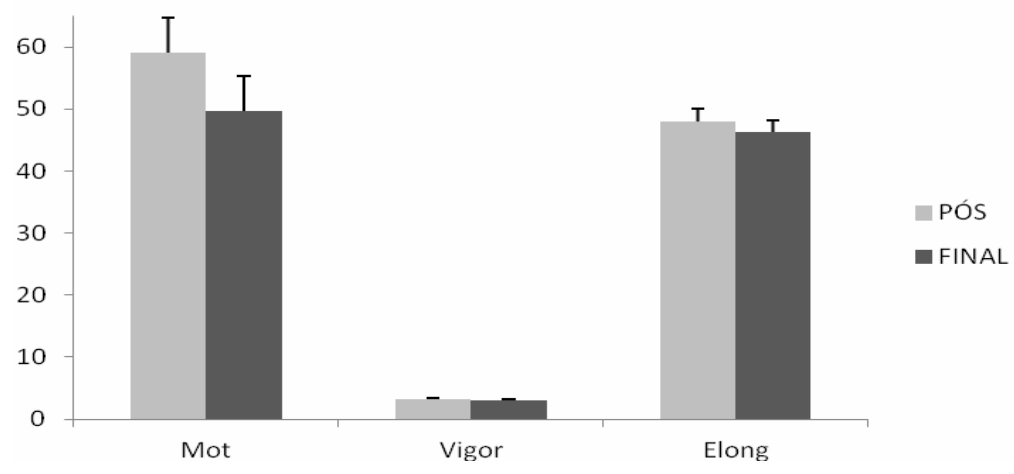

Gráfico 32 - Média e erro padrão da média ( Ł EPM) da potência $10 \mathrm{~mW}$, imediatamente após a aplicação do tratamento (PÓS) e após 30 minutos do início do tratamento para a motilidade visual (Mot), vigor e alongação das células (Elong) - São Paulo - 2011 


\subsection{EXPERIMENTO 2}

Os atributos seminais foram analisados com relação aos efeitos de tratamento (tratado ou controle), de tempo (T0, T10 e T30) e interação Tratamento*Tempo, pela análise de variância com medidas repetidas no tempo.

Os valores de $\mathrm{p}$ encontrados na análise de variância, para os atributos espermáticos analisados, nas amostras seminais submetidas à aplicação de ondas eletromagnéticas (tratado), ou incubadas a $37^{\circ} \mathrm{C}$ (controle), utilizadas na produção de embriões in vitro, estão apresentados na tabela 2 .

Tabela 2 - Valores de P para os efeitos tratamento, tempo e tratamento*tempo para os parâmetros espermáticos analisados - São Paulo - 2011

\begin{tabular}{lccc}
\hline \multicolumn{1}{c}{ ParâmetrolEfeito } & Tratamento & Tempo & Tratamento*Tempo \\
\hline Motilidade & 0.380 & 0.196 & 0.713 \\
Vigor & $\mathbf{0 . 0 1 4}$ & $<\mathbf{0 . 0 0 0 1}$ & 0.200 \\
Aglutinação & 0.245 & 0.172 & 0.260 \\
PI & 0.637 & $\mathbf{0 . 0 0 1}$ & 0.945 \\
PL & 0.630 & $\mathbf{0 . 0 0 1}$ & 0.943 \\
AI & 0.985 & $\mathbf{0 . 0 0 3}$ & 0.975 \\
AL & 0.976 & $\mathbf{0 . 0 0 3}$ & 0.979 \\
AIPI & 0.746 & $\mathbf{0 . 0 0 8}$ & 0.661 \\
AIPL & 0.557 & 0.598 & 0.399 \\
ALPI & 0.778 & 0.503 & 0.293 \\
ALPL & 0.517 & $\mathbf{0 . 0 9 2}$ & 0.356 \\
Potencial alto & 0.102 & 0.335 & 0.280 \\
Potencial intermediário & 0.140 & 0.362 & 0.366 \\
Potencial baixo & 0.987 & $\mathbf{0 . 0 4 8}$ & 0.999 \\
SCSA positivo & 0.170 & $\mathbf{0 . 0 3 8}$ & 0.614 \\
SCSA negativo & 0.167 & $\mathbf{0 . 0 3 8}$ & 0.609 \\
\hline
\end{tabular}

PL - membrana plasmática lesada; PI - membrana plasmática íntegra; AL - acrossomo lesado; AI - acrossomo íntegro; AIPI - acrossomo íntegro e plasmática íntegra; AIPL - acrossomo íntegro e plasmática lesada; ALPI acrossomo lesado e plasmática íntegra; ALPL - acrossomo lesado e plasmática lesada; SCSA+ - positivo ao ensaio da estrutura da cromatina; SCSA- - negativo ao ensaio da estrutura da cromatina

A análise de variância demonstrou efeito de tratamento apenas para o vigor. Efeito de tempo foi demonstrado para os parâmetros vigor, PL, AL, AIPI, AIPL, ALPI, baixo potencial 
de membrana mitocondrial, positividade ou negatividade ao SCSA. Foi observada uma tendência do efeito tempo para o parâmetro ALPL. E não se observou efeito de interação para nenhum dos parâmetros avaliados.

As médias, o erro padrão da média ( \pm EPM) e o valor de p para efeito de tratamento, do grupo tratado (laser) e grupo controle (incubação) estão apresentados na tabela 3.

Tabela 3 - Médias e erro padrão da média ( \pm EPM) dos grupos tratado e controle, nos atributos espermáticos analisados e respectivos valores de P para o efeito de tratamento - São Paulo - 2011

\begin{tabular}{|c|c|c|c|}
\hline Parâmetro & Tratado & Controle & $\mathbf{P}$ valor \\
\hline Motilidade(\%) & $57.50 \pm 5.24$ & $58.85 \pm 5.24$ & 0.380 \\
\hline Vigor (0-5) & $3.10 \pm 0.08$ & $3.24 \pm 0.08$ & 0.014 \\
\hline Aglutinação(0-3) & $0.91 \pm 0.11$ & $0.99+0.11$ & 0.245 \\
\hline $\operatorname{PI}(\%)$ & $50.14+2.73$ & $50.49 \pm 2.73$ & 0.637 \\
\hline PL(\%) & $49.86+2.73$ & $49.51 \pm 2.73$ & 0.630 \\
\hline $\mathbf{A I}(\%)$ & $60.02+2.60$ & $60.03 \pm 2.60$ & 0.985 \\
\hline $\mathbf{A L}(\%)$ & $39.98 \pm 2.60$ & $39.96 \pm 2.60$ & 0.976 \\
\hline $\operatorname{AIPI}(\%)$ & $41.85 \pm 2.95$ & $42.16 \pm 2.95$ & 0.746 \\
\hline AIPL(\%) & $18.41 \pm 1.61$ & $17.87 \pm 1.61$ & 0.557 \\
\hline $\operatorname{ALPI}(\%)$ & $8.50 \pm 0.79$ & $8.32 \pm 0.79$ & 0.778 \\
\hline $\operatorname{ALPL}(\%)$ & $31.03 \pm 2.38$ & $31.64 \pm 2.38$ & 0.517 \\
\hline $\operatorname{Alto}(\%)$ & $37.36 \pm 2.62$ & $39.29 \pm 2.62$ & 0.102 \\
\hline Intermediário(\%) & $37.91 \pm 2.37$ & $35.95 \pm 2.37$ & 0.140 \\
\hline Baixo(\%) & $24.68 \pm 2.87$ & $24.71 \pm 2.87$ & 0.987 \\
\hline $\mathrm{SCSA}+(\%)$ & $1.27 \pm 0.29$ & $1.77 \pm 0.29$ & 0.170 \\
\hline SCSA-(\%) & $98.73 \pm 0.29$ & $98.23 \pm 0.29$ & 0.167 \\
\hline
\end{tabular}

PL - membrana plasmática lesada; PI - membrana plasmática íntegra; AL - acrossomo lesado; AI - acrossomo íntegro; AIPI - acrossomo íntegro e plasmática íntegra; AIPL - acrossomo íntegro e plasmática lesada; ALPI acrossomo lesado e plasmática íntegra; ALPL - acrossomo lesado e plasmática lesada; Alto - alto potêncial de membrana mitocondrial; Intermediário - potêncial intermediário de membrana mitocondrial; Baixo - baixo potencial de membrana mitocondrial; (SCSA+) - positivo ao ensaio da estrutura da cromatina; (SCSA-) negativo ao ensaio da estrutura da cromatina. 
Foi observado efeito da aplicação de laser sobre o vigor das amostras seminais utilizadas na produção in vitro de embriões, nas quais a aplicação do laser diminui o vigor das amostras seminais.

As médias e o valor de $\mathrm{P}$ para o efeito tempo de cada momento de avaliação estão apresentadas na tabela 4.

Tabela 4 - Média e erro padrão da média ( $($ EPM) dos três momentos de análise e valor de P para efeito tempo

\begin{tabular}{lcccc}
\hline ParâmetrolTempo & T0 & T10 & T30 & P valor \\
\hline Motilidade(\%) & $60 \pm 5.29$ & $56.62 \pm 5.29$ & $57.91 \pm 5.29$ & 0.196 \\
Vigor (0-5) & $2.86 \pm 0.09$ & $3.17 \pm 0.09$ & $3.49 \pm 0.09$ & $<\mathbf{0 . 0 0 0 1}$ \\
Aglutinação(0-3) & $1.01 \pm 0.11$ & $0.86+0.11$ & $0.99 \pm 0.11$ & 0.172 \\
PI(\%) & $52.07 \pm 2.76$ & $50.45 \pm 2.76$ & $48.42 \pm 2.76$ & $\mathbf{0 . 0 0 1}$ \\
PL(\%) & $47.93 \pm 2.75$ & $49.56 \pm 2.75$ & $51.57 \pm 2.75$ & $\mathbf{0 . 0 0 1}$ \\
AI(\%) & $61.42 \pm 2.62$ & $59.84 \pm 2.62$ & $58.82 \pm 2.62$ & $\mathbf{0 . 0 0 3}$ \\
AL(\%) & $38.57 \pm 2.62$ & $40.18 \pm 2.62$ & $41.17 \pm 2.62$ & $\mathbf{0 . 0 0 3}$ \\
AIPI(\%) & $43.93 \pm 2.98$ & $42.06 \pm 2.98$ & $40.02 \pm 2.98$ & $\mathbf{0 . 0 0 0 8}$ \\
AIPL(\%) & $17.85 \pm 1.67$ & $17.77 \pm 1.67$ & $18.79 \pm 1.67$ & 0.598 \\
ALPI(\%) & $7.98 \pm 0.85$ & $8.86 \pm 0.85$ & $8.40 \pm 0.85$ & 0.503 \\
ALPL(\%) & $30.31 \pm 2.43$ & $30.91 \pm 2.43$ & $32.77 \pm 2.43$ & $\mathbf{0 . 0 9 2}$ \\
Alto(\%) & $39.15 \pm 2.68$ & $38.69 \pm 2.68$ & $37.14 \pm 2.68$ & 0.335 \\
Intermediário(\%) & $38.24 \pm 2.46$ & $36.48 \pm 2.46$ & $36.08 \pm 2.46$ & 0.362 \\
Baixo(\%) & $22.51 \pm 2.95$ & $24.80 \pm 2.95$ & $26.78 \pm 2.95$ & $\mathbf{0 . 0 4 8}$ \\
SCSA+(\%) & $1.04 \pm 0.34$ & $1.35 \pm 0.34$ & $2.16 \pm 0.34$ & $\mathbf{0 . 0 3 8}$ \\
SCSA-(\%) & $98.96 \pm 0.34$ & $98.64 \pm 0.34$ & $97.84 \pm 0.34$ & $\mathbf{0 . 0 3 8}$ \\
\hline
\end{tabular}

T0 - tempo de análise 0 minutos (imediatamente antes do tratamento); T10 - tempo de análise 10 minutos (imediatamente pós-tratamento); T30 - tempo de análise 30 minutos (30 minutos após o ínico do tratamento); PL - membrana plasmática lesada; PI - membrana plasmática íntegra; AL - acrossomo lesado; AI - acrossomo íntegro; AIPI - acrossomo íntegro e plasmática íntegra; AIPL - acrossomo íntegro e plasmática lesada; ALPI - acrossomo lesado e plasmática íntegra; ALPL - acrossomo lesado e plasmática lesada; Alto - alto potêncial de membrana mitocondrial; Intermediário - potêncial intermediário de membrana mitocondrial; Baixo - baixo potencial de membrana mitocondrial; (SCSA+) - positivo ao ensaio da estrutura da cromatina; (SCSA-) - negativo ao ensaio da estrutura da cromatina.

Os parâmetros vigor, PL, AL, AIPI, AIPL, ALPI, baixo potencial de membrana mitocondrial, positividade ou negatividade ao SCSA apresentaram efeito de tempo, independente do tratamento utilizado. 
As médias dos tratamentos em cada momento de análise estão demonstradas na tabela 5, juntamente com o valor de P para a interação Tratamento*Tempo.

Tabela 5 - Média e erro padrão da média ( \pm EPM) do grupo tratado e controle nos três momentos de análise e o valor de P para a interação Tratamento*Tempo - São Paulo - 2011

\begin{tabular}{|c|c|c|c|c|c|c|}
\hline Parâmetro & T0 & $\begin{array}{c}\text { Tratado } \\
\text { T10 }\end{array}$ & $\begin{array}{c}\text { Controle } \\
\text { T10 }\end{array}$ & $\begin{array}{c}\text { Tratado } \\
\text { T30 }\end{array}$ & $\begin{array}{c}\text { Controle } \\
\text { T30 }\end{array}$ & $\begin{array}{c}\mathbf{P} \\
\text { Valor }\end{array}$ \\
\hline Motilidade(\%) & $60 \pm 5.45$ & $55.11 \pm 5.45$ & $58.12 \pm 5.45$ & $57.40 \pm 5.45$ & $58.42 \pm 5.45$ & 0.713 \\
\hline Vigor (0-5) & $2.86 \pm 0.01$ & $3.06 \pm 0.10$ & $3.27 \pm 0.10$ & $3.40 \pm 0.10$ & $3.58 \pm 0.10$ & 0.200 \\
\hline Aglutinação(0-3) & $1.01 \pm 0.13$ & $0.86 \pm 0.13$ & $0.86 \pm 0.13$ & $0.87 \pm 0.13$ & $1.11 \pm 0.13$ & 0.260 \\
\hline $\operatorname{PI}(\%)$ & $52.07 \pm 2.83$ & $50.19 \pm 2.83$ & $50.71 \pm 2.83$ & $48.16 \pm 2.83$ & $48.69 \pm 2.83$ & 0.945 \\
\hline PL(\%) & $57.93 \pm 2.83$ & $49.83 \pm 2.83$ & $49.29 \pm 2.83$ & $51.83 \pm 2.83$ & $51.30 \pm 2.83$ & 0.943 \\
\hline $\mathbf{A I}(\%)$ & $61.42 \pm 2.67$ & $59.91 \pm 2.67$ & $59.76 \pm 2.67$ & $58.73 \pm 2.67$ & $58.90 \pm 2.67$ & 0.975 \\
\hline $\operatorname{AL}(\%)$ & $38.57 \pm 2.67$ & $40.12 \pm 2.67$ & $40.24 \pm 2.67$ & $41.26 \pm 2.67$ & $41.08 \pm 2.67$ & 0.979 \\
\hline $\operatorname{AIPI}(\%)$ & $44.69 \pm 3.10$ & $42.05 \pm 3.10$ & $42.07 \pm 3.10$ & $40.32 \pm 3.10$ & $39.73 \pm 3.10$ & 0.661 \\
\hline $\operatorname{AIPL}(\%)$ & $16.74 \pm 1.85$ & $17.85 \pm 1.85$ & $17.69 \pm 1.85$ & $18.41 \pm 1.85$ & $19.17 \pm 1.85$ & 0.399 \\
\hline $\operatorname{ALPI}(\%)$ & $7.38 \pm 1.00$ & $9.07 \pm 1.00$ & $8.64 \pm 1.00$ & $7.84 \pm 1.00$ & $8.96 \pm 1.00$ & 0.293 \\
\hline ALPL $(\%)$ & $31.19 \pm 2.56$ & $30.23 \pm 2.56$ & $31.60 \pm 2.56$ & $33.42 \pm 2.56$ & $32.12 \pm 2.56$ & 0.356 \\
\hline Alto(\%) & $39.15 \pm 2.86$ & $36.47 \pm 2.86$ & $40.92 \pm 2.86$ & $36.47 \pm 2.86$ & $37.79 \pm 2.86$ & 0.280 \\
\hline Intermediário(\%) & $38.24 \pm 2.70$ & $38.71 \pm 2.70$ & $34.25 \pm 2.70$ & $36.78 \pm 2.70$ & $35.28 \pm 2.70$ & 0.366 \\
\hline Baixo(\%) & $22.51 \pm 3.17$ & $24.80 \pm 3.17$ & $24.80 \pm 3.17$ & $26.74 \pm 3.17$ & $26.81 \pm 3.17$ & 0.999 \\
\hline $\operatorname{SCSA}+(\%)$ & $1.04 \pm 0.46$ & $0.96 \pm 0.46$ & $1.75 \pm 0.46$ & $1.81 \pm 0.46$ & $2.51 \pm 0.46$ & 0.614 \\
\hline SCSA-(\%) & $98.96 \pm 0.46$ & $99.04 \pm 0.46$ & $98.24 \pm 0.46$ & $98.18 \pm 0.46$ & $97.49 \pm 0.46$ & 0.609 \\
\hline
\end{tabular}

T0 - tempo de análise 0 minutos (imediatamente antes do tratamento); T10 - tempo de análise 10 minutos (imediatamente pós-tratamento); T30 - tempo de análise 30 minutos (30 minutos após o ínico do tratamento); PL - membrana plasmática lesada; PI - membrana plasmática íntegra; AL - acrossomo lesado; AI acrossomo íntegro; AIPI - acrossomo íntegro e plasmática íntegra; AIPL - acrossomo íntegro e plasmática lesada; ALPI - acrossomo lesado e plasmática íntegra; ALPL - acrossomo lesado e plasmática lesada; Alto alto potêncial de membrana mitocondrial; Intermediário - potêncial intermediário de membrana mitocondrial; Baixo - baixo potencial de membrana mitocondrial; (SCSA+) - positivo ao ensaio da estrutura da cromatina; (SCSA-) - negativo ao ensaio da estrutura da cromatina

Não foi observada interação Tratamento*Tempo em nenhum dos atributos avaliados.

Após análise das imagens do ensaio cometa alcalino (Figura 6), os parâmetros quantificados pelo software Comet Score ${ }^{\mathrm{TM}}$ (Figuras 7 e 8) foram submetidos à análise de variância. Os valores de $\mathrm{p}$ encontrados para o efeito de tratamento, tempo e a interação Tratamento*Tempo estão apresentados na tabela 6. 
D

Figura 6 - Microscopia de epifluorescência do ensaio cometa alcalino (aumento de 200X coloração sonda fluorescente Syber Green). A: espermatozóides com DNA íntegro (ausência de cauda e cabeça intensa); B: espermatozóides com fragmentação discreta (presença de cauda discreta e cabeça intensa); C: espermatozóides com fragmentação moderada (presença de cauda expressiva e cabeça com intensidade moderada) D: espermatozóides com fragmentação elevada (presença de cauda expressiva, e cabeça com baixa intensidade) - São Paulo - 2011

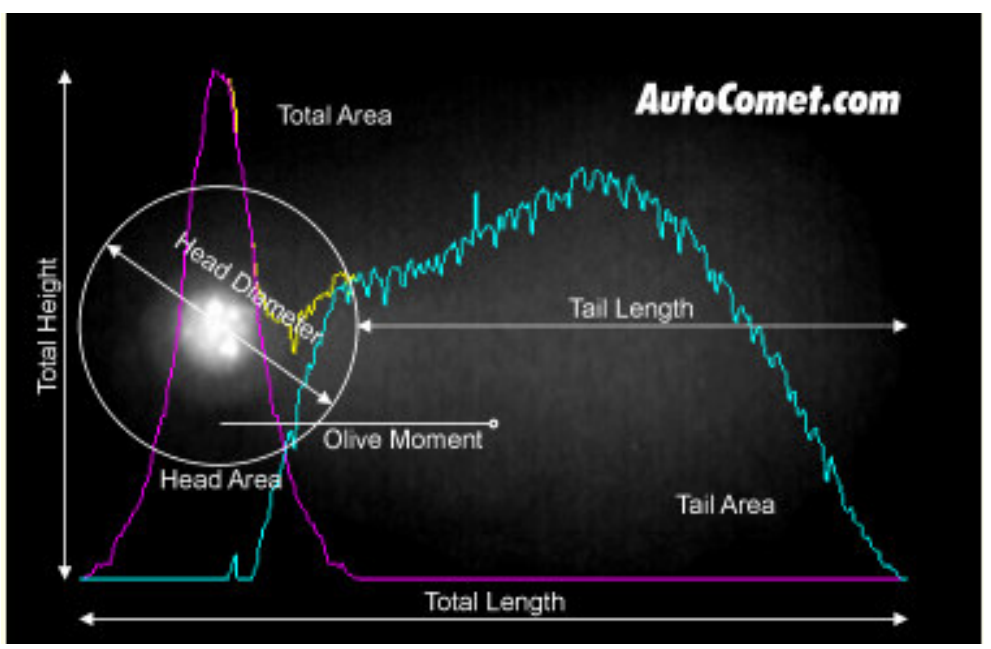

Figura 7 - Imagem ilustrativa dos parâmetros quantificados pelo software Comet Score ${ }^{\mathrm{TM}}$. 


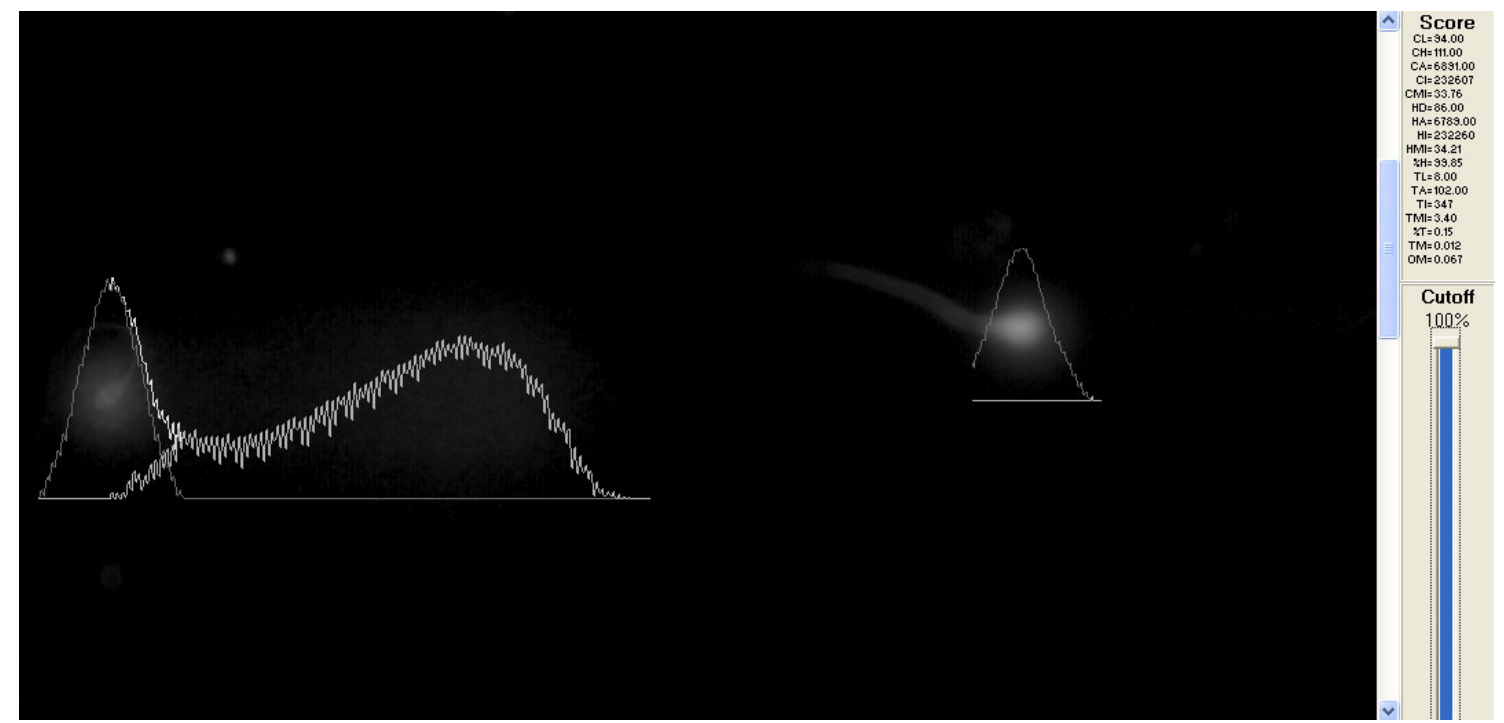

Figura 8 - Imagem de microscopia de epifluorescência submetida a quantificação no software Comet Score ${ }^{\mathrm{TM}}$.

Tabela 6 - Valores de p para os efeitos tratamento, tempo e tratamento*tempo para os parâmetros do ensaio cometa alcalino - São Paulo - 2011

\begin{tabular}{lccc}
\hline \multicolumn{1}{c}{ ParâmetrolEfeito } & Tratamento & Tempo & Tratamento*Tempo \\
\hline Comprimento cometa(px) & 0.762 & 0.127 & 0.687 \\
Altura cometa(px) & 0.417 & 0.277 & 0.541 \\
Área cometa(px) & 0.998 & 0.528 & 0.884 \\
Intensidade cometa(px) & 0.913 & 0.836 & 0.693 \\
Intensidade média cometa(px) & 0.974 & 0.265 & 0.991 \\
Diâmetro cabeça(px) & 0.406 & $\mathbf{0 . 0 0 2}$ & 0.833 \\
Área cabeça(px) & 0.864 & 0.987 & 0.958 \\
Intensidade cabeça(px) & 0.564 & 0.831 & 0.919 \\
Intensidade média da cabeça & 0.708 & 0.770 & 0.965 \\
DNA cabeça(\%) & 0.333 & 0.300 & 0.298 \\
Comprimento cauda(px) & 0.804 & 0.166 & 0.676 \\
Área cauda(px) & 0.441 & 0.104 & 0.496 \\
Instensidade cauda(px) & 0.348 & 0.187 & 0.219 \\
Intensidade média cauda(px) & 0.354 & 0.251 & 0.796 \\
DNA cauda(\%) & 0.335 & 0.302 & 0.296 \\
\hline
\end{tabular}

No ensaio cometa alcalino encontrou-se apenas efeito de tempo para o diâmetro da cabeça do cometa, este efeito foi independente do tratamento (laser ou incubação).

As médias encontradas para cada tratamento estão apresentadas na tabela 7. Já as médias de cada momento de análise no ensaio cometa alcalino estão descritas na tabela 8 . 
Tabela 7 - Média \pm EPM do grupo tratado e controle para o ensaio cometa alcalino e valores de p para o efeito de tratamento - São Paulo - 2011

\begin{tabular}{lccc}
\hline \multicolumn{1}{c}{ Parâmetro } & Tratado & Controle & P valor \\
\hline Comprimento cometa(px) & $382.33 \pm 36.49$ & $375.31 \pm 36.49$ & 0.762 \\
Altura cometa(px) & $144.12 \pm 7.26$ & $140.59 \pm 7.26$ & 0.417 \\
Área cometa(px) & $42844 \pm 5693$ & $42852 \pm 5693$ & 0.998 \\
Intensidade cometa(px) & $834607 \pm 94901$ & $827530 \pm 94901$ & 0.913 \\
Intensidade média cometa(px) & $26.30 \pm 1.54$ & $26.34 \pm 1.54$ & 0.974 \\
Diâmetro cabeça(px) & $88.37 \pm 2.84$ & $87.17 \pm 2.84$ & 0.406 \\
Área cabeça(px) & $18983 \pm 4158$ & $20664 \pm 4158$ & 0.684 \\
Intensidade cabeça(px) & $339555 \pm 39276$ & $364643 \pm 39276$ & 0.564 \\
Intensidade média da cabeça & $28.75 \pm 2.25$ & $28.06 \pm 2.25$ & 0.708 \\
DNA cabeça(\%) $\%$ & $54.39 \pm 3.42$ & 0.333 \\
Comprimento cauda(px) & $56.51 \pm 3.42$ & $288.20 \pm 36.44$ & 0.804 \\
Área cauda(px) & $293.85 \pm 36.44$ & $22188 \pm 2731$ & 0.441 \\
Instensidade cauda(px) & $23850 \pm 2731$ & $462887 \pm 63293$ & 0.348 \\
Intensidade média cauda(px) & $494891 \pm 63293$ & $55.59 \pm 16.84$ & 0.354 \\
DNA cauda(\%) & $79.03 \pm 16.84$ & $43.49 \pm 3.42$ & 0.335 \\
\hline
\end{tabular}


Tabela 8 - Média \pm EPM dos momentos de análise do ensaio cometa alcalino e valor de P para o efeito de tempo - São Paulo - 2011

\begin{tabular}{lcccc}
\hline \multicolumn{1}{c}{ Parâmetro } & T0 & T10 & T30 & P valor \\
\hline Comprimento cometa(px) & $364.49 \pm 38.27$ & $412.78 \pm 38.27$ & $359.19 \pm 38.27$ & 0.127 \\
Altura cometa (px) & $146.03 \pm 7.57$ & $143.41 \pm 7.57$ & $137.63 \pm 7.57$ & 0.277 \\
Área cometa (px) & $43492 \pm 6099$ & $45528 \pm 6099$ & $39524 \pm 6099$ & 0.528 \\
Intensidade cometa (px) & $821921 \pm 100217$ & $857932 \pm 100217$ & $813353 \pm 100217$ & 0.836 \\
Intensidade média cometa & $2717 \pm 1.66$ & $24.89 \pm 1.66$ & $26.90 \pm 1.66$ & 0.265 \\
(px) & $84.28 \pm 2.93$ & $90.95 \pm 2.93$ & $88.03 \pm 2.93$ & $\mathbf{0 . 0 0 2}$ \\
Diâmetro cabeça (px) & $20262 \pm 4636$ & $19741 \pm 4636$ & $19467 \pm 4636$ & 0.987 \\
Área cabeça(px) & $349853 \pm 44827$ & $337242 \pm 44827$ & $369204 \pm 44827$ & 0.831 \\
Intensidade cabeça (px) & $28.46 \pm 2.44$ & $27.56 \pm 2.44$ & $29.20 \pm 2.44$ & 0.770 \\
Intensidade média da & $55.83 \pm 3.59$ & $53.21 \pm 3.59$ & $57.31 \pm 3.59$ & 0.300 \\
cabeça & $2 \pm 38.17$ & $321.65 \pm 38.17$ & $271.22 \pm 38.17$ & 0.166 \\
DNA cabeça(\%) & $23230 \pm 2933$ & $25770 \pm 2933$ & $20057 \pm 2933$ & 0.104 \\
Comprimento cauda (px) & $472068 \pm 65508$ & $520450 \pm 65508$ & $444149 \pm 65508$ & 0.187 \\
Área cauda (px) & $48.79 \pm 20.97$ & $56.25 \pm 20.97$ & $96.89 \pm 20.97$ & 0.251 \\
Instensidade cauda (px) & $44.16 \pm 3.59$ & $46.78 \pm 3.59$ & $42.68 \pm 3.59$ & 0.302 \\
Intensidade média cauda & & & & \\
(px) & & & & \\
DNA cauda(\%) & & & & \\
\hline
\end{tabular}

O diâmetro da cabeça do cometa apresentou aumento em T10 seguido de uma diminuição em T30.

As médias do ensaio cometa alcalino para cada tratamento, em cada momento de análise encontram-se apresentadas na tabela 9, juntamente com o valor de p para a interação Tratamento*Tempo. 
Tabela 9 - Médias \pm EPM dos grupos tratado e controle, nos três momentos de análise (T0, T10 e T30) e valores de P para a interação Tratamento*Tempo - São Paulo - 2011

\begin{tabular}{|c|c|c|c|c|c|c|}
\hline Parâmetro & T0 & $\begin{array}{c}\text { Tratado } \\
\text { T10 }\end{array}$ & $\begin{array}{c}\text { Controle } \\
\text { T10 }\end{array}$ & $\begin{array}{c}\text { Tratado } \\
\text { T30 }\end{array}$ & $\begin{array}{c}\text { Controle } \\
\text { T30 }\end{array}$ & $\begin{array}{c}\mathbf{P} \\
\text { valor }\end{array}$ \\
\hline $\begin{array}{l}\text { Comprimento } \\
\text { cometa(px) }\end{array}$ & $364.49 \pm 43.20$ & $406.10 \pm 43.20$ & $419.46 \pm 43.20$ & $376.41 \pm 43.20$ & $341.97 \pm 43.20$ & 0.687 \\
\hline $\begin{array}{l}\text { Altura } \\
\operatorname{cometa}(\mathbf{p x})\end{array}$ & $146.03 \pm 8.44$ & $143.54 \pm 8.44$ & $143.28 \pm 8.44$ & $142.80 \pm 8.44$ & $132.46 \pm 8.44$ & 0.541 \\
\hline $\begin{array}{l}\text { Área } \\
\operatorname{cometa}(\mathbf{p x})\end{array}$ & $43492 \pm 7181$ & $44191 \pm 7181$ & $46865 \pm 7181$ & $40850 \pm 7181$ & $38199 \pm 7181$ & 0.884 \\
\hline $\begin{array}{l}\text { Intensidade } \\
\text { cometa(px) }\end{array}$ & $821921 \pm 114694$ & $829458 \pm 114694$ & $886407 \pm 114694$ & $852444 \pm 114694$ & $774262 \pm 114694$ & 0.693 \\
\hline $\begin{array}{l}\text { Intensidade } \\
\text { média } \\
\text { cometa(px) }\end{array}$ & $2717 \pm 1.97$ & $24.96+1.97$ & $24.82+1.97$ & $26.77 \pm 1.97$ & $27.03+1.97$ & 0.991 \\
\hline $\begin{array}{l}\text { Diâmetro } \\
\text { cabeça(px) }\end{array}$ & $84.28 \pm 3.19$ & $91.97 \pm 3.19$ & $89.93 \pm 3.19$ & $88.84 \pm 3.19$ & $87.22 \pm 3.19$ & 0.833 \\
\hline $\begin{array}{l}\text { Área } \\
\text { cabeça(px) }\end{array}$ & $20262 \pm 5839$ & $18526+5839$ & $20955+5839$ & $18161 \pm 5839$ & $20774 \pm 5839$ & 0.958 \\
\hline $\begin{array}{l}\text { Intensidade } \\
\text { cabeça(px) }\end{array}$ & $349853 \pm 58395$ & $318517 \pm 58395$ & $355966 \pm 58395$ & $350296 \pm 58395$ & $388111 \pm 58395$ & 0.680 \\
\hline $\begin{array}{l}\text { Intensidade } \\
\text { média da } \\
\text { cabeça }\end{array}$ & $28.46 \pm 2.92$ & $27.06 \pm 2.92$ & $28.06 \pm 2.92$ & $28.65 \pm 2.92$ & $29.74 \pm 2.92$ & 0.965 \\
\hline 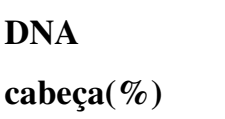 & $55.83+4.04$ & $53.50+4.04$ & $52.91+4.04$ & $53.85+4.04$ & $60.77 \pm 4.04$ & 0.298 \\
\hline $\begin{array}{l}\text { Comprimento } \\
\text { cauda(px) }\end{array}$ & $280.22 \pm 42.93$ & $313.80 \pm 42.93$ & $329.50 \pm 42.93$ & $287.56 \pm 42.93$ & $254.87 \pm 42.93$ & 0.676 \\
\hline $\begin{array}{l}\text { Área } \\
\text { cauda(px) }\end{array}$ & $23230 \pm 3468$ & $25630 \pm 3468$ & $25909 \pm 3468$ & $22688 \pm 3468$ & $17425 \pm 3468$ & 0.496 \\
\hline $\begin{array}{l}\text { Instensidade } \\
\operatorname{cauda}(\mathbf{p x})\end{array}$ & $472068 \pm 71732$ & $510459 \pm 71732$ & $530441 \pm 71732$ & $502148 \pm 71732$ & $386151 \pm 71732$ & 0.219 \\
\hline $\begin{array}{l}\text { Intensidade } \\
\text { média } \\
\text { cauda(px) }\end{array}$ & $48.79 \pm 30.14$ & $75,87 \pm 30.14$ & $36,64 \pm 30.14$ & $112.43+30.14$ & $81.35 \pm 30.14$ & 0.796 \\
\hline $\begin{array}{l}\text { DNA } \\
\text { cauda }(\%)\end{array}$ & $44.16 \pm 4.04$ & $46.47 \pm 4.04$ & $47.08+4.04$ & $46.14 \pm 4.04$ & $39.22 \pm 4.04$ & 0.180 \\
\hline
\end{tabular}


As taxas de produção in vitro de embriões foram analisadas com relação às médias obtidas quando se utilizou na fecundação in vitro, sêmen submetido à aplicação de ondas eletromagnéticas (tratado) ou incubado à $37^{\circ} \mathrm{C}$ (controle). Tanto as médias dos grupos, quanto o valor de p encontrado no teste T estão sumarizados na tabela 10.

Tabela 10 - Médias \pm EPM das taxas de produção in vitro de embriões dos grupos tratado (laser), controle e o valor de P - São Paulo - 2011

\begin{tabular}{lccc}
\multicolumn{1}{c}{ Variável } & Tratado & Controle & P valor \\
\hline Taxa de clivagem & $43,5 \pm 2,4$ & $40,2 \pm 3,8$ & 0,46 \\
Taxa de blastocisto D6 & $2,6 \pm 0,8$ & $2,9 \pm 1,0$ & 0,84 \\
Taxa de blastocisto D7 & $6,6 \pm 1,0$ & $6,3 \pm 1,4$ & 0,88 \\
Taxa de blastocisto D9 & $4.3+1,0$ & $5,3+1.2$ & 0,54 \\
Taxa de blastocisto D12 & $1,3+0.3$ & $0,9+0.3$ & 0,40 \\
Taxa de blastocisto total & $5,7+1.2$ & $6,2+1.4$ & 0,75 \\
Taxa de bloqueio & $87,8+2.1$ & $85,6+2.9$ & 0,55 \\
\hline
\end{tabular}

Não foram observadas diferenças significativas nas taxas da produção in vitro de embriões, quando utilizado sêmen do grupo controle ou sêmen do grupo tratado (submetido às ondas eletromagnéticas).

Os resultados da avaliação do ensaio TUNEL, dos embriões produzidos in vitro estão apresentados na tabela 11 e na Figura 9.

Tabela 11 - Médias £ EPM das avaliações embrionárias e o valor de P - São Paulo - 2011

\begin{tabular}{lccc}
\hline \multicolumn{1}{c}{ Variável } & Tratado $(\mathbf{n}=7)$ & Controle $(\mathbf{n}=\mathbf{8})$ & P valor \\
& & & \\
\hline Blastômero Fragmentados $(\%)$ & $16,0 \pm 3.8$ & $13,0 \pm 3.0$ & 0,53 \\
Blastômeros Totais & $178,5 \pm 37$ & $121,1 \pm 19.6$ & 0,17 \\
\hline
\end{tabular}




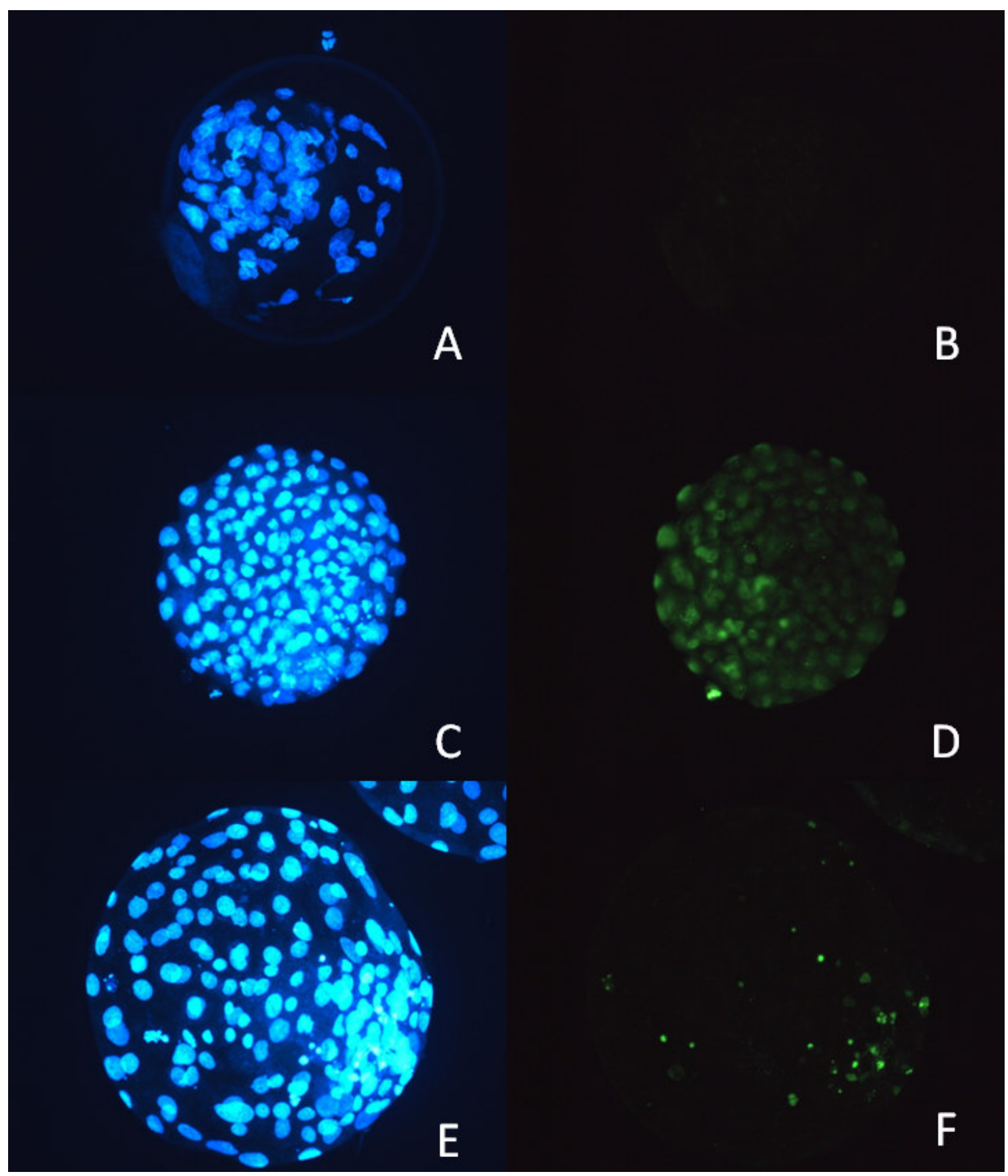

Figura 9 - Microscopia de epifluorescência de embriões submetidos ao ensaio TUNEL. A: Controle Negativo (filtro DAPI); B: Controle Negativo (filtro FITC); C: Controle Positivo (filtro DAPI); D: Controle Positivo (filtro FITC); E: Embrião analisado (filtro DAPI); E: Embrião analisado (filtro FITC) São Paulo - 2011

$\mathrm{Na}$ avaliação embrionária pelo ensaio TUNEL, não houve efeito do tratamento na porcentagem de blastômeros com fragmentação de DNA ou no número de blastômeros totais. 
DISCUSSÃO

$\sim \cos \left(x^{2}\right)$ 


\section{DISCUSSÃO}

O resultado deste trabalho permitiu observar efeitos com relação à duração do tratamento, ao tempo de análise, às interações Potência*Duração do tratamento e Potência*Tempo.

O efeito isolado da duração do tratamento e do tempo de análise, ou seja, sem a interação destas variáveis com a variável potência, demonstrou que nestes parâmetros, independentes da potência aplicada, as amostras apresentaram o mesmo comportamento, logo este fenômeno ocorre de maneira similar ao grupo controle. Estes dados sugerem que o efeito está no tempo de incubação, independente deste ser na ausência de laser (grupo controle) ou na presença de potências distintas de ondas eletro magnéticas (grupo tratado). Este fato sugere que nesta fase de incubação pós-preparação da amostra, ou seja, pós-descongelação e centrifugação, a célula espermática pode estar em fase de adaptação e de recuperação das alterações adquiridas durante a manipulação. Estas alterações já foram relatadas por Fraser (2010) e Watson (1995), que caracterizaram, respectivamente, uma pré-capacitação espermática induzida pela centrifugação e/ou criopreservação do sêmen. Esta recuperação, provavelmente consiste de uma reorganização dos lípides de membranas e do metabolismo energético, que pode ser prejudicada pela manipulação destas células neste momento crítico.

Esta hipótese explicaria a diminuição da aglutinação, da lesão da membrana acrossomal e da fragilidade da cromatina, além de alterações no formato das células e no padrão de motilidade dos espermatozóides durante o tratamento com 10 minutos de duração. Já no tratamento com 5 minutos de duração, as células parecem ainda estar neste período crítico de adaptação e recuperação, justificando o efeito negativo da manipulação do sêmen, neste momento.

Os resultados do efeito de tempo de análise (tempo PÓS e FINAL) confirmam estas alterações induzidas pela criocapacitação e centrifugação do sêmen, como alterações no padrão da motilidade e aumento do alto potencial de membrana mitocondrial. Estes associados aos resultados para o efeito de duração de tratamento sugerem uma ordem temporal dos fatores. Ou seja, após um curto período de análise, pôde ser observada, entre 5 e 10 minutos, a reorganização das membranas Já o restabelecimento do metabolismo energético e as alterações de motilidade, como diminuição de ALH e VCL, que são altos quando 
relacionados à hiperativação (Shahar et al., 2011), ficam evidentes após 30 minutos de processamento.

Também aos 30 minutos foi possível detectar um aumento da lesão da membrana plasmática sugerindo o início do efeito negativo do tempo na viabilidade espermática. Curiosamente, percebe-se uma cinética dos acontecimentos, na qual as alterações de membranas celulares precedem as alterações decorrentes do metabolismo energético.

As interações Potência*Duração do tratamento e Potência*Tempo, encontrados no presente trabalho, corroboram com os dados da literatura, os quais relacionam os parâmetros de irradiação (potência e duração da aplicação) com os efeitos biológicos do laser. No entanto, muitos trabalhos, descrevem outros parâmetros de irradiação, sendo importante discernir quais destes parâmetros apresentam uma real influência nos efeitos biológicos.

A fluência é um parâmetro de irradiação determinada pelo produto da potência e duração do tratamento pela área exposta à irradiação. Porém, não há fundamentos para a relação entre a área exposta ao laser e o efeito biológico, quando, por exemplo, de uma suspensão de células. Talvez este conceito seja herança do estudo dos efeitos biológicos em tecidos, pois nestes, uma maior área de irradiação pode resultar em uma maior quantidade de tecido/células tratadas, aumentando o efeito do laser.

Quando se trabalha com uma suspensão de células, o importante é que toda a superfície a ser tratada receba, de forma homogênea, as ondas eletromagnéticas. Para cumprir esta premissa, neste trabalho foi realizada calibração do sistema óptico de forma que fosse obtida uma frente de ondas eletromagnéticas homogêneas em toda área de exposição. Ao se conseguir esta aplicação homogênea, a área não mais influencia no efeito biológico. No entanto, muitas vezes e dependendo do aparelho, a potência aplicada difere da potência indicada pelo equipamento ou da potência aferida na saída do sistema. Em vista disto, quando estas premissas não são obedecidas, há prejuízo da confiabilidade e da repetibilidade dos resultados.

Como unidade de comparação entre tratamentos, muitos trabalhos utilizam a fluência. Contudo, este parâmetro depende da área exposta à irradiação e a ausência de padronização ou informações incompletas da mesma, torna-se difícil a reprodução e a comparação dos resultados. Ao se utilizar, portanto a fluência, a compreensão dos efeitos biológicos e o estabelecimento da relação destes com os parâmetros de irradiação ficam comprometidos.

No tocante aos efeitos envolvendo a ausência ou a aplicação de laser em diferentes potências houve interação da potência do laser com a duração do tratamento e o tempo de 
análise. A análise individual dos resultados deste estudo não é conclusiva. Já ao se analisar o comportamento dos diferentes tratamentos em cada tipo de interação, os efeitos biológicos puderam ser mais bem compreendidos, sendo esta uma ferramenta útil de análise.

Todos os parâmetros de motilidade computadorizada (motilidade progressiva, VAP, VSL e VCL) na interação Potência*Duração do tratamento demonstraram efeito positivo do laser nas potências 5, 7.5 e 10mW, quando maior duração da aplicação (10 minutos). Esta interação fica evidente, pois na ausência de laser $(0 \mathrm{~mW})$ e incubação por 10 minutos, estes parâmetros apresentam decréscimo. Estes dados sugerem que a interação do efeito da potência do laser com a duração do tratamento na melhora do padrão de motilidade espermática é mais eficiente com a duração 10 minutos, quando da utilização das potências 5, 7.5 e $10 \mathrm{~mW}$. Este efeito segundo Lubart et al. (1992) se justifica, pois o LASER acelera o transporte de cálcio no sêmen bovino, o que pode causar alterações na concentração citoplasmáticas deste íon, e portanto um efeito regulatório no controle da motilidade e na reação acrossomal.

$\mathrm{Na}$ atividade mitocondrial avaliada pelo potencial de membrana, a interação Potência*Duração do tratamento foi mais variada. A população de potencial intermediário deve ser avaliada cuidadosamente, uma vez que o aumento desta população não pode ser relacionado com um efeito estimulatório ou inibitório. Isto porque este aumento pode ser originado por uma queda do potencial de membrana da população de alto potencial, originada também pelo aumento do potencial da população de baixo potencial ou a associação destes dois eventos. Portanto, baseando-se no efeito na população de alto potencial (aumento), houve obrigatoriamente um efeito estimulatório da duração sobre a atividade mitocondrial nas potências 5 e 7,5mW. Ou seja, nas potências de 5 e $7.5 \mathrm{~mW}$ a maior duração de aplicação do tratamento pode ser mais efetiva na melhora da atividade metabólica do sêmen.

IAFFALDANO et al. (2010) demonstraram o efeito do laser resultando em maior motilidade, maior integridade das membranas plasmática e acrossomal e maior carga de energia em espermatozóides de coelho, corroborando para os resultados encontrados neste trabalho sobre o efeito do laser nos parâmetros de motilidade espermática e metabolismo energético. Estes autores sugerem que o laser afeta a cadeia respiratória mitocondrial pela mudança do potencial de membrana e consequentemente altera a permeabilidade seletiva para o cálcio e outros íons (PASSARELLA et al., 1984). Esta teoria foi comprovada por Shahar et al. (2011) que observaram um rápido aumento do cálcio intracelular e um aumento da hiperativação flagelar após a irradiação LASER, contrariando os resultados deste presente trabalho, no qual foi detectado aumento da velocidade progressiva. Tal contradição se deve à 
diferença do tipo de LASER aplicado, potência e duração do tratamento, evidenciando a importância de se padronizar estes parâmetros de acordo com a amostra a ser irradiada.

A interação Potência*Tempo, uma melhora na motilidade e vigor foi observada durante a incubação no grupo controle e na potência de $5 \mathrm{~mW}$. Na potência de 7,5 $\mathrm{mW}$, as amostras parecem não diferir entre as análises PÓS e FINAL, enquanto que na potência de 10 $\mathrm{mW}$ há uma possível queda nesta interação.

Os resultados deste estudo indicam uma ação do LASER em atributos relacionados à motilidade espermática. Este efeito do laser ao longo do tempo de incubação nos parâmetros espermáticos já foi demonstrado na literatura. Entre eles, o efeito positivo da manutenção de parâmetros de motilidade espermática como BCF e linearidade ou aumento de BCF, VAP, LIN e STR (CORRAL-BAQUÉS et al., 2005 e 2009) e aumento de BCF (BRANDÃO, 2008), em sêmen canino e equino. Em sêmen de peru, o efeito positivo do laser ao longo do tempo de armazenamento também resultou em uma menor queda na motilidade, além de menor lesão de membrana plasmática (IAFFALDANO et al., 2005). Segundo Corral-Baqués et al., (2005) as alterações no padrão de motilidade se devem a uma via de produção de energia distinta e uma melhor utilização desta, o que torna o processo mais eficiente.

Considerando-se o efeito da duração do tratamento sobre os parâmetros analisados, um melhor desempenho foi observado quando foi aplicada a maior duração de tratamento, para todos os parâmetros significativos com exceção do $\mathrm{BCF}$, associado às interações Potência*Duração e Potência*Tempo. Assim, como na literatura, os resultados neste trabalho apresentaram efeito positivo do laser, sendo que nas condições experimentais adotadas a potência de $5 \mathrm{~mW}$ sugere ser a mais efetiva. A combinação, potência $5 \mathrm{~mW}$ por 10 minutos de exposição foi aplicada no sêmen utilizado na produção in vitro de embriões no experimento 2.

Com relação à produção in vitro de embriões foi observado efeito significativo do tratamento e do tempo, no entanto, não foi observada a interação desses efeitos.

O efeito tempo sobre as análises espermáticas foi independente do tratamento, portanto como discutido anteriormente trata-se de uma variação temporal que ocorre tanto nas amostras irradiadas quando nas incubadas.

$\mathrm{O}$ efeito do tratamento (irradiação $\mathrm{X}$ incubação) diferiu apenas para o vigor, sendo inferior nas amostras submetidas ao laser. No experimento 1, o vigor apresentou interação Potência*Tempo, no qual as potências 0 e $5 \mathrm{~mW}$ apresentaram aumento deste atributo ao longo da incubação, diferentemente das demais potências. No entanto, a potência $5 \mathrm{~mW}$ não 
foi superior ao controle. Portanto, apesar da potência $5 \mathrm{~mW}$ também apresentar aumento do vigor ao longo da incubação, causou um prejuízo à amostra.

$\mathrm{Na}$ análise das taxas de produção in vitro de embriões ou na qualidade embrionária avaliada pelo ensaio TUNEL, não houve diferença significativa com a utilização de sêmen irradiado nas condições experimentais adotadas.

Estes dados sugerem que apesar do efeito do laser de baixa potência ser dependente da potência e da duração do tratamento, nas condições utilizadas, não houve alteração do potencial de fecundação e do efeito paterno no desenvolvimento embrionário inicial. Como podemos observar o efeito biológico do laser provoca alterações em diversos atributos espermáticos simultaneamente. Estas alterações são sugestivas de efeito positivo para determinados atributos, porém negativo para outros dentro de um mesmo padrão de irradiação. Fica difícil determinar quais alterações espermáticas escolher em detrimento de outras. Para a utilização do laser de baixa potência como ferramenta de melhora do potencial de fecundação de amostras seminais, ainda é necessário uma maior elucidação dos efeitos biológicos do laser, da influência dos parâmetros de irradiação e da correlação de atributos espermáticos com a fertilidade.

Baixos índices de produção in vitro foram obtidos nas condições experimentais adotadas, tanto para o grupo tratado quanto para o grupo controle. Estes índices são provavelmente decorrentes de alterações do protocolo adotado como, uma baixa dose inseminante, alterações de meios, ausência de técnicas para a seleção das células móveis como percoll e swim up, quando comparado aos protocolos convencionais.

Estas adaptações foram necessárias para possibilitar a utilização do sêmen submetido às ondas eletromagnéticas na produção in vitro de embriões, sem que este sofresse algum processamento entre a aplicação e a inseminação dos oócitos na FIV, e também para que o volume e o número de células espermáticas utilizadas no grupo tratado e controle, para os diferentes animais fossem os mesmos. A utilização de metodologias para seleção de células móveis pós-tratamento laser, poderia mascarar o efeito deste pela remoção das células imóveis ou com baixa motilidade que podem se beneficiar dos efeitos positivos do laser na motilidade e na atividade metabólica.

Porém é importante ressaltar que a utilização de uma dose inseminante inferior, proporciona grande aumento na correlação dos atributos espermáticos com a fertilidade (SAACKE et al. 1994). Esta medida visou aumentar o efeito do espermatozóide nas taxas obtidas e ampliar a chance de detectar o efeito deste na fertilidade e de sinalizar possíveis alterações nos atributos espermáticas em decorrência da aplicação das ondas eletromagnéticas. 


\section{CONCLUSÃO}

Os resultados do presente trabalho permitem concluir que:

1) O laser de baixa potência apresenta efeito sobre diversos atributos relacionados à viabilidade espermática. Este efeito foi dependente da potência e da duração do tratamento. Nas condições experimentais estabelecidas para este trabalho, o comportamento da potência de $5 \mathrm{~mW}$ por 10 minutos de aplicação sugere efeitos positivos na viabilidade espermática.

2) Não foi detectada melhora nas taxas da produção in vitro de embriões bovinos nem na qualidade destes embriões, quando da utilização do sêmen bovino irradiado com LASER na potência de $5 \mathrm{~mW}$ por 10 minutos de aplicação. 
REFERÊNCIA BIBLIOGRÁFICA 


\section{REFERÊNCIA BIBLIOGRÁFICA}

AMMAN, R. P.; PICKETT, B. W. Principles of cryopreservation and a review of cryopreservation on stallion spermatozoa. Journal of Equine Veterinary Science, v. 7, p. 145-173, 1987.

ARRUDA, R. P. Avaliação dos efeitos de diluidores e crioprotetores para o espermatozóide eqüino pelo uso de microscopia de epifluorecência, citometria de fluxo, análises computadorizadas da motilidade (CASA) e da morfometria (ASMA). 2000. $121 \mathrm{f}$. Tese (Livre Docência) - Faculdade de Medicina Veterinária e Zootecnia, Universidade de São Paulo, Pirassununga, 2000.

BAGNATO, V. S. Os fundamentos da luz laser. Física na Escola, v. 2, n. 2, p. 4-9, 2001.

BALLACHEY, B. E.; EVENSON, D. P.; SAACKE, R.C. The sperm chromatin structure assay relationship with alternate tests of semen quality and heterospermic performance of bulls. Journal of Andrology, v. 9, p. 109-115, 1988.

BARD, H.; BONGIONI, G.; ABDOON, A. S. S.; KANDIL, O.; PUGLISI, R. Gene expression in the in vitro-produced preimplantation bovine embryos. Zygote, v. 15, n. 4, p. 355-367, 2007.

BAXTER, G. D. Therapeutic lasers: theory and practice. New York: Churchill Livingstone, 1994, p. 253.

BOE-HANSEN, G. B.; MORRIS I. D.; ERSBOLL A. K.; GREVE T.; CHRISTENSEN, P. DNA integrity in sexed bull sperm assessed by neutral comet assay and sperm chromatin structure assay. Theriogenology, v.63, p. 1789-1802, 2005.

BORDIGNON, V.; SMITH, L. C. Ultraviolet-irradiated spermatozoa activate oocytes but arrest preimplantation development after fertilization and nuclear transplantation in cattle. Biology of Reproduction, v. 1513-1520, 1999.

BRANDÃO, A. C. Efeito do laser diodo sobre as características de motilidade, de integridade das membranas plasmáticas e acrossomal e de potencial de membrana mitocondrial de espermatozóides criopreservados de eqüinos. 2008. 87f. Dissertação (Mestrado em Ciências 
Biológicas) - Faculdade de Medicina Veterinária e Zootecnia, Universidade de São Paulo, São Paulo, 2008.

BREITBART, H.; LEVINSHAL, T.; COHEN, N.; FRIEDMANN, H.; LUBART, R. Changes in calcium transport in mammalian sperm mitochondria and plasma membrane irradiated at $633 \mathrm{~nm}$ (HeNe laser). Journal of Photochemistry and Photobiology Biology, n. 34, p. 117$121,1996$.

CELEGHINI EC, DE ARRUDA RP, DE ANDRADE AF, NASCIMENTO J, RAPHAEL CF. Practical techniques for bovine sperm simultaneous fluorimetric assessment of plasma, acrosomal and mitochondrial membranes. Reproduction of Domestic Animals,_v. 42, n. 5, p. 479-88, 2007.

CORMIER, N.; SIRARD, M.C.; BAILEY, J. L. Journal of Andrology, v. 18, n. 4, p. 461468, 1997

CORRAL-BAQUÉS, M. I.; RIGAU, T.; RIVERA, M.; RODRIGUEZ, J. E.; RIGAU, J. Effect of 655-nm diode laser on dog sperm motility. Lasers in Medical Science, v. 20, p. 28 $34,2005$.

DIAZ-PERES, E.; THOMAS, P.; MEIZEL, S. Evidence suggesting a role for sperm methaloendoprotease activity in penetration on zone-free hamster egg by human sperm. Journal of Experimental Zoological, v. 248, p. 213-221, 1988.

DONNELLY, E. T.; O'CONNELL, M.; MCCLURE, N.; LEWIS, S. E. M. Differences in nuclear DNA fragmentation and mitochondrial integrity of semen and prepared human spermatozoa. Human Reproduction, v. 15, n. 7, p. 1552-1561, 2000.

EBNER, T.; MOSER, M.; YAMAN, C.; SOMMERGRUBER, M.; TEWS, G. Successful birth after laser assisted immobilization of spermatozoa before intracytoplasmic injection. Fertility and Sterility, v. 78, n. 2, p. 417-418, 2002.

EDDY, E. M.; O`BRIEN, D. A. The spermatozoon. In: KNOBIL, E.; NEILL, J. D. The physiology of reproduction. New York: Raven Press, 1994, p. 29-77.

ENWEMEKA, C. S. Laser biostimulation of healing wounds: specific effects and mechanism of action. The Journal of Orthopaedic and Sports Physical Therapy, v. 9, p. 333-338, 1988.

ERENPREISS, J.; SPANO, M.; , EREPREISA, J.; BUNGUM, M.; GIWERCMAN, A. Sperm chromatin structure and male fertility: biological and clinical aspects. Asian Journal of Andrology, v. 8, n. 1, p. 11-29, 2006. 
EVENSON, D. P.; WIXON, R. Clinical aspects of sperm DNA fragmentation detection and male infertility. Teriogenology, v. 65, p. 979-991, 2006.

FATEHI, A. N.; BEVERS, M. M.; SCHOEVERS, E.; ROELEN, B. A. J.;

COLENBRANDER, B.; GADELLA, B. M. DNA damage in bovine sperm does not block fertilization and early embryonic development but induces apoptosis after first cleavages. Journal of Andrology, v. 27, p. 176-188, 2006.

FIRESTONE, R. S.; ESFANDIARI, N.; MOSKOVTSEV, S. I.; MOSKOVTSEV, S. I.; BURSTEIN, G. T. V.; LIBRACH, C.; BETOV, Y.; CASPER, R. F. The effects of low-level laser light exposure on sperm motion characteristics and DNA damage. Journal of Andrology, 2011. doi: 10.2164/jandrol.111.013458

FORD, W.C.L. Glycolysis and sperm motility: does a spoonful of sugar help the flagellum go round? Human reproduction update, v.12, n.3, p. 269-274, 2006.

doi:10.1093/humupd/dmi053

FRASER, L.; STRZEZEK, J. The use of comet assay to assess DNA integrity of boar spermatozoa following liquid preservation at $5{ }^{\circ} \mathrm{C}$ and $16^{\circ} \mathrm{C}$. Folia Histochem Cytobiol, v. 42, n. 1, p. 49-55, 2004.

FRASER, L. The "Switching on" of mammalian spermatozoa: Molecular Events Involved in promotion and Regulation of Capacitation. Molecular Reproduction and Developmentv, v. 77, p. 197-208, 2010.

GILLAN, L.; EVANS, G.; MAXWELL, W.M.C. Flow cytometric evaluation of sperm parameters in relation to fertility potential. Theriogenology, v. 63, p.445-457, 2005.

HAMMADEH, M. E.; ASKARI, A. S.; GEORG, T.; ROSENBAUM, P.; SCHMIDT, W. Effect of freeze-thawing procedure on chromatin stability, morphological alteration and membrane integrity of human spermatozoa in fertile and subfertile men. International Journal of Andrology, v. 22, n. 3, p. 155-62, 1999.

HANSEN, P. J. Realizing the promise of IVF in cattle--an overview. Theriogenology, v. 65, n. 1, p. 119-25, 2006.

HUGHES, C. M.; LEWIS, S. E.; MCKELVEY-MARTIN, V. J.; THOMPSON, W. A. Comparison of baseline and induced DNA damage in human spermatozoa from fertile and infertile men, using a modified comet assay. Molecular Human Reprododuction, v. 2, n. 8, p. 613-619, 1996. 
IAFFALDANO, N.; MELUZZI, A.; MANCHISI, A., PASSARELLA, S. Improvement of stored turkey semen quality as a result of He-Ne laser irradiation. Animal Reproduction Science, v. 85, p. 317-325, 2005.

IAFFALDANO, I.; ROSATO, M. P.; PAVENTI, G.; PIZZUTO, R.; GAMBACORTA, M.; MANCHISI, A.; PASSARELLA, S. The irradiation of rabbit sperm cells whit He-Ne laser prevents their in vitro storage dependent damage. Animal Reproduction Science, v. 119, p.123-129, 2010.

IRVINE, D. S.; TWIGG, J. P.; GORDON, E. L.; FULTON, N.; MILNE, P. A.; AITKEN, R. J. DNA integrity in human spermatozoa: relationships with semen quality. Journal of Andrology. v. 21, n. 1, p. 33-44, 2000.

KANEPS, A. J.; HULTEREN, B. D.; RIEBOLD, T. W.; SHIRES, G. M. H. Laser therapy in horse: histopathologic response. American Journal of Veterinary Research, v. 45, n. 3, p. 581-582, 1983.

KARU, T. I. Photobilogical fundamentals of low-power lase therapy. IEEE Journal of Quantum Eletronics, OE-23, v. 10, p. 1703-1717, 1987.

KHURANA, N. K.; NIEMANN, H. Effects od cryopreservation on glucose metabolism and survival of bovine morulae and blastocysts derived in vitro or in vivo. Theriogenology, v. 54, n. 2, p. 313-326, 2000.

KIERSZENBAUM, A. L. Histologia e biologia celular: uma introdução a patologia. 2. ed. Elsevier, 2008.

KNOBILL, E.; NEILL, J. D. The physiology of reproduction. 3. ed, Raven Press, 1994.

KRISHER, R. L.; BAVISTER, B. D. Response of oocytes and embryos to the culture environment. Theriogenology, v. 49, p. 103-114, 1998.

KRZYZOSIAK, J.; EVENSON, D.; PITT, C.; JOST, L.; MOLAN, P.; VISHWANATH, R. Changes in susceptibility of bovine sperm to in situ DNA denaturation during prolonged incubation at ambient temperature under conditions of exposure to reactive oxygen species and nuclease inhibitor. Reproduction, Fertility and Development, v. 12, n. 5-6, p. 251-261, 2000 .

LAVI R, ANKRI R, SINYAKOV M, EICHLER M, FRIEDMANN H, SHAINBERG A, BREITBART H, LUBART R. The Plasma Membrane is Involved in the Visible Light-Tissue Interaction. Photomedicine Laser Surgery, 2011. DOI: 10.1089/pho.2011.3083 
LINFOR, J. J.; MEYERS, S. A. Detection of DNA damage in response to cooling injury in equine spermatozoa using single-cell gel electrophoresis. Jounal of Andrology, v. 23, n. 1, p. $107-13,2002$.

LOHUIS, M. M. Potential benefits of bovine embryo-manipulation technologies to genetic improvement programs. Theriogenology, v. 43, p. 51-60, 1995.

LUBART, R.; FRIEDMANN, H.; LAVIE, R. Photobiostimulation as a function of different wavelengths. Laser Therapy, v. 12, p. 38-41, 2000.

LUBART, R.; FRIEDMANNB, H.; LEVINSHAL, T.; LAVIEB, R.; BREITBART, H. Effect of light on calcium transport in bull sperm cells. Journal of Photochemistry and Photobiology. B: Biology, v. 15, p. 337-341, 1992.

McLAY, D. W.; CLARKE, H. J. Remodelling the paternal chromatin at fertilization in mammals. Reproduction, v. 1125, n. 5, p.625-633, 2003.

MÉNÉZO, Y. J. R. Paternal and maternal factors in preimplantation embryogenesis: interaction with the biochemical enviroment. Reproductive Biomedicine Online, v. 12, p. 616-621, 2006.

MONTAG, M.; RINK, K.; DELACRÉTAZ, G.; VAN DER VEM, H. Laser-induced immobilization and plasma membrane permeabilization in human spermatozoa. Human Reproduction, v. 15, n. 4, p.846-852, 2000.

OCAÑA-QUERO, J. M.; GOMEZ-VILLAMANDOS, R.; MORENO-MILLAN, M.; SANTISTEBAN-VALENZUELA, J. M. Biological effects of hellium-neon (He-Ne) laser radiation on acrosome reaction in bull sperm cells. Journal of Photochemistry and Photobiology B: Biology, v. 40, p. 294-298, 1997.

OZDEMIR, F.; BIRTANE, M.; KOKINO, S. The clinical efficacy of low-power laser therapy on pain and function in cervical osteoarthritis. Clinical Rheumatology, v. 20, n. 3, p. 181-184, 2001.

PASSARELA, S.; DECHECCHI, M. C.; QUAGLIARIELLO. Optical and biochemical properties of NADH irradiated by high peak power q-switched ruby laser or by low power C.W. HeNe laser. Bioelectrochemistry and Bioenergetics, v. 8, p. 315-326, 1981.

PEPLOW, P. V.; CHUNG, T. Y.; BAXER, G. D. Laser photobiomodulation of proliferation of cells in culture: a review of human and animal studies. Photomedicine and Laser Surgery, v. 28, n. 1, p. S3-S40, 2010. 
PINHEIRO, A. L. B.; MEIRELlES, G. C. S.; CARVALHO, C. M.; VIEIRA, A. L. B.; SANTOS, J. N.; RAMALHO, L. M. P. Biomodulative effects of polarized light on the healing of cutaneous wounds on nourished and undernourished Wistar Rats. Photomedicine \& Laser Surgery, v. 24, p. 616-624, 2006.

PONTES, J. H. F. NONATO-JUNIOR, I. SANCHES, B. V. Comparison of embryo yield and pregnancy rate between in vivo and in vitro methods in the same Nelore (Bos indicus) donor cows. Theriogenology, v. 71, n. 4, p. 690-7, 2009.

PORTER, M. Equine rehabilitation therapy for joint disease. Veterinary Clinics Equine Practice, v. 21, p. 599-607, 2005.

RIZOS, D.; FAIR, T.; PAPADOPOULOS, S.; BOLAND, M. P.; LONERGAN, P. Developmental, qualitative, and ultrastructural differences between ovine and bovine embryos produced in vivo or in vitro. Molecular Reproduction and Development, v. 62, n. 3, p. 320 327,2002

ROCHA JUNIOR, A. M.; VIEIRA, B. J.; DE ANDRADE, L. C. F.; AARESTRUP, F. M. Effect of low-level laser therapy on the progresso of wound humans: the contribution of in vitro in experimental studies. Jornal Vascular Brasileiro, v. 6, n. 3, p. 258-266, 2007.

ROCHA, H. L. O. G.; BELETTI, M.E.; MARCOLINI, T.T.; AMORIM, D. A. Z. Uso de laranja de acridina e azul de toluidina na avaliação da fertilidade masculina. Journal of bioscince, v. 18, n. 1, p. 65-77, 2002.

SAACKE, R.G. NADIR S.; NEBEL, R.L. Relationships of semen quality to sperm transport, fertilization and embryo quality in ruminants. Theriogenology, v. 41, p. 45-50, 1994.

SAACKE, R.G. Semen quality in relation to semen preservation. Journal Dairy Science, v. 66, p. 2635-2644, 1987.

SHAHAR. S.; WISER, A.; ICKOWICZ, D.; LUBART, R.; SHULMAN, A.; BREITBART, $\mathrm{H}$. Light-mediated activation reveals a key role for protei kinase A and sarcoma protein kinase in the development of sperm hyper-activated motility. Human Reproduction, doi: 10.1093/humrep/der232, 2011

SCREENAN, J. M.; DISKIN, M. G. Early embryonic mortality in the cowa: its relationship with progesterone concentration. The Veterinary record, v. 112, n. 22, p. 517-521, 1983.

SILVA, P. F. N.; GADELLA, B. M. Detection of damage in mammalian sperm cells. Theriogenology, v. 65, p. 958-978, 2006. 
SINGH, N. P.; MULLER, C. H.; BERGER, R. E. Effect of age on DNA double-strand breaks and apoptosis in human sperm. Fertility and sterility, v. 80, n. 6, p. 1420-1430, 2003.

SLOWISKA, M.; KAROL, H.; CIERESZKO, A. Comet assay of fresh and cryopreserved bull spermatozoa. Cryobiology, v. 56, p. 100-102, 2008.

TANEJA, M.; BOLS, P. E. J.; VELDE, A. V.; JU, J. C., SCHREIBER, D.; TRIPP, M. W.; LEVINE, H.; ECHELARD, Y.; RIESEN, J.; YANG, X. Development competence of juvenile calf oocytes in vitro and in vivo: influence of donor animal variation and repeated gonadotropin stimulation. Biology of Reproduction, v. 62, p. 206-213, 2000.

TERVIT, H. R. Laparoscopy/laparotomy oocyte recovery and juvenile breeding. Animal Reproduction Science, v. 42, p. 227-238, 1996.

TESARIK, J. Paternal effects on cell division in human preimplantation embryo. Reproductive Biomedicine Online, v. 10, n. 3, p. 370-375, 2005.

TESARIK, J.; GRECO, E.; MENDONZA, C. Late, but not early, paternal effect on human embryo development is related to sperm DNA fragmentation. Human Reproduction, v. 19, n. 3, p. 611-615, 2004.

THOMAS, C. A.; GARNER, D. L.; DEJARNETTE, J. M.; MARSHALL, C. E. Effect of cryopreservation on bovine sperm organelle function and viability as determined by flow cytometry. Biology of Reproduction, v. 58, p. 786-793, 1998.

TROIANO, L.; GRANATA, A. R.; COSSARIZZA, A.; KALSHNIKOVA, G.; BIANCHI, R.; PINI, G.; TROPEA, F.; CARANI, C.; FRANCESCHI, C. Mitochondrial membrane potential and DNA stain ability in human sperm cells, a flow citometry analysis with implication for male infertility. Experimental Cell Research, v. 241, p. 384-393, 1998.

VERSTEGEN, J., IGUER-OUADA, M., ONCLIN, K. Computer assisted semen analysers in andrology research and veterinary practice. Theriogenology, v. 57, p.149-179, 2002.

VIANA, J. H. M. SIQUEIRA, L. G. B. PALHÃO, M. P.; ALMEIDA CAMARGO, L. S. DE. Use of in vitro Fertilization Technique in the Last Decade and its Effect on Brazilian Embryo Industry and Animal Production. Acta Scientiae Veterinariae, v. 38, n. 2, p. s661-s674, 2010.

WATSON, P.F. Recent Developments and Concepts in the Cryopreservation of Spermatozoa and the Assessment of their Post-thawing Function. Reproduction, Fertility and Development, v.7, p. 871-891, 1995 


\section{ANEXO A - Meio utilizado para o sêmen}

- Talp Sêmen

\begin{tabular}{|c|c|c|c|}
\hline Reagente & Fabricante & Catálogo & Concentração \\
\hline $\mathrm{NaCl}$ & Sigma & $\mathrm{S}-5886$ & $0,1 \mathrm{M}$ \\
\hline $\mathrm{KCl}$ & Sigma & $\mathrm{P}-5405$ & $0,003 \mathrm{M}$ \\
\hline $\mathrm{MgCl} 2$ & Sigma & $\mathrm{M}-2393$ & $0,0004 \mathrm{M}$ \\
\hline $\mathrm{NaH} 2 \mathrm{PO} 4$ & Sigma & $\mathrm{S}-0876$ & $0,0003 \mathrm{M}$ \\
\hline $\mathrm{NaHCO} 3$ & Sigma & $\mathrm{S}-8875$ & $0,025 \mathrm{M}$ \\
\hline $\mathrm{CaCl} 2 \mathrm{H} 2 \mathrm{O}$ & Sigma & $\mathrm{C}-5670$ & $0,003 \mathrm{M}$ \\
\hline Ác. Lático syr. & Sigma & $\mathrm{L}-7900$ & $0,3 \%(\mathrm{v} / \mathrm{v})$ \\
\hline $\mathrm{Hepes}$ & Sigma & $\mathrm{H}-0891$ & $0,01 \mathrm{M}$ \\
\hline $\mathrm{pH}=7,4$ & & & $\mathrm{OSM}=295-300$ \\
\hline
\end{tabular}


Anexos

ANEXO B - Soluções de sondas fluorescentes

- FITC-PSA

\begin{tabular}{c|c|c|c}
\hline Reagente & Fabricante & Catálogo & Concentração \\
\hline FITC-PSA & Sigma & L0770 & $100 \mu \mathrm{g} / \mathrm{ml}$ \\
\hline Ázida Sódica & Fisher & BP9221-500 & $10 \%(\mathrm{~m} / \mathrm{v})$ \\
\hline DPBS (q.s.p) & - & - & $20 \mathrm{ml}$ \\
\hline
\end{tabular}

- Iodeto de Propídeo

\begin{tabular}{c|c|c|c}
\hline Reagente & Fabricante & Catálogo & Concentração \\
\hline Iodeto de Propídeo & Sigma & $\mathrm{P} 4170$ & $0,5 \mathrm{mg} / \mathrm{ml}$ \\
\hline $\mathrm{NaCl}$ & Fisher & $\mathrm{S} 5886$ & $0,9 \%(\mathrm{v} / \mathrm{v})$ \\
\hline
\end{tabular}

- JC-1

\begin{tabular}{c|c|c|c}
\hline Reagente & Fabricante & Catálogo & Concentração \\
\hline JC-1 & Molecular Probes & T3168 & $76,5 \mu \mathrm{M}$ \\
\hline DMSO & Sigma & D2650 & - \\
\hline
\end{tabular}


ANEXO C - Soluções para teste SCSA

- Tampão TNE

\begin{tabular}{c|c|c|c}
\hline Reagente & Fabricante & Catálogo & \\
\hline Tris-HCl & Fluka & 93363 & $0,01 \mathrm{M}$ \\
\hline $\mathrm{NaCl}$ & Sigma & $\mathrm{S}-5886$ & $0,15 \mathrm{M}$ \\
\hline $\mathrm{EDTA}$ & Sigma & $\mathrm{E}-5134$ & $1 \mathrm{mM}$ \\
\hline $\begin{array}{c}\text { Água destilada } \\
\text { (q.s.p) }\end{array}$ & & & $500 \mathrm{ml}$ \\
\hline
\end{tabular}

Solução pH 7.4

- Solução detergente ácida

\begin{tabular}{c|c|c|c}
\hline Reagente & Fabricante & Catálogo & \\
\hline $\mathrm{HCl}$ & Merck & K24537117 & $0,08 \mathrm{M}$ \\
\hline $\mathrm{NaCl}$ & Sigma & $\mathrm{S}-5886$ & $0,15 \mathrm{M}$ \\
\hline Triton $\mathrm{x}-100$ & Sigma & $\mathrm{X}-100$ & $0,1 \%(\mathrm{v} / \mathrm{v})$ \\
\hline Água destilada & & & $500 \mathrm{ml}$ \\
\hline
\end{tabular}

Solução pH 1.2

- Solução de Laranja de Acridina (L.A) - estoque

\begin{tabular}{c|c|c|c}
\hline Reagente & Fabricante & Catálogo & \\
\hline Laranja de Acridina & Sigma & A-6014 & $1 \mathrm{mg} / \mathrm{ml}$ \\
\hline $\begin{array}{c}\text { Água destilada } \\
\text { (q.s.p) }\end{array}$ & & & $10 \mathrm{ml}$ \\
\hline
\end{tabular}

- Solução de Laranja de Acridina - Uso

\begin{tabular}{c|c|c|c}
\hline Reagente & Fabricante & Catálogo & \\
\hline Ácido cítrico & Sigma & 0,12 & $0,1 \mathrm{M}$ \\
\hline $\mathrm{Na} 2 \mathrm{HPO} 4$ & Sigma & $\mathrm{S}-5136$ & $0,2 \mathrm{M}$ \\
\hline $\mathrm{EDTA}$ & Sigma & E-5134 & $0,001 \mathrm{M}$ \\
\hline $\mathrm{NaCl}$ & Sigma & $\mathrm{S}-5886$ & $0,15 \mathrm{M}$ \\
\hline L.A estoque & & & $6 \mu \mathrm{g} / \mathrm{ml}$ \\
\hline $\begin{array}{c}\text { Água destilada } \\
\text { (q.s.p) }\end{array}$ & & & $120 \mathrm{ml}$ \\
\hline
\end{tabular}

Solução pH 6.0 
Anexos

ANEXO D- Meio de fatiamento e meios para maturação in vitro - MIV

- Meio de fatiamento

\begin{tabular}{c|c|c|c}
\hline Reagente & Fabricante & Catálogo & Concentração \\
\hline Médium 199 & Gibco & $31100-035$ & - \\
\hline NaHCO3 & Sigma & S-8875 & $2,2 \%(\mathrm{~m} / \mathrm{v})$ \\
\hline Água milli-Q (q.s.p) & - & - & $1 \mathrm{~L}$ \\
\hline $\mathrm{pH}=7,2$ & & & \\
\hline
\end{tabular}

Filtrar em 0,22 $\mu \mathrm{m}$

- Meio de lavagem MIV (Pré-MIV)

\begin{tabular}{c|c|c|c}
\hline Reagente & Fabricante & Catálogo & Concentração \\
\hline M-199 com HEPES & Gibco & $12380-028$ & $90 \%(\mathrm{v} / \mathrm{v})$ \\
\hline Soro Fetal Bovino & Gibco & $16140-014$ & $10 \%(\mathrm{v} / \mathrm{v})$ \\
\hline Pyruvato & Sigma & P-4562 & $0,2 \mathrm{mM}$ \\
\hline Gentamicina & Sigma & G-1264 & $50 \mu \mathrm{g} / \mathrm{ml}$ \\
\hline
\end{tabular}

Filtrar em $0,22 \mu \mathrm{m}$

- Meio de maturação in vitro

\begin{tabular}{c|c|c|c}
\hline Reagente & Fabricante & Catálogo & Concentração \\
\hline M-199 com BICARBONATO & Gibco & $11150-026$ & $90 \%(\mathrm{v} / \mathrm{v})$ \\
\hline Soro Fetal Bovino & Gibco & $16140-014$ & $10 \%(\mathrm{v} / \mathrm{v})$ \\
\hline Piruvato & Sigma & P-4562 & $0,2 \mathrm{mM}$ \\
\hline Gentamicina & Sigma & G-1264 & $50 \mu \mathrm{g} / \mathrm{ml}$ \\
\hline FSH & Bioniche & Folltropin-V & $0,5 \mu \mathrm{g} / \mathrm{ml}$ \\
\hline hCG & Intervet & Chorulon & $7 \mathrm{UI} / \mathrm{ml}$ \\
\hline
\end{tabular}

Filtrar em $0,22 \mu \mathrm{m}$

\begin{tabular}{|l|c|c|c|} 
Estradiol & Sigma & E-4389 & $1 \mu \mathrm{g} / \mathrm{ml}$ \\
\hline
\end{tabular}


ANEXO E - Soluções estoques e meio para FIV

- Soluções estoque para FIV (Parrish et al., 1988)

\begin{tabular}{|c|c|c|c|c|}
\hline Reagente & Fabricante & Catálogo & $\begin{array}{c}\text { TALP } \\
\text { STOCK }\end{array}$ & $\begin{array}{c}\text { TALP } \\
\text { SÊMEN }\end{array}$ \\
\hline $\mathrm{NaCl}$ & Sigma & S-5886 & $0,01 \mathrm{M}$ & $0,01 \mathrm{M}$ \\
\hline $\mathrm{KCl}$ & Sigma & P-5405 & $0,003 \mathrm{M}$ & $0,003 \mathrm{M}$ \\
\hline $\mathrm{MgCl} 2$ & Sigma & M-2393 & $0,5 \mu \mathrm{M}$ & $0,4 \mathrm{mM}$ \\
\hline $\mathrm{NaH} 2 \mathrm{PO} 4$ & Sigma & S-0876 & $0,35 \mu \mathrm{M}$ & $0,3 \mathrm{mM}$ \\
\hline $\mathrm{NaHCO} 3$ & Sigma & S-8875 & $0,025 \mathrm{M}$ & $0,025 \mathrm{M}$ \\
\hline $\mathrm{CaCl} 2 \mathrm{H} 2 \mathrm{O}$ & Sigma & C-5670 & $0,003 \mathrm{M}$ & $0,003 \mathrm{M}$ \\
\hline Ác.Lactico syr. & Sigma & L-7900 & $0,15 \%(\mathrm{v} / \mathrm{v})$ & $0,3 \%(\mathrm{v} / \mathrm{v})$ \\
\hline Hepes & Sigma & H-0891 & *********** & $0,01 \mathrm{M}$ \\
\hline \multicolumn{2}{|c|}{$\mathrm{pH}=7,4$} & & & $\mathrm{OSM}=295-300$ \\
\hline
\end{tabular}

Filtrar em $0,22 \mu \mathrm{m}$

- Solução de Gentamicina

\begin{tabular}{c|c|c|c}
\hline Reagentes & Fabricante & Catálogo & Concentração \\
\hline Sulfato de Gentamicina & Sigma & G-1264 & $50 \mu \mathrm{g} / \mathrm{ml}$ \\
\hline Solução fisiológica (q.s.p) & - & - & $100 \mathrm{ml}$ \\
\hline Aliquotar e manter a $-20^{\circ}$ C. & &
\end{tabular}

- Solução de Piruvato

\begin{tabular}{c|c|c|c}
\hline Reagentes & Fabricante & Catálogo & \\
\hline Ácido Pirúvico & Sigma & P-3662 & $0,02 \mathrm{M}$ \\
\hline Água Destilada (q.s.p) & - & - & $10 \mathrm{ml}$ \\
\hline
\end{tabular}

Aliquotar e manter a $\mathbf{- 2 0}^{\circ} \mathbf{C}$.

- Preparo da solução PHE

Solução pH 4.0

\begin{tabular}{c|c|c|c}
\hline Reagente & Fabricante & Catálogo & Concentração \\
\hline Na Lactato & Sigma & L-7900 & $0,03 \mathrm{M}$ \\
\hline Na metabisulfito & Sigma & S-1516 & $0,005 \mathrm{M}$ \\
\hline Água Milli-Q (q.s.p) & & & $50 \mathrm{ml}$ \\
\hline
\end{tabular}

$$
\mathrm{pH}=\mathbf{4 , 0}
$$




\section{Componentes da solução PHE}

\begin{tabular}{c|c|c|c}
\hline Reagente & Fabricante & Catálogo & \\
\hline Penicilamina $2 \mu \mathrm{M}$ & Sigma & P-40-3 & $0,3 \mathrm{mg} / \mathrm{ml} \mathrm{salina} 0,9 \%$ \\
\hline Hipotaurina $1 \mu \mathrm{M}$ & Sigma & H-1384 & $0,109 \mathrm{mg} / \mathrm{ml}$ salina $0,9 \%$ \\
\hline Epinefrina $0,25 \mu \mathrm{M}$ & Sigma & $21,930-4$ & $0,04575 \mathrm{mg} / \mathrm{ml} \mathrm{sol.} \mathrm{pH} 4,0$ \\
\hline
\end{tabular}

\section{Solução PHE}

\begin{tabular}{c|c|c|c}
\hline Reagente & Fabricante & Catálogo & Volume \\
\hline Penicilamina & Sigma & P-40-3 & $2,5 \mathrm{ml}$ \\
\hline Hipotaurina & Sigma & H-1384 & $2,5 \mathrm{ml}$ \\
\hline Epinefrina & Sigma & $21,930-4$ & $2 \mathrm{ml}$ \\
\hline Solução salina $0,9 \%$ & & & $4 \mathrm{ml}$ \\
\hline
\end{tabular}

- Meio de lavagem FIV (Pré-FIV)

\begin{tabular}{c|c|c|c}
\hline Reagente & Fabricante & Catálogo & Volume \\
\hline M-199 com HEPES & Gibco & $12380-028$ & $10 \mathrm{ml}$ \\
\hline BSA - V & Sigma & A-9647 & $\begin{array}{c}0,003 \%(\mathrm{~m} \\
/ \mathrm{v})\end{array}$ \\
\hline Piruvato $0,2 \mathrm{mM}$ & Sigma & P-4562 & $0,2 \mathrm{mM}$ \\
\hline Gentamicina $50 \mu \mathrm{g} / \mathrm{ml}$ & Sigma & G-1264 & $50 \mu \mathrm{g} / \mathrm{ml}$ \\
\hline
\end{tabular}

Filtrar em 0,22 $\mu \mathrm{m}$

- Meio FIV

\begin{tabular}{|c|c|c|c|}
\hline Reagente & Fabricante & Catálogo & $10 \mathrm{ml}$ \\
\hline TL - Stock & & & $10 \mathrm{ml}$ \\
\hline BSA - Livre de Ácidos Graxos & Sigma & A-7511 & $\begin{array}{c}0,006 \% \\
(\mathrm{~m} / \mathrm{v})\end{array}$ \\
\hline Piruvato $0,2 \mathrm{mM}$ & Sigma & P-4562 & $20 \mu 1$ \\
\hline Gentamicina $50 \mu \mathrm{g} / \mathrm{ml}$ & Sigma & G-1264 & $50 \mu l$ \\
\hline
\end{tabular}

Filtrar em 0,22 $\mu \mathrm{m}$

- Meio FIV gota

\begin{tabular}{c|c|c|c}
\hline Reagente & Fabricante & Catálogo & 4ml \\
\hline Meio - FIV & & & $3.640 \mathrm{ml}$ \\
\hline Heparina 140usp/mg & Sigma & H-9399 & $40 \mu \mathrm{l}$ \\
\hline PHE & & & $160 \mu \mathrm{l}$ \\
\hline
\end{tabular}

Filtrar em 0,22 $\mu \mathrm{m}$ 
ANEXO F - Meio para cultivo (SOFaa)

- Solução SOFaa estoque

\begin{tabular}{c|c|c|c}
\hline Reagentes & Fabricante & Catálogo & Concentração \\
\hline $\mathrm{NaCl}$ & Sigma & S-5886 & $0,1 \mathrm{M}$ \\
\hline $\mathrm{KCl}$ & Sigma & P-5405 & $0,007 \mathrm{M}$ \\
\hline $\mathrm{KH} 2 \mathrm{PO} 4$ & Sigma & P-5655 & $0,0012 \mathrm{M}$ \\
\hline $\mathrm{NaHCO3}$ & Sigma & S-5761 & $0,025 \mathrm{M}$ \\
\hline $\mathrm{Na} \mathrm{Lactato}$ & Sigma & L-7900 & $0,003 \mathrm{M}$ \\
\hline Ácido Pirúvico & Sigma & P-3662 & $0,0062 \mathrm{mM}$ \\
\hline L-glutamina & Sigma & G-8540 & $0,001 \mathrm{M}$ \\
\hline $\mathrm{MgCl} 26 \mathrm{H} 2 \mathrm{O}$ & Sigma & M-2393 & $0,0005 \mathrm{M}$ \\
\hline $\mathrm{CaCl} 2$ & Sigma & C-5670 & $0,002 \mathrm{M}$ \\
\hline
\end{tabular}

Filtrar em 0,22 $\mu \mathrm{m}$

- Meio SOFaa (Uso)

\begin{tabular}{c|c|c|c}
\hline Reagentes & Fabricante & Catálogo & $\mathbf{5 m l}$ \\
\hline Meio SOF estoque & & & $4,6 \mathrm{ml}$ \\
\hline Aminoácidos essenciais & Sigma & M-5550 & $0,100 \mathrm{ml}$ \\
\hline Aminoácidos não essenciais & Sigma & M-7145 & $0,050 \mathrm{ml}$ \\
\hline Soro Fetal Bovino & Gibco & $16140-014$ & $0,250 \mathrm{ml}$ \\
\hline
\end{tabular}

Preparar na hora do uso 
Anexos

ANEXO G - Soluções para ensaio de TUNEL

- Solução de PBS 0.2M

\begin{tabular}{c|c|c|c}
\hline Reagentes & Fabricante & Catálogo & \\
\hline $\mathrm{K} 2 \mathrm{HPO} 40.2 \mathrm{M}$ & Sigma & $\mathrm{P}-5655$ & $0.2 \mathrm{M}$ \\
\hline $\mathrm{NaCl}$ & Sigma & $\mathrm{S}-5886$ & $0,15 \mathrm{M}$ \\
\hline Água Milli Q (q.s.p) & & & $1 \mathrm{~L}$ \\
\hline
\end{tabular}

pH 7.4

- Solução de PBS 10mM

\begin{tabular}{c|c|c|c}
\hline Reagentes & Fabricante & Catálogo & \\
\hline K2HPO4 10mM & Sigma & P-5655 & $10 \mathrm{mM}$ \\
\hline $\mathrm{NaCl}$ & Sigma & S-5886 & $0,15 \mathrm{M}$ \\
\hline Água Milli Q (q.s.p) & & & $1 \mathrm{~L}$ \\
\hline pH 7.4
\end{tabular}

- Solução de PBS-PVP

\begin{tabular}{c|c|c|c}
\hline Reagentes & Fabricante & Catálogo & 1L \\
\hline PBS 10mM & & & $10 \mathrm{mM}$ \\
\hline Polivinilpirrolidona (PVP) & Sigma & P-0930 & $1 \%(\mathrm{~m} / \mathrm{v})$ \\
\hline
\end{tabular}

- Solução de Hidróxido de Sódio 2 N

\begin{tabular}{c|c|c|c}
\hline Reagentes & Fabricante & Catálogo & 1L \\
\hline $\mathrm{NaOH}$ & Synth & H 1017.01.AH & $2 \mathrm{~N}$ \\
\hline Água Milli Q (q.s.p) & & & $1 \mathrm{~L}$ \\
\hline
\end{tabular}

- Solução de Paraformaldeído $8 \%$ (estoque)

\begin{tabular}{c|c|c|c}
\hline Reagentes & Fabricante & Catálogo & 1L \\
\hline Paraformaldeído & EMS & 19210 & $8 \%(\mathrm{~m} / \mathrm{v})$ \\
\hline $\begin{array}{c}\text { Água Milli Q (55- } \\
\text { 60oC) (q.s.p) }\end{array}$ & & & $1 \mathrm{~L}$
\end{tabular}

* adicionar algumas gotas de $\mathrm{NaOH} 2 \mathrm{~N}$ até a solução ficar incolor. Filtrar $(0,22 \mu \mathrm{m})$ e estocar a $-20 \mathrm{oC}$

- Solução de Paraformaldeído 4\% (uso)

* fazer uma solução 1:1 de paraformaldeído 8\% e PBS 0.2M no momento do uso. 
Anexos

- Solução de Permeabilização

\begin{tabular}{c|c|c|c}
\hline Reagentes & Fabricante & Catálogo & $\mathbf{2 0 0 m l}$ \\
\hline Triton X-100 0,5\% & Sigma & X-100 & $0,5 \%(\mathrm{v} / \mathrm{v})$ \\
\hline Solução de Citrato de Sódio 0,1\% & & & $0,1 \%(\mathrm{v} / \mathrm{v})$ \\
\hline
\end{tabular}

- Solução de citrato de sódio $0,1 \%$

\begin{tabular}{c|c|c|c}
\hline Reagentes & Fabricante & Catálogo & \\
\hline Citrato de Sódio & Sigma & S-4641 & $0,01 \%(\mathrm{~m} / \mathrm{v})$ \\
\hline Água MilliQ (q.s.p) & & & $200 \mathrm{ml}$ \\
\hline
\end{tabular}

- Solução de DNase

\begin{tabular}{c|c|c|c}
\hline Reagentes & Fabricante & Catálogo & \\
\hline DNase I & Invitrogen & $18047-019$ & $50 \mathrm{U} / \mathrm{ml}$ \\
\hline PBS-PVP (q.s.p) & & & $100 \mathrm{ml}$ \\
\hline
\end{tabular}

* preparar a solução apenas no momento do uso

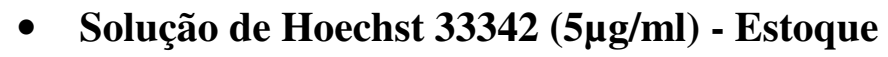

\begin{tabular}{c|c|c|c}
\hline Reagentes & Fabricante & Catálogo & \\
\hline Hoechst 33342 & Sigma & B-2261 & $5 \mu \mathrm{g} / \mathrm{ml}$ \\
\hline PBS (q.s.p) & Nutricell & 01.002 .1000 & $1 \mathrm{ml}$ \\
\hline
\end{tabular}

Estocar a $\mathbf{- 2 0}{ }^{\circ} \mathrm{C}$

- Solução de Hoechst 33342 - Uso

\begin{tabular}{c|c|c|c}
\hline Reagentes & Fabricante & Catálogo & $\mathbf{1 m l}$ \\
\hline Solução de Hoechst 33342 estoque & & & $1 \mu 1$ \\
\hline PBS-PVP & & & $1 \mathrm{ml}$ \\
\hline
\end{tabular}

* Preparar apenas no momento do uso

- Solução de DABCO

\begin{tabular}{c|c|c|c}
\hline Reagentes & Fabricante & Catálogo & $\mathbf{1 0 m l}$ \\
\hline $\begin{array}{c}\text { 1,4-Diazabicyclo [2.2.2]octane } \\
\text { (DABCO) }\end{array}$ & Sigma & D-2522 & $0,23 \mathrm{~g}$ \\
\hline Tris 0.5M, pH 8.0 & Fluka & 93363 & $0,4 \mathrm{ml}$ \\
\hline Glicerol & Sigma & G-5516 & $5 \mathrm{ml}$ \\
\hline Água destilada & & & $4,6 \mathrm{ml}$ \\
\hline
\end{tabular}

Manter a $4^{\circ} \mathrm{C}$, abrigado da luz. 
Anexos

ANEXO H - Soluções para ensaio COMETA

- Solução de TBE 1X

\begin{tabular}{c|c|c|c}
\hline Reagentes & Fabricante & Catálogo & \\
\hline Trizma Base & Fluka & 93362 & $0,089 \mathrm{M}$ \\
\hline Ácido Bórico & Carlo Erba & 402766 & $0,089 \mathrm{M}$ \\
\hline EDTA & Sigma & E-5134 & $0,002 \mathrm{M}$ \\
\hline Água destilada q.s.p & & & $1 \mathrm{~L}$ \\
\hline
\end{tabular}

- Agarose Normal Melting (NM)

\begin{tabular}{c|c|c|c}
\hline Reagentes & Fabricante & Catálogo & \\
\hline Agarose Normal Menting & Sigma & A-9539 & $1 \%(\mathrm{~m} / \mathrm{v})$ \\
\hline TBE 1X (q.s.p) & & & $100 \mathrm{ml}$ \\
\hline
\end{tabular}

Manter a $4^{\circ} \mathrm{C}$

- Agarose Low Melting (LM)

\begin{tabular}{c|c|c|c}
\hline Reagentes & Fabricante & Catálogo & $\mathbf{1 0 0 m l}$ \\
\hline Agarose Low Melting & Sigma & A-4018 & $0,75 \%(\mathrm{~m} / \mathrm{v})$ \\
\hline TBE 1X & & & $100 \mathrm{ml}$ \\
\hline
\end{tabular}

- EDTA-Na2

\begin{tabular}{c|c|c|c}
\hline Reagentes & Fabricante & Catálogo & \\
\hline EDTA & Sigma & E-5134 & $1 \mathrm{M}$ \\
\hline Água MilliQ (q.s.p) & & & $1 \mathrm{~L}$ \\
\hline
\end{tabular}

pH 7.8

- Tris-HCl

\begin{tabular}{c|c|c|c}
\hline Reagentes & Fabricante & Catálogo & \\
\hline Tris-HCl & Fluka & 93363 & $1 \mathrm{M}$ \\
\hline Água MilliQ (q.s.p) & & & $100 \mathrm{ml}$ \\
\hline
\end{tabular}

pH 7.8 
- $\mathrm{NaCl}$

\begin{tabular}{c|c|c|c}
\hline Reagentes & Fabricante & Catálogo & 1L \\
\hline $\mathrm{NaCl}$ & Sigma & S-5886 & 5M \\
\hline Água MilliQ & & & $1 \mathrm{~L}$ \\
\hline
\end{tabular}

- DTT

\begin{tabular}{c|c|c|c}
\hline Reagentes & Fabricante & Catálogo & \\
\hline Dithiothreitol (DTT) & Invitrogen & $15508-013$ & $1 \mathrm{M}$ \\
\hline Água MilliQ (q.s.p) & & & $4 \mathrm{ml}$ \\
\hline
\end{tabular}

Aliquotar e manter a $-20^{\circ} \mathrm{C}$

- Solução de ressuspensão da proteinase $K$

\begin{tabular}{c|c|c|c}
\hline Reagentes & Fabricante & Catálogo & \\
\hline Tris-HCl; $\mathrm{pH} 7.5$ & Fluka & 93363 & $10 \mathrm{mM}$ \\
\hline CaCl2 & Sigma & C-5670 & $20 \mathrm{mM}$ \\
\hline Glicerol & Sigma & G-5516 & $50 \%(\mathrm{v} / \mathrm{v})$ \\
\hline Água MilliQ q.s.p & & & $10 \mathrm{ml}$ \\
\hline
\end{tabular}

pH 7.5

- Solução de Proteinase K

\begin{tabular}{c|c|c|c}
\hline Reagentes & Fabricante & Catálogo & \\
\hline Proteinase K & Invitrogen & $25530-015$ & $2 \mathrm{mg} / \mathrm{ml}$ \\
\hline Solução de ressuspensão (q.s.p) & & & $2 \mathrm{ml}$ \\
\hline
\end{tabular}

Aliquotar e manter a $-\mathbf{2 0}^{\circ} \mathrm{C}$

- Solução de Cloreto de cálcio hidratado

\begin{tabular}{c|c|c|c}
\hline Reagentes & Fabricante & Catálogo & \\
\hline CaCl2 & Sigma & C-5670 & $0,2 \mathrm{M}$ \\
\hline Água MilliQ & & & $10 \mathrm{ml}$ \\
\hline
\end{tabular}


Anexos

- Poli-L-Lisina 0,01\%

\begin{tabular}{c|c|c|c}
\hline Reagentes & Fabricante & Catálogo & \\
\hline Poly-L-Lysine & Sigma & P-8920 & $0,01 \%$ \\
\hline Água destilada (q.s.p) & & & $200 \mathrm{ml}$ \\
\hline
\end{tabular}

Manter a $-4^{\circ} \mathrm{C}$

- Solução de Lise I

\begin{tabular}{c|c|c|c}
\hline Reagentes & Fabricante & Catálogo & \\
\hline EDTA-Na2 & & & $100 \mathrm{mM}$ \\
\hline Tris HCl & Fluka & 93363 & $10 \mathrm{mM}$ \\
\hline $\mathrm{NaCl}$ & Sigma & S-5886 & $2,5 \mathrm{M}$ \\
\hline Proteinase K $(20 \mu \mathrm{g} / \mathrm{mL})$ & Invitrogen & $25530-015$ & $20 \mu \mathrm{g} / \mathrm{mL}$ \\
\hline Água MilliQ (q.s.p) & & & $1 \mathrm{~L}$ \\
\hline
\end{tabular}

Manter a $-4^{\circ} \mathrm{C}$

- Solução de Lise II

\begin{tabular}{c|c|c|c}
\hline Reagentes & Fabricante & Catálogo & \\
\hline EDTA-Na2 & & & $100 \mathrm{mM}$ \\
\hline Tris HCl & Fluka & 93363 & $10 \mathrm{mM}$ \\
\hline $\mathrm{NaCl}$ & Sigma & $\mathrm{S}-5886$ & $2,5 \mathrm{M}$ \\
\hline Triton X-100 & Sigma & $\mathrm{X}-100$ & $4 \%(\mathrm{v} / \mathrm{v})$ \\
\hline DTT; $\mathrm{pH} 11.0$ & Invitrogen & $15508-013$ & $40 \mathrm{mM}$ \\
\hline Água MilliQ (q.s.p) & & & $1 \mathrm{~L}$ \\
\hline
\end{tabular}

Manter a -4oC

- Solução alcalina de eletroforese

\begin{tabular}{c|c|c|c}
\hline Reagentes & Fabricante & Catálogo & 1L \\
\hline $\mathrm{NaOH}$ & Synth & H1017.01.AH & $300 \mathrm{mM}$ \\
\hline .EDTA-Na2 & & & $1 \mathrm{mM}$ \\
\hline Água MilliQ (q.s.p) & & & $1 \mathrm{~L}$ \\
\hline
\end{tabular}

pH>13.0 
Anexos

- SYBR Green I

\begin{tabular}{c|c|c|c}
\hline Reagentes & Fabricante & Catálogo & \\
\hline SYBR Green I & Sigma & S9430 & 5000x \\
\hline Água destilada (q.s.p) & & & $1 \mathrm{ml}$ \\
\hline
\end{tabular}

* solução para coloração de cada lâmina 